TECHNICAL REPORT NO. 73645-80

\title{
A STUDY OF POST CRITICAL HEAT FLUX HEAT TRANSFER \\ IN A FORCED CONVECTION SYSTEM
}

\author{
by \\ David N. P1ummer \\ Onwuamaeze C. Iloeje \\ Peter Griffith \\ Warren M. Rohsenow
}

\author{
Sponsored by the \\ General Electric Company \\ Agreement No. 205-J4069 \\ DSR Project No. 73645
}

March 1973

\author{
Heat Transfer Laboratory \\ Engineering Projects Laboratory \\ Department of Mechanical Engineering \\ Hassachusetts Institute of Technology \\ Cambridge, Massachusetts 02139
}




\section{DISCLAIMER}

This report was prepared as an account of work sponsored by an agency of the United States Government. Neither the United States Government nor any agency Thereof, nor any of their employees, makes any warranty, express or implied, or assumes any legal liability or responsibility for the accuracy, completeness, or usefulness of any information, apparatus, product, or process disclosed, or represents that its use would not infringe privately owned rights. Reference herein to any specific commercial product, process, or service by trade name, trademark, manufacturer, or otherwise does not necessarily constitute or imply its endorsement, recommendation, or favoring by the United States Government or any agency thereof. The views and opinions of authors expressed herein do not necessarily state or reflect those of the United States Government or any agency thereof. 


\section{DISCLAIMER}

Portions of this document may be illegible in electronic image products. Images are produced from the best available original document. 
ABSTRACT

A transient boiling experiment has been run in such a way that one can acquire data in forced convection film, transition, and nucleate boiling regions for a specified pressure, quality and mass flux. Transient boiling experiments were conducted at the Nuclear Energy Division of the General Electric Company for water in a 0.492 inch I.D. inconel X-750 tube at mass fluxes of $50,000,100,000$ and $250,0001 \mathrm{bm} / \mathrm{hr}-\mathrm{ft}^{2}$, quality range of $30-100 \%$ and a pressure of 1000 psia.

The reduced boiling curves for this data indicated temperature differences at burnout on the order of 100-200 degrees $F$ and temperature differences at the minimum ranging from 700 to 1100 degrees $F$. These results (which are somewhat higher than in other experiments) are felt to be caused by a scale deposit on the test surface. Physical evidence indicates that the test surface became coated with an appreciable scale deposit when subjected to the initial temperatures in excess of 1500 degrees $F$ in a steam atmosphere. It has been found (Ref. 21) that BWR fuel will normally have scale deposit on the heat transfer surface, and thus the data in this report should be applicable to BWR Loss-of-Coolant accldent evaluation.

An empirical correlation was developed for this data for minimum film bolling temperature differences. The correlation was based on Berenson's minimum pool film boiling temperature difference correlation in order to provide a technique for extrapolating to different pressures.

The film bolling data was compared against the Groeneveld Correlation and found to be considerably underpredicted by the Groeneveld Correlation. An empirical correction term was developed to use in conjunction with the Groeneveld Correlation to predict the experimental data.

A calculation procedure is presented which allows one to predict the heat transfer history of a General Electric Boiling Water Reactor in the event of a Loss-of-Coolant accident. 


\section{ACKNOWLEDGMENTS}

The financial support for this project by the General Electric Company is gratefully acknowledged. We would especlally wish to thank Dr. Richard Lahey and Mr. Bruce S1ifer for their advice and recommendations for this report.

We also want to thank Ms. Rosalyn Mamlak for typing the report. 
TABLE OF CONTENTS

TITLE PAGE

ABSTRACT

ACKNOWLEDGMENTS

TABLE OF CONTENTS

LIST OF FIGURES

NOMENCLATURE

I. INTRODUCTION

II. G.E. DATA AND DATA REDUCTION

Experimental Apparatus

Steady State Experiment

Translent Experiment

Data Reduction

Determination of Derivatives

Error Analysis

III. THE $\triangle T$ AT THE MINIMUM POINT

Impulse Cooling Collapse

Axial Conduction Controlled Collapse

Dispersed Flow Rewet

Effect of Mass Flux

Effect of Quality

Effect of Pressure

History and Flow Regime

Thermal Conductivity and kpc Ratio

Oxidation of or Solid Matter Deposition on Surface

Contact Angle and Surface Tension

Proposed Correlation

IV. FILM BOILING HEAT TRANSFER

General Remarks

Groeneveld Correlation and Its Problems
1

11

ii1

Iv

vi

viii

1

3

3

4

4

5

9

10

13

13

14

15

16

16

17

18

19

20

20

21

24

24

25 
Experimental Heat Transfer Results

v. DISCUSSION

VI. RECOMMENDATIONS

REFERENCES

42

APPENDIX A

44

APPENDIX B: Data Reduction Computer Program

45

TABLES

55

FIGURES 


\section{LIST OF FIGURES}

Test Loop

Transient Test Section

Physical Geometry and Boundary Conditions for Solution of Inverse Heat Transfer Problem

Pictoral Represenation of Curve Fitting Procedure Used in Obtaining Functional Form for $T_{0}(t)$ and Its Derivatives

Sample of Quench Temperature-Time Data from Thermocouple on Qutside Wall of Transient Test Section

Sample of Accuracy of Curve Fitting Technique

Reduced Boiling Data from G.E. Transient Test Section

Approximate Error Due to Axial Conduction in Transient Test Section

Film Boiling Minimum $\Delta T$ Sketch Showing Effect of Quality Film Boiling $\Delta T$ vs Equilibrium Quality, Effect of Mass Flux Pool Film Boiling $\Delta \mathrm{T}_{\mathrm{min}}$, Berenson's Correlation Film Boiling Minimum $\Delta T$ vs Equilibrium Quality, Effect of History of Flow Regime

Film boiling Minimum $\Delta T$ vs Equilibrium Quality, Effect of Mass Flux

Tube Wall Temperature Profiles - 0.228 inch ID Tube (Fig-10 of Ref 16)

Surface Temperature Profiles in CHFC for a Mass Velocity of $3.86 \times 10^{6} 1 \mathrm{~b}-\mathrm{ft}^{-2} \mathrm{~h}^{-1}$ with Increasing Heat Flux (Fig 9 of Ref 11)

Comparison of General Electric Data with the Groeneveld Correlation

Comparison of General Electric Data with Heat Transfer Data Generated from Two-Step Model of Hynek(17)

Film Boiling Correction Term vs Equilibrium Quality with Mass Flux as Parameter 
40

41

42

43

44

45

46

Axial Power Shape (NEDE - 13204)

Collapse Temperature Difference vs Mass Flux (NEDE - 13204)

Quench Profiles for $G=0.24 \times 10^{6} 1 \mathrm{~b} / \mathrm{hr}-\mathrm{ft}^{2}$ (NEDE - 13204)

Quench Profiles for $G=0.516 \times 10^{6} 1 \mathrm{~b} / \mathrm{hr}-\mathrm{ft}^{2}$ (NEDE - 13204)

Pictoral Representation of Boiling Curve

Extrapolations for $\Delta \mathrm{T}_{\mathrm{m} \text { in }}$ Correlation

Extrapolations for Correction Factor Correlation 
NOMENCLATURE

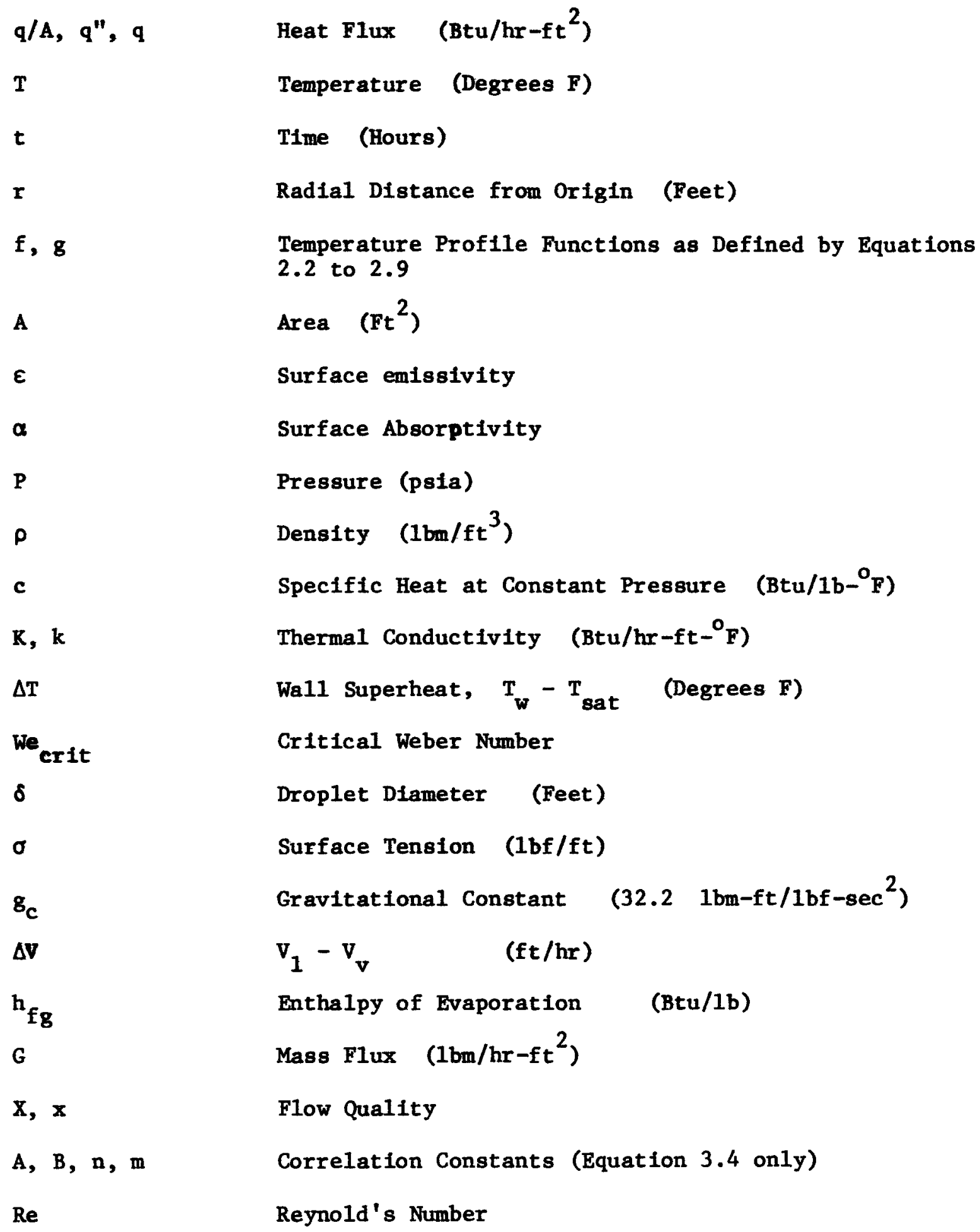




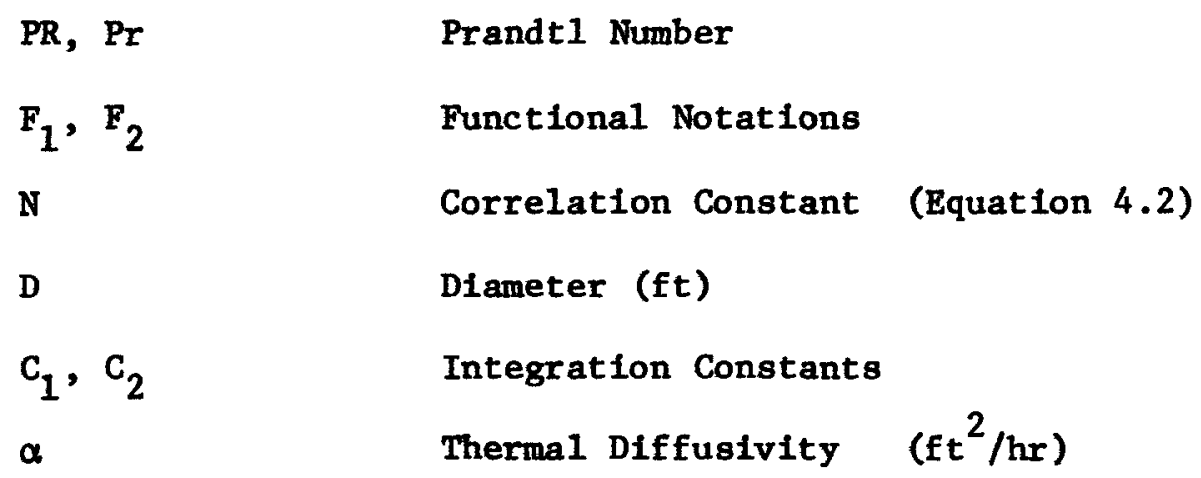

Prand 1 Number

Functional Notations

Correlation Constant (Equation 4.2)

Diameter (ft)

Integration Constants

Thermal Diffusivity $\left(\mathrm{ft}^{2} / \mathrm{hr}\right)$

Reference Boundary

Outside Boundary (radius)

Inside Boundary (radius)

Wa11

Iiquid

Radiation Component

Thermodynamic Critical state

Wetting Value

Vapor

Saturation

Minimum

Berenson's

Equilibrium

Groeneveld 's

Film Temperature $\left(T_{v}+T_{w}\right) / 2$ 
I. INTRODUCTION

The BWR design basis loss-of-coolant accident (LOCA) is described completely in reference (1) and in shortened form in reference (2). In brief, one of the main coolant pipes is assumed to break so the net flow of coolant through the core drops to near zero over a period of many seconds. As a result of the receding coolant level in the pressure vessel and the reduced flow rate through the core some of the fuel rods are calculated to pass through the critical heat flux and to overheat. Using conservative assumptions about the heat transfer mechanisms involved, temperatures in excess of $1500^{\circ} \mathrm{F}$ may be calculated to occur. The primary purpose of this report is to suggest more realistic heat transfer correlations which are appropriate for the calculation of rod surface temperatures during the postulated loss-ofcoolant accident.

As all the bolling heat transfer regimes occur during the LOCA, the following point of view is taken in this report: If we had the complete heat flux versus temperature difference curves with the quality, mass flux,

pressure, and other relevant variables as parameters, it would be possible to calculate the cooling curves for the fuel elements. As nucleate boiling, critical heat flux, transition bolling, the minimum $q / A$ point, and film boiling all occur at some time or place during the accident, it means we must have ways to calculate all these quantities. 
For small temperature differences nucleate boiling occurs, and the Jens and Lottes correlation is appropriate (3). When the quality becomes high enough, or the heat flux becomes great enough, the critical heat flux (CHF) is attained. Existing CHF correlations can be used to calculate when this occurs (4). Beyond CHF there is a poorly understood region of heat transfer which is called the transition region. It is suggested here that a straight line on $\log -\log$ (i.e. power law relationship) should be used to estimate the temperature and heat flux between the minimum $q / A$ and the CHF points.

The bulk of this report will deal with the method of determining the remaining two quantities, the temperature difference at the minimum and the fllm boiling heat transfer at the temperatures and pressures which are calculated to arise during LOCA. The experiments upon which these recomendations are based were conducted at the Nuclear Energy Division of the General Electric Company, the details of which follow. 
II. GE DATA AND DATA REDUCTION

Experimental Apparatus

The experimental program herin described consisted of two test series, a transient serieg and a steady state series.

The experimental test loop shown in fig. 1 was constructed to allow one to perform either the transient or the steady state-type tests. The loop is a high pressure (1500 psig) water system consisting of a circulating pump, bọiler, preheater, primary test section, transient test section, steam drum and condenser. The desired quality for the test section inlet was obtained by regulating the preheater. There is a system of quick acting valves at the entrance to the primary test section that allows the flow to be diverted to or away from the test section. The primary test section consists of an electrically heated tube $.492 "$ I.D. and .625" O.D. with a heated length of 219 inches. Thermocouples are spaced at three, six, or twelve inch intervals along the primary test section.

Fig. 2 gives a detailed drawing of the transient test section. It is $.492 "$ in I.D. and 1.0" in O.D. and has a 4" heated length. The transient section as well as the primary test section were constructed of inconel $\mathrm{X}-750$, since the resistivity of this material has only a very small dependence on temperature. The transient section was instrumented with thermocouples at $1 / 2$ inch intervals along its length. The power to the transient section is independent of the primary section. There is an unheated section of tube about 1.5 inches in length between the primary and transient test sections that could not be avoided due to bus bar connections. The entire loop was monitored for the standard system variables of mass flux, heat flux, quality, and pressure. 
Steady State Experiment

The General Electric steady state experiments were a duplicate of those performed by Bennett, et al (11) but at mass fluxes of $.05-.5 \times 10^{6}$ $1 \mathrm{bm} / \mathrm{hr}$. $-\mathrm{ft}^{2}$ and pressure levels of $100-1000$ PSIA. The experimental technique was the same. Water with a certain amount of subcooling was directed into the primary test section. The power was then turned on, and increased in steps until some desired steady state temperature profile was achieved. The resulting data was used in this report only as means of verifying the transient data results.

Transient Experiment

The transient experiments were designed to allow one to produce a whole bolling curve in one experiment. Due to the nature of a quench experiment all the regimes of boiling are experienced. The size of the transient section was purposely kept at a minimum to reduce the quality variation with length and time, through the quenching process. The transient section was placed at the exit of the primary section to allow one to control the inlet quality to the transient section. Therefore, throughout the entire quench process the value of quality and mass flux remained virtually constant and determinable.

The procedure that was followed in obtaining the transient data involved:

1. Establishing, for each $r$ un, the desired steady state mass flow rate and quality at the entrance to the transient test section. 2. Applying power to the transient section until steady film boiling was established in the transient section.

3. Cutting off the power to the transient section and recording the temperature transient on a Sanborn recorder.

The signal from one of the eight thermocouples was also inputted to 
DYMEC (a system that digitizes a continuous signal with time at a certain rate and has various output options) and was considered as the data thermocouple of that particular run. The choice of the particular thermocouple used was made by inspecting the thermocouple traces on the Sanborn recorder. The data thermocouple must have

1. Clearly shown film bolling condition

2. Been as close to the midplane of the transient section as possible (to avold or minimize end effects)

3. Been relatively free of noise.

Because of the presence of the preheater in the test loop it was possible to produce a given quality at the entrance to the test section In two ways. It could be produced elther by the primary test section or by the preheater. For runs numbered 4-16, the preheater power was off, and Inlet subcooling and temperature were evaluated at the inlet of the primary test section. The desired quality was regulated by the power to the primary test section. For runs 17-23 the primary test section power was off and conditions were set by using the preheater power only. For these latter runs, inlet subcooling and temperature were evaluated at the inlet of the preheater. In every case, the quality was evaluated by making due allowance for heat loss from the primary test section and preheater.

Data Reduction

General Solution:

In order to transform the temperature-time data as recorded from the thermocouples welded to the outside tube wall of the transient test section into heat flux and wall temperature on the inside surface one needs the solution of the so-called inverse heat transfer problem. 
6

Unlike the direct heat transfer problem where boundary conditions are completely defined allowing one to solve for interior points, the inverse problem consists of prescribed conditions in the interior and desired conditions on the surface. There are several methods for solving this type of problem. These include finite difference techniques and integral methods requiring iterative calculations. These methods, therefore, require fairly bulky and complicated computer codes. Instead, an exact solution in the form of a rapidly converging series developed by $0 . R$. Burggraf (12) was used. With this method one merely needs to know boundary conditions at one point as a function of time to determine conditions at any other point in the solid. The general solution for any shape solid is as follows.

Given $T_{b}(t)$ and $q_{b}(t)$ on a normal to surface $r=r_{b}$ the general solutions for $T(t)$ at any $r$ is

$$
T(r, t)=\sum_{n=0}^{\infty} f_{n}(r) \frac{d^{n} T_{b}}{d t^{n}}-\frac{1}{k} \sum_{n=0}^{\infty} g_{n}(r) \frac{d^{n} q_{b}}{d t^{n}}
$$

where $f_{n}$ must satisfy:

$$
\begin{gathered}
\nabla^{2} f_{0}=0 \\
\nabla^{2} f_{n}=\frac{1}{\alpha} f_{n-1} \quad \text { for } n=1,2,3 \ldots \\
f_{0}\left(r_{b}\right)=1, f_{n}\left(r_{b}\right)=0 \text { for } n=1,2,3 \ldots \\
f_{n}^{\prime}\left(r_{b}\right)=0 \quad \text { for } n=0,1,2,3 \ldots
\end{gathered}
$$

and $g_{n}$ must satisfy:

$$
\nabla^{2} g_{0}=0
$$




$$
\begin{aligned}
& \nabla^{2} g_{n}=\frac{1}{\alpha} g_{n-1} \text { for } n=1,2,3 \ldots \\
& g_{n}\left(r_{b}\right)=0 \quad \text { for } n=0,1,2,3 \ldots \\
& g_{0}^{\prime}\left(r_{b}\right)=1, g_{n}^{\prime}\left(r_{b}\right)=0 \text { for } n=1,2,3 \ldots
\end{aligned}
$$

The general solution is somewhat shortened when it is applied to the solution of the heat transfer problem assoclated with the G.E. transient test. The specific problem can be formulated by looking at Fig. 3 . Given a hollow cylindrical body completely insulated at $r=r_{0}$ and a known (measured) temperature variation with time, $T_{0}\left(r_{0}, t\right)$ at $r=r_{0}$, what are the values of $q(t) / A$ and $T_{i}(t)$ on the inside radius, $r_{i}$, of the tube. The condition of zero heat flux at $r_{0}$ allows us to drop the g-series immediately. Equation 2.10 is the resulting series solution (truncated to three terms) for the inside wall temperature in terms of wall properties, geometry, and time derivatives of the outside wall temperature $T_{0}(t)$.

$$
\begin{aligned}
& T\left(r_{i}, t\right)=T_{0}(t)+\left\{\frac{r_{0}^{2}}{4 \alpha}\left[\left(\frac{r_{i}}{r_{0}}\right)^{2}-1-2 \ln \left(\frac{r_{i}}{r_{0}}\right)\right]\right\} \frac{d T_{0}}{d t} \\
& +\left\{\frac{1}{64 \alpha^{2}}\left[r_{i}^{4}-5 r_{0}^{4}\right]-\frac{r_{0}^{2} r_{i}^{2}}{8 \alpha^{2}} \ln \left[\frac{r_{i}}{r_{0}}\right]-\frac{r_{0}^{4}}{16 \alpha^{2}} \ln \left[\frac{r_{i}}{r_{0}}\right]+\frac{r_{0}^{2} r_{i}^{2}}{16 \alpha^{2}}\right\} \frac{d^{2} T_{0}}{d t^{2}}
\end{aligned}
$$

The solution for $f_{0}, f_{1}$ and $f_{2}$ are given in Appendix $A$ to detail their solution from equations 2.2 through 2.5 . In order to determine the inside wall heat flux one merely differentiates equation 2.10 with respect to $r_{i}$ and multiply the result by the thermal conductivity of the 
solid. In order to have a three term series for $q / A(r, t)$ one has to know $\mathrm{f}_{3}$, as $\mathrm{df}_{\mathrm{o}}$ is zero. Equation 2.11 is the resulting form for $q / A\left(r_{i}, t\right)$. Note $\overline{d r}$ that the first term is the standard lumped heat

$$
\begin{aligned}
& \text { capacity formulation. } \\
& \qquad / A\left(r_{i}, t\right)=\left\{\rho c\left[\frac{r_{i}^{2}-r_{0}^{2}}{2 r_{i}}\right] \frac{d T_{0}}{d t}+\left\{\frac { ( \rho c ) ^ { 2 } } { k } \left[\frac{r_{i}^{3}}{16}-\frac{r_{0}{ }^{4}}{16 r_{i}}\right.\right.\right. \\
& \left.\left.-\frac{r_{0}^{2} r_{i}}{4} \ln \left(\frac{r_{i}}{r_{0}}\right)\right]\right\} \frac{d^{2} T_{0}}{d t^{2}}+\left\{\frac { ( \rho C ) ^ { 3 } } { k ^ { 2 } } \left[\frac{r_{i}^{5}}{384}-\frac{3 r_{0}^{4} r_{i}}{128}\right.\right. \\
& \left.\left.+\frac{3 r_{0}^{2} r_{i}^{3}}{128}-\frac{r_{0}^{6}}{384 r_{i}}-\frac{r_{0}^{2} r_{i}^{3}}{32} \ln \left(\frac{r_{i}}{r_{0}}\right)-\frac{r_{0}^{4} r_{i}}{32} \ln \left(\frac{r_{i}}{r_{0}}\right)\right]\right\} \frac{d^{3} T_{0}}{d t^{3}}
\end{aligned}
$$

By investigation of the results using the three term series solution for the highest heat flux encountered and comparing the difference that one more term in the series would make towards the result it was determined that the extra term changed the result by less than $0.5 \%$. This is somewhat fortuitous as the accuracy of the solution is directly related to how accurately one knows the higher order derivatives of the outside wall temperature. If an extra term is required to converge the series one must first consider how accurately the higher order derivative is known before the effectiveness of adding the extra term can be determined. If these derivatives are evaluated from experimental data, then the higher order derivative cannot help but have Inaccuracies associated with it. Since we are indeed working with experimental data in our data reduction scheme, knowledge of the exact solution for the inverse problem brings us only halfway towards the final reduced results. Some method for obtaining the time derivatives of the data is needed. The following section describes the methods used in this report for determining the function relationship of the outside wall temperature and the necessary derivatives. 


\section{Determination of Derivatives}

The experimental data consisted of a series of temperatures measured by one given thermocouple for each run, with the time interval between points equal to .2 seconds. A sample of the type of experimental data to be processed 18 given in Fig. 5. It is readily apparent that due to the presence of a small random nolse level in the data, finite difference methods for obtalning the derivatives are out of the question. The next thought was to try to filter the data and then apply finite difference techniques, but again there still appeared to be too great an uncertainty associated with finite difference techniques. The method finally chosen was that of applying a least square polynomial curve fit through the data points. The least square curve fiţ not only smoothe. out the data, but more importantly gives a functional relationship for the outside wall temperature and all its derivatives (up to the order of the curve fit) with time. As some runs contained as many as 500 points, it was thought that better representation of the data could be obtained by dividing the data into several segments and putting separate curve fits through each of the segments. Fig. 4 gives a pictorial view of the entire curve fitting procedure. The curve fitting segments were overlapped to make the separate pleces fit together as continuously as possible. In regard to each segment there was a choice as to the number of data points to be included in the section and what order curve fit up to a maximum of order 6 to be put through the points. Because there are certain tradeoffs one makes In using higher order curve fits to represent data it was decided to allow the curve fit order to be varlable. On one hand the higher order polynomials can follow the data better, but on the other side these curves fits tend to be wavey in nature causing the higher order 
derivative to behave badly. So with these three variables, number of points per segment, number of points to be overlapped into previous curve fit region, and the order of curve fit for each segment it was possible by trial and error to obtain in some sense an optimum data reduction for each run. Fig. 6 compares the data against the curve fit for a typical run to give one an idea of how well the curve fit method works. Figures 7 through 25 give the reduced boiling curves for all the transient test runs. The computer program used in the reduction process is given in Appendix B. The next section gives a description of possible sources of error in the reduction procedure and attempts to determine limits of accuracy of the results.

\section{Error Analysis}

In analyzing possible sources of error in the results of this report there is considered to be no error assoclated with the solution method itself as it is almost an exact solution. Errors involved in the representation of the time derivatives of the outside wall temperature are considered negligible as there was no significant change in results when the curve fit polynomial varfed from order 4 to order 6 . There is a possibility of thermocouple error and/or heat losses through the insulation. These two possible sources of error have been partly corrected for in the data supplied by G.E. Any remaining error is represented by G.E. as being negligible.

In the transient test section there are two other possible sources of heat 1oss. These are radiation from the wall to two phase mixture and axial conduction in the tube wall.

The radiation term can be approximated as radiation between two parallel plates. The radiation term therefore is:

$$
(\mathrm{q} / \mathrm{A})_{\mathrm{RAD}}=\sigma\left(\mathrm{T}_{\mathrm{w}}^{4}-\mathrm{T}_{\mathrm{L}}^{4}\right) /\left(\frac{1}{\varepsilon}+\frac{1}{\alpha}-1\right)
$$


The highest wall temperature encountered in any run was $T_{w}=1900^{\circ} \mathrm{F}$. For a conservative calculation we let $\varepsilon=\alpha=1$ and $T_{L}=T_{\text {sat }}=544^{\circ} \mathrm{F}$. Therefore the radiation component for this maximum case turns out to be $38,000 \mathrm{Btu} / \mathrm{hr} .-\mathrm{ft} .^{2}$. For some of the film boiling heat fluxes this is not a negligible portion of the total heat flux. It was decided though not to correct the film boiling results. (see Section IV Film Boiling Heat Transfer for further discussion of this problem).

As for the axial conduction loss, it was stated in Section II that the specific thermocouple used in the data taking process was chosen for, among other things, its being as close to the mid-plane of the transient test section as possible in order to minimize the end effects. Unfortunately, due to various effects including possibly: 1) the scale on the boiling surface 2)transition from annular vapor flow at the transient test section inlet to nucleate boiling, it proved impossible to obtain uniform film boiling throughout the entire 4 inch length. In investigating the entire eight thermocouple readings from the Sanborn traces, an axial temperature distribution resembling a parabola was observed. The maximum temperature for the bulk of the data was at the data thermocouple. Therefore there was heat loss both upstream and downstream due to axial conduction. In order to estimate what percentage the heat loss is relative to the film bolling heat transfer calculated, the initial values of the neighboring upstream thermocouple, data thermocouple, and neighboring downstream thermocouple were noted. A straight line slope was passed through the points and a heat flux was calculated. Fig. 26 gives the general model used and the resulting percentages of heat loss relative to the calculated film boiling heat loss. Observing the relative magnitude of these three thermocouple readings throughout any particular run it was determined that the use of just the initial values before the start of 
the quench gave the maximum 1osses. The point of collapse for each run tended to have losses of the order of $1 / 4$ the values quoted in Fig. 26. Though the error in the calculated values of this report could be as great as the errors quoted but its our feeling that the error will be less due to the lumping procedure. 
III. THE $\triangle T$ AT THE MINIMUM POINT

Three different controlling mechanisms for forced convection transition from film to nucleate bolling have been proposed in an earlier work by O.C. Iloeje and D. Plummer (13). These mechanfoms have been called Impulse Cooling Collapse, Axial Conduction Controlled Collapse, and Dispersed Flow Rewet. The features distinguishing these three possibilities are the hydrodynamics of the fluid flow and the geometry of the fluid in the heat transfer process leading into transition.

Impulse Cooling Collapse

It is known that in the annular vapor film boiling regime [rod regime] the 1iquid vapor interface is wavy and pulsates about a mean position. With falling surface temperature or applied heat flux, the film thickness falls and the wavy crest eventually contacts the surface. At the higher temperature levels, the liquid is in contact with the surface for some minimum residence time before a vapor film forms pushing the liquid bulk away from the surface and momentarily leaving the surface dry. The residence time has been modelled by Kalinin (6) to be equal to the time needed to heat a layer of liquid equal to the nucleating bubble diameter to a temperature equal to the nucleation superheat. During each contact, an impulsive cooling of the wall occurs and repeated contacts will eventually cool the wall to a temperature at which permanent liquid contact can be maintained. Kalinin correlated his 
experiments completely in terms of the (kpc)ratio of liquid and wall. Neither mass flux nor quality nor other fluid properties entered into his empirical equation. The absence of the quality variable may be understood in the light of arguments in later sections of this report, since the quality ranges he dealt with were most probably very low.

$\frac{\mathrm{T}_{\text {cr } 2}-\mathrm{T}_{\text {sat }}}{\mathrm{T}_{\mathrm{c}}-\mathrm{T}_{\mathrm{L}}}=1.65\left(0.16+2.4\left[(\text { pck })_{\mathrm{L}} /(\text { pck })_{\mathrm{w}}\right]^{.25}\right)$

where $\mathrm{T}_{\mathrm{cr} 2}=$ Temperature at minimum

$T_{\text {sat }}=$ Saturation temperature

$\mathrm{T}_{\mathrm{c}} \quad=$ Thermodynamic Critical Temperature

pck = Density, specific heat, and thermal conductivity, respectively liquid "L" and wa11 "w"

Axial Conduction Controlled Collapse

This deals more with the propagation of a wetting interface over a heated surface. The solid-1iquid-vapor interface is taken to be at the wetting temperature and is propagated downstream through axial conduction which brings successive points to the wetting temperature enabling the interface to advance to those points. In the work by Simon and Simoneau (14) they assumed this wetting temperature to be a thermodynamic property of the fluid and to be given by the expression of Spiegler (19) et a1.

$$
\frac{\mathrm{T}_{\text {wet }}}{\mathrm{T}_{\text {crit }}}=0.13 \frac{\mathrm{P}}{\mathrm{P}_{\text {crit }}}+0.84
$$

The constant term 0.84 was corrected to 0.872 based on the experimental results of Merte and Clarke (5). Again hydrodynamic effects were not considered to be important in the value of $T_{\text {wet }}$. In each of the above two types of rewet considered, heat transfer to the vapor contributes to the rewetting process. 


\section{Dispersed Flow Rewet}

In the dispersed flow film boiling regime with a distribution of liquid droplets, rewet is controlled by the presence of liquid droplets close to the heated wall. Some droplets do penetrate through the superheated vapor boundary to the heated wall, but the transition process is seen here more clearly in terms of the limiting effects of two processes, namely heat transfer to the vapor and heat transfer to the droplets which may or may not be touching the heated surface. At higher wall temperatures, the 11quid droplets are generally farther away from the wall because the repulsive force of vapor formed as a droplet approaches the wall is larger. The heat transfer to the droplets is therefore sma1ler, and that to the vapor larger (see fig. 27). The sum of the two gives the total heat transferred and indicates the wall superheat at which the minimum heat flux will occur.

The transition process in General Electric's experiments which is presented in this report is controlled by this phenomenon. With dispersed flow controlled rewet, such geometric factors as the size of the droplets and the general nearness of the drops from the wall are important factors. These in turn are related to the presssure quality and mass flux at rewet and the flow history prior to the collapse point.

Before discussing the variables affecting the transition temperature at the minimum, the salient results of the GE experiments will be presented.

The reduced GE data are shown in figures (7-25) as plots of $q / A$ vs $\Delta \mathrm{T}$. From these, the transition temperatures from film to nucleate boiling were taken as the minimum on the bolling curves. Not a11 the experimental runs went through this transition. Some remained in film bolling for essentlally the entire transient (run numbers 14 and 15) while others started the transient without getting completely into fil. boiling (run nos. 11, 16, 22 and 23). 
Table 1 gives the complete minimum data, including the mass flux, quality and $\Delta T$ at the minimum point.

At very low mass velocity and quality, the droplets may not be entrained and an "Interface" separating a dense phase and a less dense phase In the test section may occur. This is not a steady state phenomenon but in a quench test it may occur. Effect of Mass Flux

At higher mass fluxes for a given quality, there is greater mixing of the flow, reduced superheating of the vapor, and consequently higher heat transfer coefficients as a result of all three effects. Because of the higher momentum of the randomly moving liquid droplets and the lower temperature of the desuperheated vapor boundary layer, any droplet projected towards the wall will have a higher probability of getting very close to 1 t. Since the transition has been modelled as heat transfer controlled, Improvement in the heat transfer due to the higher mass flux would lead to transition occuring at a higher wall superheat, as may be seen from figure 28 .

Figure 21 (run 16) shows the translent bolling process starting with transition bolling. Consequently, no minimum $\Delta T$ was recorded. It is quite possible that: at such a high mass $\left(250,000 \mathrm{lb} / \mathrm{hr} \mathrm{ft} .^{2}\right)$ the wall superheat at minimum heat flux would be higher than the superheat at which the transient was started. Hence the bolling curve obtained. Effect of Quality

Figure 27 shows a sketch of heat transfer to the 1iquid droplets and to the vapor for the same mass flux at two quality levels. At a given quality, the heat transfered to the droplets is higher at lower wall superheat levels. The inverse is true at higher superheats. On the other hand vapor heat transfer continues to increase with wall 
superheat. The sum of the two indicates the level of $\Delta \mathrm{T}$ at the minimum total heat flux. At a higher quality heat transfer to the droplets falls while that to the vapor increases. The result is to lower the level of $\Delta \mathrm{T}$ at the minimum total heat flux for higher quantities. Hence the observed trend in figure 28 .

The above described additive effects can be very clearly seen from figures 16 and 17, [run nos. 14 and 15] in which the equilibrium qualities at inlet to test plece were greater than 1.0 . Consequently the droplet population and sizes must have been very small. The vapor film would have been highly superheated making it difficult for droplets to have penetrated towards the wall. The average distance of drops from the wall would be higher. Consequently the heat transferred to the droplets was almost negligible. The q/A vs. $\Delta T$ profile would then resemble that for heat transfer to single phase vapor as figures 16 and 17 indicate. No rewetting could be expected and none occurred, Effect of Pressure

Previous work on the accelerating flow of 1iquid droplet/vapor mixture have shown that a critical Weber Number, We ${ }_{\text {crit, }}$ exists at which a droplet breaks into two or more droplets of same total mass but smaller sizes. Thus

$$
\delta \leq \frac{\sigma g_{c}}{\rho_{v}(\Delta v)}{ }^{W e}{ }_{c r i t}
$$

At higher pressures, the droplet sizes are smaller for the same quality and mass flux. The total droplet surface area is larger and the vapor superheat smaller. Droplet heat transfer is thus larger. Moreover, due to the decreasing vapor specific volume with pressure, the pressure differential which repels the droplet from the wall, and which arises from the expansion of the evaporating liquid, is smaller. This allows 
the droplets to penetrate deeper into the vapor thermal boundary layer, enhancing the heat transfer. These two factors have the effect of increasing the overall heat transfer with increasing pressure, at the same quality and mass flux. The transition $\Delta T$ minimum will thus be higher.

The effects of pressure on $\Delta \mathrm{T}_{\mathrm{min}}$ in pool boiling follows the same trend. Fig. 29 shows a plot of pool boiling $\Delta T_{\text {min }}$ vs. $T_{\text {sat }}$. The parameters whose large variations with pressure are of greatest significance are the densities $\rho_{v}, \rho_{1}$ and heat of evaporation $h_{f g}$. Since it is not necessary for a droplet to touch the surface at the minimum, the minimum can occur at a temperature greater than the thermodynamic critical temperature. History and Flow Regime

In considering the effects of the presence of liquid droplets, it is not only the quality at the region of transition that is important, but also, the spatial distribution of the droplets across the channel. In the G.E. experiments for example, the inlet qualities to the transient test section were developed efther in the preheater with no heating of $181 / 4 \mathrm{ft}$. 1ong primary test section, or by heating of the primary section only. Figure 30 shows the results of tests for the two cases. The $\Delta \mathrm{T}_{\text {min }}$ data with no heating of the primary section were significantly higher. With no heating of the primary section, the two phase flow could come to equilibrium and any superheat in the vapor layer would be eliminated. In addition, more of the liquid droplets would tend to migrate to the wall and form a liquid film and probably there would be nucleate boiling at the entrance to the short test piece. The improved heat transfer that results, during the transient, will probably cause transition at a higher wall superheat. However axial conduction may also be significant. In all cases in the GE data the wall was wet 
approaching the test section. For the unheated inlet tube there was more liquid on the walls than when the inlet tube was heated but the wall was always wet.

Experiments with the heated inlet tube are closer to the conditions existing in a reactor and these have been used in the analysis and correlations presented in this report. Surface or Boundary Effects

Thermal Conduct ivity and kpc ratio

Various experimenters, e.g. Stock (9), Kalinin (6), Berensen (7), who have investigated film boiling transition in either pool boiling or with low quality flows, have indicated that the liquid consistently touched the surface prior to collapse. This phenomenon is not deemed restricted to pool bolling or low quality flows. During the period of contact, heat transfer over the contact region is controlled mostly by the phenomenon of pure conduction. A depression in temperature over this region occurs and its magnitude depends on the rate at which heat Is supplied from the surrounding heater material to the contact region. Thus a very highly conducting material will supply heat at such a high rate as to retard wetting to a lower temperature, while the contrary is true for a poor conductor.

Transient one dimensional conduction analysis of a slab of liquid in contact with a slab of solid material shows that the term $(k \mathrm{pc})_{\mathrm{L}}$ ' $(\mathrm{kpc})_{\mathrm{w}}$ is the relevant thermal property group controlling the variation of temperature with time and distance from the contact surface. As Indicated earlier, Kalinin used this parameter to correlate his experiments for transition in the rod flow low quality regime.

In order to determine the extent of the effect of conduction and non1sothermality of the heating surface, it is necessary to know not only the 
1iquid contact time and extent of the region of influence of conduction, but also the frequency of contacts over the transient period leading to transition. It is thought that though occasional contact occurs between the drops and metal in film boiling, the fraction of heat transferred during these contacts is small and is not essential in giving a minimum.

Oxidation of or Solid Matter Deposition on Surface

As with varying material conductivity, the presence of a solid film on the heating surface either from oxidation or deposition of foreign matter (crud) alters the nature of the boundary interaction between the fluid and the solid, hence introducing a completely new heat transfer mechanism. Accepting the arguement that $\Delta \mathrm{T}_{\min }$ is not a thermodynamic property of the fluid, but is a consequence of a variety of heat transfer processes, one would expect varlations in $\Delta \mathrm{T}_{\mathrm{min}}$ as a result of the formation of crud. The increased resistance to heat transfer imposed by the film allows the inside surface of the heating materlal to be at a higher temperature at transition. Moreover, as the film material is generally of low conductivity, the peaks of the non-uniform film surface projecting into the flow act as cold spots that intercept and trap some liquid into itself. Via the contact heat transfer that results, liquid can then migrate to the rest of the crudded surface, causing transition to occur at a higher temperature. This effect is hidden in the results plotted. However, in general we expect this kind of a heat transfer at a crudded surface.

Contact Angle and Surface Tension

Because of the fact that liquid contacts the surface prior to collapse, any increase in the wettability of the surface either via the introduction of a wetting agent or change in surface tension with temperature 
will increase the transition $\Delta T$. Berenson ( 7 ) observed this when he introduced oleic acid into pentane in pool bolling. The trend is expected to be the same in film bolling, but perhaps not as significant. Proposed Correlation

It is reasonable to expect that the correlation for film boiling transition $\Delta \mathrm{T}$ in forced convection would tend towards that for pool bofling when the quality and mass flux become very small. It may be pointed out of course that one is not certain as to what effective quality one should assign to pool boiling but intuition suggests that it would be small as the void fraction is small.

In 1962 Berenson (7) conducted a series of pool boiling experiments on 2 inch diameter horizontal surfaces. Data for all the boiling regimes were obtained, including the burn out and the minimum film boiling heat flux points. Heat was supplied in a steam chamber (allowing for controlled constant temperatures) through a copper block finned on the steam side, to the experimental surfaces. By soldering thin slabs of nickel and Inconel to the base copper block, three different surface materials were obtained. He tested also for the effects of surface roughness (cavity density) by applying different finishes from mirror finish to Lap $E$, to the surfaces. In addition to the experiments, Berenson developed a model in which bubble formation at the 1iquid/vapor interface was controlled by the unstable growth of a disturbance introduced at the interface, using the Taylor-Helmholtz instability equation. Of all possible frequenctes that might disturb the interface the most likely frequency is that which would cause the fastest rate of growth of the amplitude of the disturbance. Using this criterion as well as simplifying assumptions regarding the effects of vapor velocity and vapor film thickness in the vieinfty of the 
minimum heat flux, on the value of the most unstable frequency together with the energy and force balance equations, he determined expressions for the heat flux and wall superheat at the minimum heat flux in film boiling. The expression for $\Delta \mathrm{T}$ is given below (eqn. 3.5). The model used is very similar to the earlier one proposed by Zuber (20).

Since it was not necessary for the liquid to be in contact with the wall prior to collapse, two features of the correlation become apparent. The first is that the properties of the heating surface do not enter into the equation. The second is that it is then possible to predict a transition surface temperature in excess of the thermodynamic critical temperature of the liquid. This last feature is particularly important in the choice of Berenson's equation as that to be used in our correlation. G.E.'s experimental results show wall temperatures higher than the critical temperature for water. Berenson's equation also contained the relevant effects of pressure via the fluid properties, and as was pointed out earlier, was successfully used to correlate our results with Nitrogen (13).

It may be pointed out that Berenson found neither the cavity density nor surface thermal properties to have had any significant effects on the transition temperature. As long as the roughness heights were lower than the vapor film thickness, surface smoothness or lack of it would not affect the transition temperature.

With respect to other factors that may be taken into account in developing a correlation, it has been observed that $\Delta \mathrm{T}_{\min }$ generally falls with increasing quality and increases with mass flux. Axial and radial conduction effects in the wall have been ignored. It may be argued that the droplet residence time at any one point is so fleeting that surface 
transient conduction effects may be ignored.

A correlation of the form:

$$
\Delta T_{\text {min }}=\Delta T_{B E R} . \quad\left(1-A X^{n}\right)\left(1+B G^{m}\right)
$$

whore $\Delta \mathrm{T}_{\mathrm{BER}}$ is given by

$$
\Delta T_{B E h}=0.127 \frac{\rho_{w f} h_{f g}}{k_{v f}}\left[\frac{g\left(\rho_{L}-\rho_{v}\right)}{\rho_{L}+\rho_{w}}\right]^{2 / 3}\left[\frac{g_{c} \sigma}{g\left(\rho_{L}-\rho_{w}\right)}\right]^{1 / 2}\left[\frac{\mu_{f}}{g_{c}\left(\rho_{L}-\rho_{v}\right)}\right]^{1 / 3}
$$

was used with data for $50,000 \mathrm{lb} / \mathrm{hr}$. ft ${ }^{2}$ and $100,000 \mathrm{lb} / \mathrm{hr} . \mathrm{ft}^{2}$ at qualities of $0.3,0.6$ and 0.8 . The resulting equation is

$\Delta \mathrm{T}_{\min }=0.29 \Delta \mathrm{T}_{\mathrm{BER}}\left(1-0.295 \mathrm{x}_{\mathrm{E}}^{2.45}\right)\left(1+\left(\mathrm{G} \times 10^{-4}\right)^{.49}\right)$

FIgure 31 shows a superposition of this correlation on the experimental data. We do not profess much confidence in using equation 3.6 for extrapolation to mass fluxes outside the range $50,000 \leq \mathbf{G} \leq 100,000$ $1 \mathrm{~b} / \mathrm{hr}$. $\mathrm{ft}^{2}$. At a high enough mass velocity the superheat in the vapor will disappear and the drops will be very small with consequent higher heat transfer. It is suggested that for $G>100,000$ use $G=100,00$ in equation 3.6. The transition $\Delta T$ thus obtained will be lower than the actual value, implying a conservative estlmate. Since the effect of mass flux is considered to be not very pronounced for low mass fluxes, the value of $G=50,000 \mathrm{lb} / \mathrm{hr} \mathrm{ft}^{2}$ may be used for $G \leq 50,0001 \mathrm{~b} / \mathrm{hr} . \mathrm{ft}^{2}$, in equation 3.6 . 
IV. FILM BOILING HEAT TRANSFER

Genera1 Remarks

Post critical heat transfer film boiling has been quite extensively investigated in the last decade. Laverty (15), Forslund (16), and Hynek (17) of M.I.T. and Bennett (11) of Harwell have developed the two step heat transfer process in the Post CHF film boiling region. This model implies that heat is transferred first to vapor and then from vapor to drops. The basic difference between the Bennett model and the M.I.T. model is the allowance of a direct wall to droplet heat transfer in the M.I.T. model which is missing in Bennett's formulation. The relative magnitude of this wall to droplet term is defined by constant $\mathrm{K} 1 \mathrm{~K} 2$ which is determined from experimental data. The drawback with both of the models is that they are awkward to work with from an applications point of view. Both are differential models requiring initial conditions and a computerized finite difference solution scheme. The perfect tool for the determination of post critical heat transfer is a correlation in terms of local and easily calculable variables such as mass flux and equilibrium quality.

Before we can do this, there are certain difficulties that must be overcome. First, the heat transfer in Dispersed Flow Film Boiling is history dependent, that is, it is a function of events occuring upstream. In relation to this there is also a certain amount of superheat in the vapor that depends on such things as heat flux, mass flux and fluid properties. This thermal non-equilibrium means therefore that actual flow quality and the equilibrium quality will be different. As yet there is no easy way to relate the two. Therefore any correlation in terms of mass flux, equilibrium quality and fluid properties alone will of necessity be compromised in some 
portion of the test section if the history effect is not accounted for. As of this time we are not able to overcome this problem, but we feel certain that the answer lies in returning to the theoretical two step model and trying to find simple trends in some of the key varlables that will allow one to reduce the solution of post critical heat transfer to a closed form correlation.

Groeneveld Correlation and its Problems

Out of necessity and for lack of a better scheme, correlations have been devised based solely on experimental data. The one now used by G.E. (In accordance with the AEC Interim Acceptance Criterion) is due to Groeneveld (18). This correlation is basically a forced convection vapor heat transfer correlation with a quality correction. The coefficients were optimally determined by a least square program applied to a wide range of data from the 1iterature. Coneveld correlation for tubes is given by

$$
\begin{aligned}
& N u_{g}=0.00124\left[R_{e g}\left(x+\frac{\rho}{\rho_{l}}(1-x)\right)\right]^{.877} y^{-.6} P R^{1.52}(q / A) \\
& \text { where } \left.y=1-0.1 \frac{\left(\rho_{l-1}\right)}{\rho_{\dot{g}}}\right)^{0.4}(1-x)^{0.4}
\end{aligned}
$$

The general functional relationships are that heat transfer increases for increasing mass flux and increases for increasing quality.

If we now observe temperature - length plots both experimentally determined as in Fig. 32 and theoretically derived from the 2-step model, the following dependence of heat flux with quality has been noted. Considering the absicissa in Fig. 32 as directly proportional to quality and ordinate as inversely proportional to heat transfer coefficient, $h$, one sees that as quality increases, $h$ first increases to some maximum at some quality and decreases after the maximum. This maximum point depends upon such things as the CHF point, mass flux, heat 
flux and fluld properties. The relatively low $h$ at low quality is caused by the low vapor velocity while the low $h$ at higher quality flow is due in part to the superheat in the vapor. It $1 \mathrm{~s}$ evident that Groeneveld's correlation does not follow this trend of increasing heat transfer with quality to a certain maximum value and subsequent decrease. One must say though that the heat transfer coefficient increases at a decreasing rate with quality. But why does it never show the reversal condition? (see Fig. 34 through 36 for plots of Eqn. 5.1).

The first step is to examine the data from which the correlation was made. Generally the quality was above $40 \%$ and the mass fluxes were above 500,000 with just a few points at $200,0001 \mathrm{~b} / \mathrm{hr}-\mathrm{ft}^{2}$. It is Important to note the general experimental method too. Saturated or subcooled flow was put into the tube and then heat flux was applied so the resulting CHF point occurred somewhere inside the tube. Because of heat flux limits the resulting CHF quality tended to be in the middle to high quality range. Fig. (33) is a temperature - length plot from Bennett (11) which 1llustrates very well this kind of data. This data was taken in an experiment such as described above and was used in Groeneveld's correlation. For each heat flux the heat transfer coefficient increases with increasing quality, which substantiates eqn. 4.1, but due to the limitations of the apparatus (1.e. the tube was not long enough) the full temperature-length plot was never achleved. Due to the relationship between the value of quality at burnout and the position of CHF point relative to the exit of the tube, the heat transfer coefficient was never able to reach its maximum and begin to decrease. Also there could be a significant difference between actual and equilibrium quality with equilibrium quality being always the higher. In fact fig. 32 used to argue the quality reversal phenomenon demonstrates the problem of superheating the vapor. The quality reversal is indeed 
present, but due to the tendency of liquid nitrogen (the test fluid used in generating fig. 32) to support high vapor superheating the reversal point was at an equilibrium quality greater than 100 percent $\left(x_{E}^{\prime}=1.0\right.$ is indicated on fig. 32). This means that the Groeneveld correlation would adequately predict the heat transfer up to an equilibrium quality of 100 percent, as indeed the heat transfer coefficient increases with quality between zero and 100 percent for this one graph. But for fluids such as water which generally has a lower vapor superheating capacity due to the high vapor thermal conductivity, the reversa1 point is less than 100 per cent quality.

These two points, therefore, show how an observer can overlook the $h$ reversal with quality. First, his quality calculation reaches $100 \%$ with no sign of reversal in $h$ because the actual flow quality is still somewhat less than $100 \%$, while in the case of low quality CHF there is not enough tube length left after CHF to allow $h$ to reach a value that would indeed indicate a reversal.

Understanding now that there is a need for a correlation in terms of local conditions, and that one should be careful that the experiment to be used to base the correlation on is completely representative of the phenomenon, the next step would be to formulate such an experiment. One such method is the experiment from which data in Fig. 32 was obtained. This plot was obtained by first heating the tube to a temperature that would sustain film boiling and then inftiating the flow thereby creating zero quality CHF at the entrance to the test section. By increasing the power incrementally and measuring each steady state temperature distribution the boiling region can be formed for a given mass flux with quality as the parametric varlable. This method works well for 
freons and Cryogens but has not as yet been attempted with water for fear that the tube walls might melt.

The transient experimental method employed in this report was chosen because of its simplicity, the large amount of information obtained from each experiment, and the accurate knowledge of the independent variables throughout the run. Aside from being able to give minimum $\Delta T$ 's as a function of quality and mass flux this experiment allows us to examine the film bolling heat transfer also in terms of quality and mass flux. Experimental Heat Transfer Results

Returning therefore to the experimental results of this report, the film bolling data from Figs. 7 through 25 were grouped according to mass flux in Figures 34 through 36. As these figures present a great deal of information on which the film bolling heat transfer correlation to be presented in this report is based, a rather detailed explanation of these graphs is required. The mass flux range covered in these graphs is .05 to $.25 \times 10^{6} 1 \mathrm{bm} / \mathrm{hr}-\mathrm{ft}^{2}$ at a pressure of $1000 \mathrm{psia}$. In each figure corresponding to one of the three mass fluxes there are presented in the standard boiling curve coordinates q/A vs. $\Delta T$ with quality as parametric variable, Groeneveld correlation, the G.E. transient data, and G.E. steady state data. The solid lines represent Groeneveld's prediction for the specified conditions. The dashed lines represent the G.E. transient data and will be considered as the true film boiling heat transfer.

These lines were constructed in the following manner. The most conservative film boiling data point was chosen from each run and plotted on the figure corresponding to its mass flux. Then a dashed line bearing the Groeneveld slope was passed through the data points and was considered 
to have the quality corresponding to the single data point. For example the top most dashed line in Fig. 34 which intercepts the hexagonal symbol (Run 22) is assigned the quality of $24 \%$. This method was thought to be better than plotting all the film boiling data points from each run onto the graph and determining the slope of a best fit curve because of the lack of a film boiling data range in the separate runs. Any slope drawn through such a small range would have to be questionable whereas the choosing of the lowest film boiling data point and using the Groeneveld slope would tend to be conservative.

For purposes of further substantiating the transient data and more importantly to insure that the dashed lines accurately represent the lower portions of the film boiling curves, the G.E. steady state data was plotted on the figures. To conserve the number of symbols necessary to display the data, all the data points for any one steady state run was plotted using the same symbol, even though each point represents a different quality. In order to obtain the approximate value of quality for each steady state data point the following information is placed on Figures 34 through 36 . In the steady state data symbol key, along side a symbol representing a steady state data set there is quoted a minimum and maximum value of quality for that particular G.E. data run. The minimum value is associated with the left most point in the set and the maximum value with the right most point. The inside points are 1inearly interpolated with quality. With this in mind for all three mass fluxes the steady state data was always above the dash line of the same quality. Unfortunately the G.E. steady state data was all taken in the high quality range and, therefore, could not be used to verify the lower quality lines. 
As it was deemed essential to attempt any means possible to further verify the low quality lines, so called "theoretical data" was produced using the Hynek model (17). Hynek's model was used to predict a temperaturelength profile given a mass flux of $50,0001 \mathrm{bm} / \mathrm{hr}-\mathrm{ft}^{2}$ for several values of K1K2. K1K2, you will recal1, is the measure of droplet heat transfer. From ref. (17) it was found that a value of about 1 or 2 successfully predicted water data. The dashed line or real film boiling data of Fig. 34 have been replotted, onto Fig. 37 where the results of the theoretical experiment have been plotted. The $50 \%$ quality data point predicted almost exactly the $50 \%$ line of the real data for $\mathrm{K} 1 \mathrm{~K} 2=1.0$ but predicted higher for $\mathrm{K} 1 \mathrm{~K} 2=2.0$ and considerab1y lower for $\mathrm{K} 1 \mathrm{~K} 2=0$. This, therefore, helps to support the low quality lines for the film boiling region.

Considering now the dashed lines to be the true film boiling heat transfer the following observations are made. Within the limits of the quality range obtained from the apparatus, the data supports the functional relationship between quality and heat flux proposed earlier. That is starting from the high quality end the heat transfer should increase with quality to a certain point then decrease. At least for figures 34 and 35 the reversal point seems to be in the vicinity of $50 \%$ quality. The second important observation is the high degree of conservatism displayed by the Groeneveld equation at low mass flux levels. It is felt that this discrepancy arises from the fact that the correlation was based on high mass flux data. The reason the correlation does not extrapolate well to low mass fluxes is the relative magnitude of direct wall to drop heat transfer and wall to vapor heat transfer. Even though droplet heat transfer is a part of the total heat transfer and therefore indirectly correlated by Groeneveld at the high mass fluxes, 
its functional dependence with velocity is apparently not well correlated. That is it is felt that droplet heat transfer decreases at a lower rate than the forced convection component. This is indicated by the fact that at zero velocity, forced convection heat transfer is zero whereas droplet heat transfer isn't.

The correction term is derived in the following manner. The Groeneveld heat transfer is subtracted from the G.E. transient data as displayed in Figures 34 through 36 . Remembering that the functional form for the Groeneveld equation and the heat transfer is

$$
q / A=F(G, x) \Delta T^{N}
$$

the subtraction process gives the correction term as

$$
\begin{aligned}
& (\mathrm{q} / \mathrm{A}){ }_{\text {Actual }}-(\mathrm{q} / \mathrm{A})_{\text {Groen. }}=\left[\mathrm{F}_{2}(\mathrm{G}, \mathrm{x})-\mathrm{F}_{1}(\mathrm{G}, \mathrm{x})\right] \Delta \mathrm{T}^{\mathrm{N}}=\text { (Correction Term) } \Delta \mathrm{T}^{\mathrm{N}} \\
& \text { or Correction Term }=\mathrm{F}_{2}(\mathrm{G}, \mathrm{x})-\mathrm{F}_{1}(\mathrm{G}, \mathrm{x})
\end{aligned}
$$

where subscript 2 = actual heat transfer subscript 1 = Groeneveld heat transfer

The correction term is plotted in Fig. 38 in terms of mass flux and quality. There is a marked trend in the correction term for the 50,000 and 100,000 mass flux ranges between 50 and 110 percent quality. There are only three points for the 250,000 mass flux but with a hint of the same trend. With the lack of data at low qualities, one does not really know whether the correction term will continue to increase, remain constant or decrease at qualities below 50 percent. Just from the general trend of the data as we11 as a consideration for conservatism the downward trend was chosen. An attempt was made to verify this trend by postulating that the data at 10 percent was quality would be about the same as that obtained at 90 percent quality. The correction 
term was then calculated and plotted as a solid symbol on Fig. 38. This procedure does seem to indicate that a downward sloping trend of correction term with quality beyond 50 percent will be conservative. Therefore the general trend chosen for the quality variation was that the correction term be zero at an equilibrium quality of $110 \%$,maximum at $50 \%$, and slope down as the quality decreases below 50\%. For the mass flux variation, the correction term doubles itself in going from 50,000 to 100,000 . The resulting correlation is given in equation 4.5 .

$\frac{(\text { Correction Term })}{G / 50,000}=45\left(1+0.3193 x+1.3894 x^{2}-2.278 x^{3}\right)$

The comparison between equation 4.5 and data is given in Figure 39 . The total film boiling heat transfer becomes

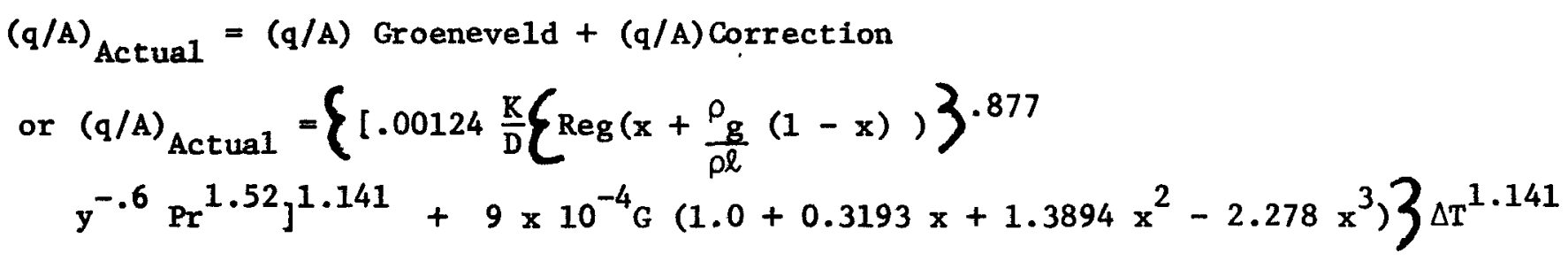
where $y=1-0.1\left(\rho_{\ell / \rho_{g}}-1\right)^{0.4}(1-x)^{0.4}$ 
V. DISCUSSION

By the use of an analytic solution, in the form of a rapidly convergent serles, for the transient temperatures and heat fluxes at the inside wall surface, an attempt has been made to make the data reduction as rigorous as possible. Frrors in the data presented as the total transient bolling curves, from which the $\Delta t_{\text {min }}$ and film bolling analysis were made, could therefore be attributed to those arising from the experimental method itself.

The radiation $10 s s e s$ have been estimated using a black body model and the maximum wall temperature occuring at the beginning of the transient. Both assumptions overestimate the radiation component of heat transfer over the transient period. The quantity computed merely gave an optimum level of radiation losses and was not used to correct the results. With respect to the axial conduction heat 1osses, it would be very difficult to maintain near uniform wall temperatures, and thus minimize the conduction heat 1oss, with a transient test piece that is 4" long, not including an additional total of $3^{\prime \prime}$ allowed at the ends for buss connections. A much shorter tube would have been better. With regards to the transition temperature from film to nucleate bolling, there is some uncertainty in the literature as to what is the wetting temperature, as opposed to the wall temperature at the minimum in the q/A vs temperature difference curve. Semeria and Martinet (8) studied the conditions for the simultaneous and stable existence of nucleate and film boiling on the same heated surface. The wetting temperature is the wall temperature at the tip of the liquid front seperating the two boiling regimes. A thermodynamic definition has been given to this temperature as the maximum superheat 
temperature at which liquid can exist (see eqn. 3.1). Being a thermodynamic property of the fluid, it has to be less than the critical temperature. However, in transition experiments where the measured temperatures, or the actual bolling surface temperatures, are controlled by the heat transfer process in the vicinity of the transition, what is obtained is not the wetting temperature. In Kalinin's experiment, for example, the correlated minimum wall temperatures were those taken in a transient flow quenching experiment [rod flow regime], in which axial conduction was occuring and the wetting boundary was being propogated downstream. The temperatures measured at the back of the tube included an averaging effect due to axial conduction in the metal and heat transfer in the dry and wet regions of the tube. Nevertheless, the 1iquid/vapor interface temperature inside the tube would be brought to the wetting temperature in order to allow the propagation to continue.

The Leidenfrest experiment does not measure the wetting temperature but measures the limiting wall temperature at which the heat transfer process to a drop, from a heated wall, can generate vapor at such a rate as to maintain the drop in suspension above the surface. Continued contact between the liquid and the solid is not necessary in order to obtain this turning point. Since the temperature is usually recorded at the back of the heated surface, and since the drop is stationary above the surface for the whole of the process, the temperature must be corrected for the effects of both normal and lateral conduction.

Transition in dispersed flow differs from the Leidenfrest experiment in two respects. Firstly, a number of droplets rain down towards the surface in the region where transition originates. The ratio between the region of the heated surface covered by Iiquid and the total relevant heated surface area is therefore different. It is obvious that the 
more this ratio tends to one, the more uniform the wall cemperature will be within that relevant region. The more uniform the wall temperature is, the less is the effect of axial conduction. Secondly, because of the flow the droplet residence time above any given point is sma11. Both the area ratio and the droplet residence time influence the effective heat transfer coefficients, and since the transition is heat transfer dependent, the resulting temperature differences w111 be different for the single stationary drop [Leidenfrost] and the dispersed flow experiments. In conclusion, therefore, what one measures as the minimum temperature difference in film bolling depends on the process that leads into transition.

The process by which deposits on the heated surface affect the transition temperature have already been discussed, although the data we have analyzed did not give isolatable information on it. The experiment was not designed to do so. However it seems inevitable that such a process would have taken place, particularly when one considers the fact that the text plece was raised to temperatures as $\mathrm{h} 1 \mathrm{gh}$ as $1900^{\circ} \mathrm{F}$ during the experiments. At such temperatures, metal-water reactions alone are known capable of leaving substantial deposits on the heated surface. The General Electric quench data reported in June 1972 (NEDE 13204) present a very interesting comparison. In these experiments, a $1691 / 4$ inch diameter vertical test section, with a 144 inch heated length, was raised to desired test temperatures before a pre-set flow was passed through 1t. The heat was supplied via a "Calrod" type heater, Nichrome V wire wound, with a chopped cosine axial power distribution, see Fig. 40 . The fuel rod was clad with stainless steel such that a 0.570 inch / 0.820 inch annulus was created for the flow. Thermocouples were placed at $1.2^{\prime} 4^{\prime}, 6^{\prime}, 7^{\prime}, 8^{\prime}$, and $10.8^{\prime}$ positions from the start of the heated 
length. Transition wall superheats in the range of $200^{\circ} \mathrm{F}$ to $600^{\circ} \mathrm{F}$ were recorded for various mass fluxes and initlal wall temperatures, at the different axial positions. Fig. 41 khows a plot of $\Delta T$ at transition vs mass flux. It shows, in particular, an average of $300^{\circ} \mathrm{F}$ to $450^{\circ} \mathrm{F}$ for the various axtal positions. It was also observed that for low mass fluxes the collapse sequence progressed from the bottom thermocouple up the tube, sequentially. At high mass fluxes the middle thermocouple indicated collapse after the first thermocouple but before the $4 \mathrm{ft}$. and the seven ft. thermocouples (See figs. 42 and 43), an observation which could not be explained in the report.

The problem now exists of explaining why such an unexpected collapse sequence occurred and why the recorded transition wall superheat were so far below those reported in the current data (around $900^{\circ} \mathrm{F}$ ). In attempting to do this, we sha11 recall the observation, in NEDE 13204, that the time to transition increased with an increase in the wall temperature at the beginning of the transient. From the heat flux distribution, one would expect the six foot position to be at the highest temperatures in the absence of any cooling effects. Prior to the transient being started, there was usually about $1 \mathrm{ft}$ of water at the bottom of the unheated section. Natural convection, and evaporation from this pool would have the effect of shifting the position of the maximum up the tube, since the heat flux at the $5 \mathrm{ft}$. to seven foot levels was constant. Table (2) shows a record of the wall temperatures at the beginning of the transient, for those positions for which data were available. The seven foot position appeared to be at slightly higher temperature than the six foot position, though not excessively so. As far as transition time is concerned, one would therefore expect the six foot level to collapse before the seven foot level. Additionally 
the crud deposition would be highest between the five-foot and seven foot levels. With crud on the surface, transition can occur at higher temperatures. It is then possible for the six foot level to go into transition before the four foot level and the possibility would increase with mass flux, particularly where the test section heat generation remained fairly at the same level, as was the case with NEDE 13204.

As far as the difference between the wall superheats reported for the two experiments 18 concerned, the same crud effect arguments may be used to supply an explanation. The maximum wall temperature level of NEDE 13204 report was $1500^{\circ} \mathrm{F}$ while the short transient test piece was ralsed to as $\mathrm{high}$ as $1900^{\circ} \mathrm{F}$. One would expect the metal water reaction to be higher at the higher temperature with a consequent increase in the transition temperature level. A closer look at Fig. 41 would show in fact, that the six foot level had the highest transition temperatures, reaching close to $600^{\circ} \mathrm{F}$ at the highest.

An attempt to explain the difference $\Delta T^{\prime}$ s from possible different processes to transition was not possible. One would, for example, expect the temperature for droplet deposition controlled collapse, in which the liquid does not have to touch the surface, to be higher than for axial conduction controlled rewet. However, both processes could very much have occurred in both experiments. Whereas axial conduction controlled rewet may have been responsible for the transition of the $1.2 ; 4^{\prime}, 7^{\prime}$, $8^{\prime}$ and $10.8^{\prime}$ levels, transition of the $6^{\prime}$ level may have been due to dispersed flow rewet, particularly at the higher mass fluxes. The short tube experiment could also have been similarly subjected to both types of collapse.

The film boiling program has made very clear, two important defficlencies of the Groeneveld correlation. The first is that it 
underestimates the total heat transfer, particularly at low mass fluxes and low qualities, by not adequately accounting for the droplet heat transfer. Secondly, the correlation falled to reflect the trend of the Improvement in overall heat transfer due to the droplets, as the quality changes from very low to very high values. This should increase with quality, reach a maximum at an intermediate quality and then decrease at higher qualities. Groeneveld's correlation was empirically determined from data, such as those of Bennett(11), which were at higher qualities and mass fluxes, and their quality ranges in particular were such that the aforementioned trend was completely missed. It should be noted that in the formation of the correction term with quality the variation was forced to be a maximum at a quality of 50 per cent regardless of mass flux. It is possible that the reversal point can shift with mass flux. The suggested correction term does not include pressure effects, just as the correlations for $\Delta \mathrm{T}_{\mathrm{min}}$ and $\mathrm{film}$ boiling heat transfer are strictly valid for $50,000 \leq G \leq 100,000$. However in the recommendation section extrapolation procedures are given to be used as guides outside this range.

In closing it is felt that emphasis should be placed on the importance of scale deposition on the test surface. We know for a fact that there was a significant deposition of scale on the test surface. First, the actual physical observation of the transient test section which was sliced in half after the experiments allowed one to find a dull grey deposit on the inside surface of the tube. Second, the nucleate boiling regions for all the reduced data plots (Figures 7 through 25) are shifted to the right of that predicted by Jens and Lottes. This can be seen by observing that the burnout temperature difference is on the order of 100 to 200 degrees for the data as compared to 20 degrees for Jens and Lottes. 
When we compared the film boiling data and minimum film boiling temperature differences in this report to that of other researchers in this field we seemed to be somewhat higher than most of the presently avallable data especially in the comparison of the minimun film boiling temperature differences. But in the context of scale deposits our seemingly high values may very well be the correct description of the phenomenon in actual practice. At least the experiments in this report indicate that the bolling curves for forced convection are affected by forced convection heat transfer to vapor wall to droplet heat transfer, radiation heat tranfer and scale deposition. This scale deposition affects the bolling curve by increasing the minimum film bofling temperature due to the addition of a resistance between the wall and fluid heat tranfer due to the so called wicking effect.

This scale deposit phenomenon has not been emphasized before because of its temperature dependence. Researchers have not run transition experiments that allow the test surface to reach the temperature necessary for the scale to accumulate. The scale accumulation does not seem, though, to be time dependent as our data does not have strong indications that results differed from Run 1 to Run 24 (other conditions being constant). Therefore we feel that, especially in a nuclear reactor loss of coolant accident, the scale will be present auch that our correlations w111 predict the heat transfer characteristics. We do feel, also, that more research should be applied to this area of scale build up to insure that our susplcions are correct. There is some evidence now, Blok (21), that in normal operation of a reactor scale deposits are built up. 


\section{RECOMMENDATIONS}

The investigations undertaken in this report were intended to provide quantitative methods for the analysis of the heat transfer phenomena associated with the postulated loss-of-coolant accident for a boiling water reactor. It was the view of the authors that the best solution is a complete definition of the boiling curve in terms of local variables. In pursuit of this goal, data was taken that described the boiling curve for a limited range of heat flux and quality. The following procedure for determining the forced convection boiling, curve is recomended for water in the mass flux range of $.05-.1 \times 10^{6} 1 \mathrm{bm} / \mathrm{hr} .-\mathrm{ft} .^{2}$ at 1000 PSIA. With reference to Fig. 44 the pertinent equations to use are

1) Nucleate bolling region (1ine 1):

Jens and Lottes

$\Delta T_{S A T}=\frac{60\left(q^{\prime \prime} / 10^{6}\right)^{1 / 4}}{e^{p / 900}}$

2) CHF POINT ( point 2 ):

Use proprietary G.E. Correlation

3) Transition bolling (1ine 3):

Straight line on $\log -\log$ paper from CHF point to minimum point.

4) Minimum $q / A$ point (point 4)

MIT Correlation given as equation

$$
\Delta \mathrm{T}_{\mathrm{MIN}}=0.29 \Delta \mathrm{T}_{\mathrm{BER}}\left(1-0.295 \mathrm{x}_{\mathrm{E}}^{2.45}\right)\left(1+\left[\mathrm{G} / 10^{4}\right]^{0.49}\right)
$$

5) Film bolling regime (line 5):

Groeneveld correlation with the M.I.T. Correction

$$
(\mathrm{q} / \mathrm{A})_{\text {TOTAL }}=\mathrm{q} / \mathrm{A} \text { Groeneveld }+9 \times 10^{-4} \mathrm{G}\left(1.0+0.3193 \mathrm{x}+1.3894 \mathrm{x}^{2}-2.278 \mathrm{x}^{3}\right) \Delta \mathrm{T}^{1.41}
$$

These corrections form a complete picture only at the above specified conditions. Due to this lack of range of the experiments upon which these recommendations are based an extrapolation and interpolation procedure is 
needed. In this regard we are mainly interested in extrapolating the minimum point and film boiling heat transfer to other pressures and mass fluxes.

The pressure effect was built into the $\Delta \mathrm{T}_{\mathrm{min}}$ correlation through Berenson's pool boiling correlation. However, there is no actual confirmation of the calculated results. For mass flux variations the calculated values should go to the Berenson result for any given pressure as the mass flux goes to zero. It happened though that Berenson's result was higher than the values of $\Delta \mathrm{T}_{\min }$ for the $50,0001 \mathrm{bm} / \mathrm{hr}-\mathrm{ft}^{2}$ mass $\mathrm{flux}$ at $1000 \mathrm{psia}$. Therefore we recommend that one $1 \mathrm{ump}$ the $0-50,0001 \mathrm{bm} / \mathrm{hr}-\mathrm{ft}^{2}$ mass flux range and use that result which the correlation gives for a mass flux of 50,000 to represent it. For mass fluxes above 100,000 we recommend using the value given by 100,000 to represent all higher mass fluxes.

In the film boiling correlation the Groeneveld term already has a pressure dependence through the fluid properties and saturation temperatures, but the correction factor does not. In order to estimate the pressure effect on the correlation for the correction term, we assumed that the correction term was due to droplet heat transfer which we assumed to be primarily a function of void fraction. The pressure dependence on void fraction for a given slip ratio and quality is proportional to vapor density. In going from 1000 psia to 300 psia the vapor density changes by a factor of 3 . From 300 psia to atmospheric pressure the vapor density changes by a factor of 18 . We feel, therefore, that the vapor density has not changed significantly enough to affect the droplet heat transfer correction term in going from 1000 to 300 psia.

The variation in the correction term with mass flux was developed to predict only the two mass fluxes given and does not tend toward the correct 
asymptotes at high mass fluxes. We feel that the correction term should tend to zero as the mass flux reaches the order of $10^{6} 1 \mathrm{bm} / \mathrm{hr}-\mathrm{ft}{ }^{2}$, and not go to zero as the mass flux reaches zero. It should, instead, asymptote to some value higher or lower than the value at $G=50,0001 \mathrm{bm} / \mathrm{hr}-\mathrm{ft}^{2}$. Therefore as a best estimate we feel that the values of $G$ below 50,000 should use the results given by the $50,0001 \mathrm{bm} / \mathrm{hr}-\mathrm{ft} \mathrm{t}^{2}$ mass flux. Values of $\mathrm{G}$ above 100,000 should use that determined by the 100,000 mass flux. These ranges are shown graphically in Figures 45 and 46. 
REFERENCES

1) Slifer, B.C., "Loss of Coolant Accident and Emergency Core Cooling Models for General Electric Boiling Water Reactors." NEDO-10329, April 1971, General Electric Company, San Jose, California

2) Rogers, Alan E. "A Realistic Evaluation of Core Thermal Response During the Loss of Coolant Accident for a BWR." Paper to be presented at the ASME-Wam 1972.

3) Tong, L.S. "Boiling Heat Transfer and Two Phase F1ow" Wiley, 1965 p. 117

4) Appropriate General Electric CHF correlation (proprietary)

5) Merte, H. and Clark, J.A., "Boiling Heat Transfer Data for Liquid Nitrogen at Standard and Near Zero Gravity." Advances in Cryogenic Engineering $\underline{7}, 246-250 \quad 1961$

6) Kalinin, E.K., S.A. Yarkho, I.I. Ber1in, Yskochelaev, V.V. Kostyutz "Investigation of the Crisis of Film Boiling in Channels" Proceedings "Two Phase Flow and Heat Transfer in Rod Bundles" Winter Annual Meeting of ASME, Los Angeles, California, 1969

7) Berenson, P.J. "On Transition Boiling Heat Transfer from a Horizontal Surface" Ph.d thesis in Mechanical Engineering, MIT, February 1960

8) Semeria, R., B. Martinet "Califaction Spot on a Heated Wa11, Temperature Distribution and Resorption." presented at IME Symposium on Boiling Heat Transfer in Steam Generating Units and Heat Exchangers, Manchester, England, September 15-16, 1965.

9) Stock, Bernard J. "Observations on Transition Boiling Heat Transfer Phenomena" ANL-6175 June 1960.

10) Griffith, P. and J.D. Wallis "The Role of Surface Conditions in Nucleate Boiling", AICHE Symposium Series, No. 30 Vol. 56, Storrs, Connecticut, August 1958.

11) Bennett, A.W. et al "Heat Transfer to Steam-Water Mixtures Flowing in Uniformly Heated Tubes in which the Critical Heat Flux has been Exceeded." AERE-R5373 (1967)

12) Burggraf, O.R. "An Exact Solution of Inverse Problem in Heat Conduction Theory and Applications" Journal of Heat Transfer pg 373382 August 1964

13) Iloeje, O.C., Plummer, D.N., Rohsenow, W.M. "Transition from Film Boiling to Nucleate Boiling in Forced Convection Vertical Flow" MIT Report 72718-78 1972 
14) Simon, F.F. and Simoneau, R.J. "Transition from Film to Nucleate Bolling in Vertical Forced Flow" NASA TMX-52597, 1967

15) Laverty,W. F. and Rohsenow, W.M. "F1lm Bolling of Saturated Liquid Flowing Upward through a Heated Tube: High Quality Range" MIT Report 9857-32, September 1964 (Trans. ASME, J. Heat Transfer, Vo1 86 1967, pp. 90-98)

16) Forslund, R.P. and Rohsenow, W.M. "Thermal Non-Equilibrium in Dispersed Flow Film Bolling in a Vertical Tube." MIT Report No. 75312-44, 1966.

17) Hynek, S.J., Rohsenow, W.M. and Bergles, A.E. "Forced Convection Dispersed Flow Bolling", MIT Report No. 70586-63, 1969

18) Groeneveld,D.C. "Investigation of Heat Transfer in Liquid Deficlent Regime" CRNL-232, 1968

19) Splegler, P. et al, "Onset of Stable Film Bolling and the Foam Limit" Int. J. Heat and Mass Transfer, Vol 6, 1963.

20) Zuber, N. "Hydrodynamic Aspects of Heat Transfer" Phd Thesis, Department of Engineering, UCLA June 1959

21) Blok, J., Sawochka, S. G. and Snyder, D.T. "Corrosion Products on Fuel at the Nine Mile Point Bolling Water Reactor". To be published June 10-15, 1973 at the 19th Annual Meeting of ANS, Chicago, Illinois 


\section{APPENDIX A}

From O.R. Jurggraf (12), the values of $f_{0}$ and $f_{1}$ have already been calculated and as such does not warrant recalculation. The calculation of $f_{2}$ will suffice to demonstrate the procedure. In knowing $f_{1}$ and the relationship for the del operator in cylindrical coordinates, equation (3.3) becomes

$\left.\frac{1}{r} \frac{d}{d r}\left(r \frac{d f_{2}}{d r}=\frac{r_{0}^{2}}{4 \alpha^{2}}\left[\frac{(r}{r_{0}}\right)^{2}-1-2 \ln \frac{(r}{r_{0}}\right)\right]$

with boundary conditions

1) $\frac{d f_{2}}{d r}\left(r_{0}\right)=0$

2) $f_{2}\left(r_{0}\right)=0$

Integrating once with respect to $r$ gives

$\left.r \frac{\mathrm{df}_{2}}{\mathrm{dr}}=\frac{\mathrm{r}_{0}^{2}}{4 \alpha^{2}}\left[\frac{\mathrm{r}^{4}}{4 \mathrm{r}_{0}^{2}}-\frac{\mathrm{r}^{2}}{2}-2 \frac{\left(\mathrm{r}^{2}\right.}{2} \ln \frac{(\mathrm{r})}{\mathrm{r}_{0}}-\frac{\mathrm{r}^{2}}{4}\right)\right]+\mathrm{c}_{1}$

Rearranging gives

$\frac{d f_{2}}{d r}=\frac{r_{0}^{2}}{4 \alpha^{2}}\left[\frac{r^{3}}{4 r^{2}}-r \ln \frac{(r)}{r_{0}}\right]+\frac{c_{1}}{r}$

Integrating once more with respect to $r$ and rearranging terms gives

$\left.f_{2}=\frac{r^{4}}{64 \alpha^{2}}-\frac{r_{0}^{2} r^{2}}{8 \alpha^{2}} \quad \ln \frac{[r}{r_{0}}\right]+\frac{r_{0}^{2} r^{2}}{16 x^{2}}+c_{1} \ln r+c_{2}$

From (A-2)

$$
c_{1}=\frac{r_{0}^{4}}{16 \alpha^{2}}
$$

and from (A-6)

$$
c_{2}=-\frac{5 r_{0}^{4}}{64 \alpha^{2}}+\frac{r_{0}^{4}}{16 \alpha^{2}} \ln r_{0}
$$

Therefore $\mathrm{f}_{2}$ becomes

$\left.\left.f_{2}=\frac{1}{64 \alpha^{2}}\left[r^{4}-5 r_{0}^{4}\right]-\frac{r_{0}^{2} r^{2}}{8 \alpha^{2}} \ln \frac{[r}{r_{0}}\right]-\frac{r_{0}^{4}}{16 \alpha^{2}} \ln \frac{\operatorname{lr}}{r_{0}}\right]+\frac{r_{0}^{2} r^{2}}{16 \alpha^{2}}$ 
APPENDIX B 
C* * jEDRP IS A PRÜ̈RAM DESIGNED TO TAKE TRANSIENT TEMPERATURE-TIME C* * \#ATA UN THE OUTSIDE SURFACE OF A TURF THAT HAS EXPERIENCFO A C** QUENCH TYPF HEAT TRANSFER PROCESS AND RECONSTRUCT THF INSIDC C * * *ALL HEAT FLUX AVD TEMPE?ATURE. THIS DATA REDUCTIDN SCHEME C* * ALLOWS. THEREFORT, O.VE TO CONSTRUCT A BOILING CURVE CORPESPONDING C***IO THE QUALITY AVD MASS FLUX FOR WHICH THE EXPERIMENT WAS RUN. C*** *XPLICIT IN THIS REUUCTION SCHEME IS THE ASSUMPTION OF ZFRO AXIAL $C * *$ CUNDUCTION.

C*** INPUT VARIABLES

C** * NOAT... NuMGER of SePARATE data RUNS

$C$ * * * VO...ORDER OF CUPVE FIT DES IRED 11 TH GTH URDER )

C*** XOOLII),DDP $(I, J) \ldots$...PLUTTING INFURMATION FOR PICTA

C* G,XX,TSAT, NUM... MASS FLUX (BIU/HR-SQ.FT.), QUALITY (PERCENT),

C* * * SATURATION TEMPERATURF IDEgreES FI, RUN NUMBER

C* * * NP,NTRA,MZZP,N7ZP, CDP...NUMHER OF POINTS PER RUN, TOTAL NUMBER UF

C* * PUINTS TO HE I VCLUDED IN ANY UVE CURVE FIT SEgMENT, NUMBFR OF

C* * * POINTS TO BE OVERLAPPED IN SUCCESSIVE CURVE FITS, NUMRER OF

C* * * POINTS TO BE OROPPED AT THF END UF EACH CURVE FIT SEGMENT IN THE

C* * WRITE AND PLOT CYCLE SO AS NUT TO DUPLICATE THE OUTPUT OF RESULTS

C*3* DUE TO THE OVtRLAP PROCEOURE, DIGITIZING RATE (SECONDS)

$C$ * Y Y I I... CAATA ARRAY CINSISTING OF TEMPERATURES IV DERREES F

DIMENSION Y $(1000), 4(20,20), B(20,1), \operatorname{SUM}(40), X O D L(4)$

DIMENSION XSCL(4), ,2(999), DOP(2,1)

$L I=8$

$L L=5$

READ(LI, I) NDAT

1 FORMAT $(12)$

READ (LI, 2) NO

2 FORMAT (I I)

3 FORMAT $(6 \mathrm{~F} 10.2)$ 


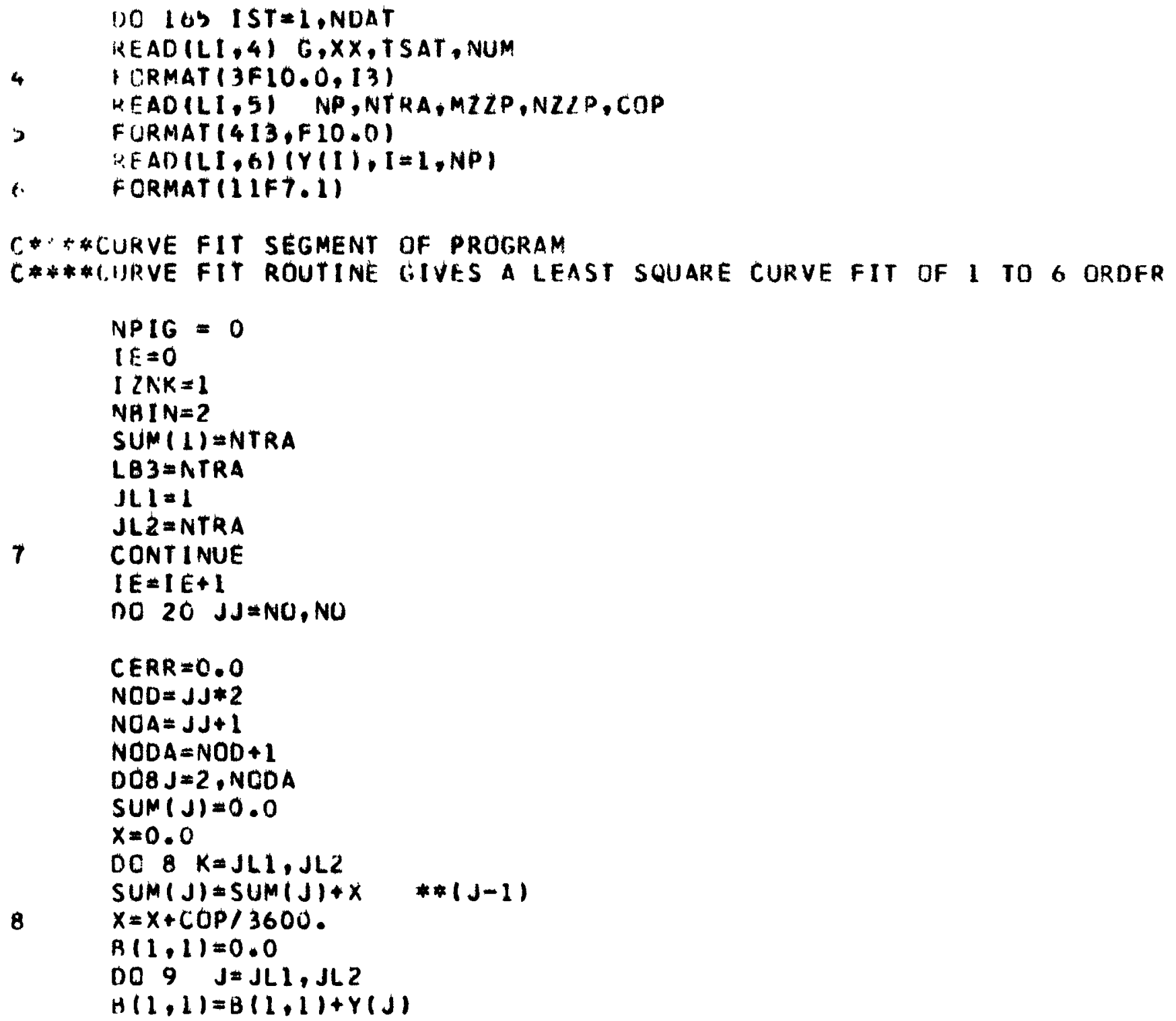


$D O 1 O J=2, N O D A$

$X=0.0$

$B(J, 1)=0,0$

DO $10 \quad K=J L L, J L 2$

$B(J, 1)=A(J, 1)+X \quad * *(J-1) * Y(K)$

10 $X=X+C O P / 3600$.

DO1 $1 \mathrm{~J}=1$, NOA

DO1 $1 K=1$, NOA

$L I=J+K-1$

$A(J, K)$

$=\operatorname{SUM}(L 1)$

11 CONTINUE

C**** SHADE IS A MATRIX INVFRSION SUBROUTINE

CALL SHADE (A, NOA,B, 1, DETER)

C****GeNERAL SCLUTIONS

WRITE (LL, 12) JJ

12 FORMATI 1 H $1,5 X$, EQQUATIONS FUR ORDER', 141

WRITE(LL, 13$)(B(J, 1), J=1, N O A)$

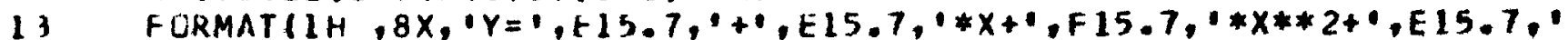
$\left.\left.1 * x * 3^{\prime} / 8 x, 1+1, E 15,7,1 * x * * 4+1, E 1\right\}, 7,0 * x * * 5+1, E 15,7,1 * x * * 60^{\prime}\right)$

WRITE(LL, 14)

14 FURMATIIH, $8 x$, 'XVALUES',9X, 'YVALUES', $11 x$, 'YCVALUES')

(.** * $*$ RRCR CHECK WITH RESIIDUAL

$X=0.0$

$11018 \mathrm{~J}=\mathrm{JLL}, \mathrm{JL} 2$

$Y C=B(1,1)$

$1) O 15 K=2$, NOA

15 CONTINUE

(C) $=Y C+B(K, 1) * X \quad *(K-1)$

C.ERR $=C E R R *(Y C-Y(J)) * * 2$

CALL DATSW $(0,144)$

GO TC $(16,18), 144$

is WRITE(LL, 17$) \mathrm{J}, X, Y(\mathrm{~J}), Y C$

17 FORMATIL, $14,3(2 x, t 15,7))$ 


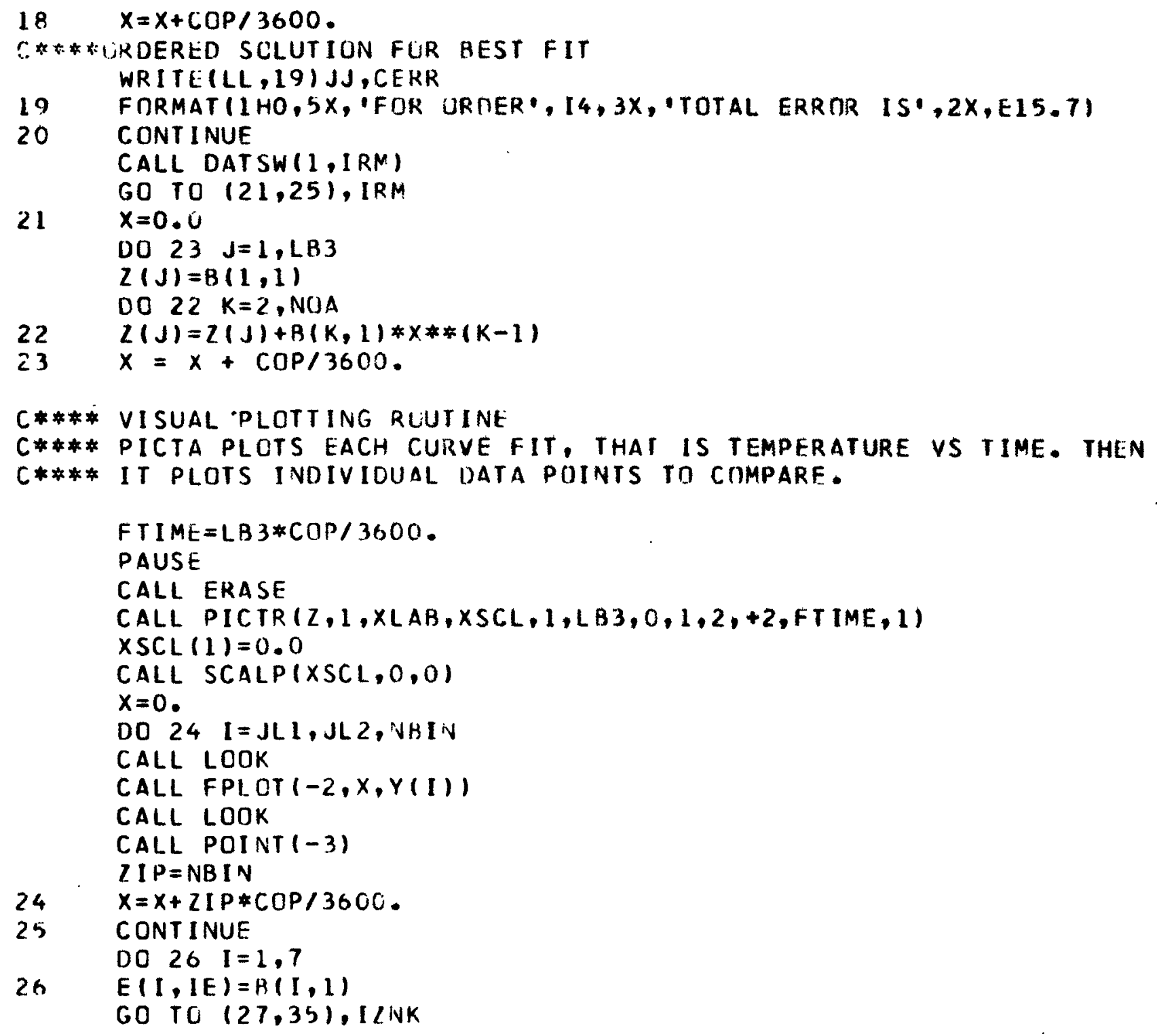




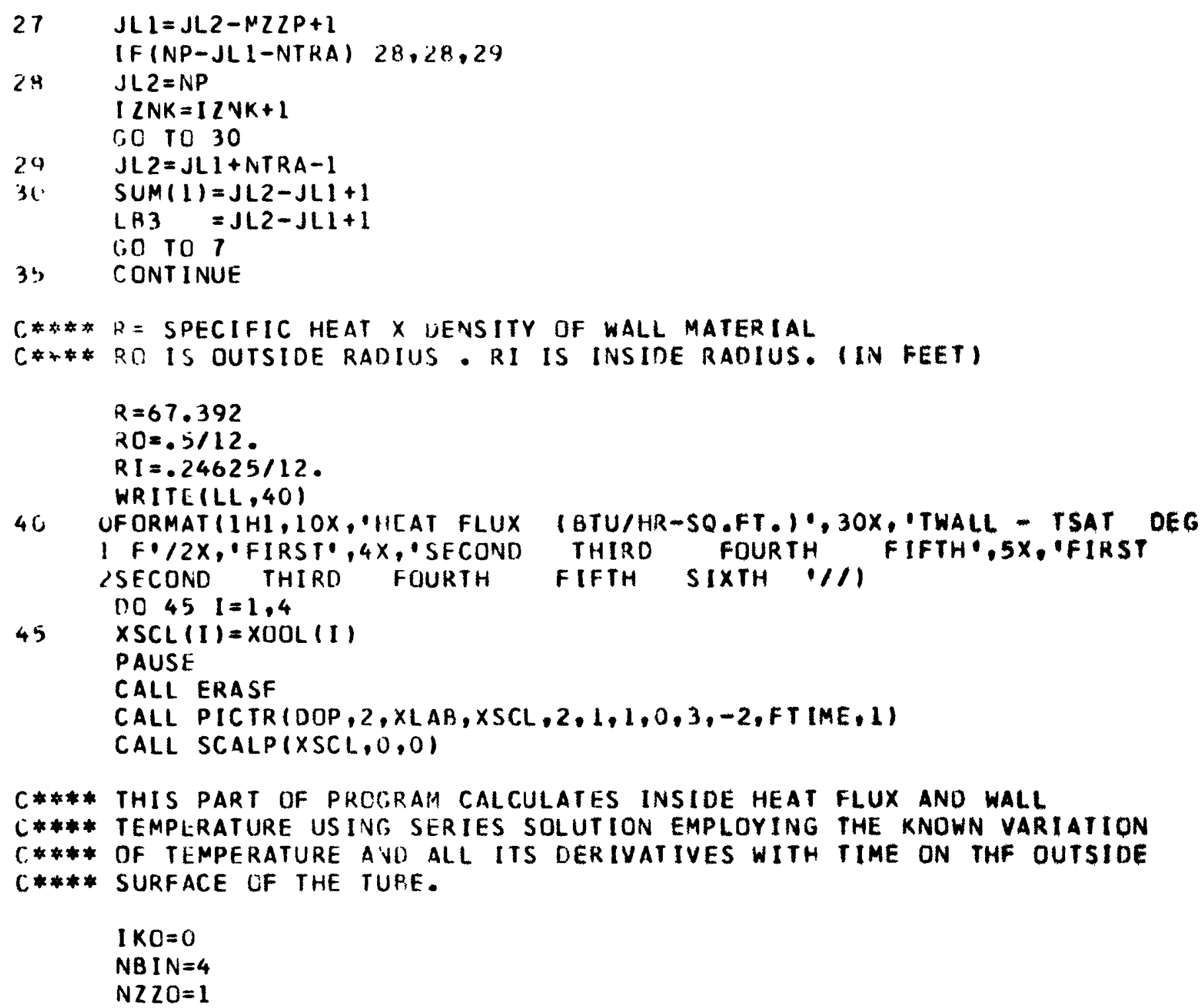


$X=0$.

$I E E=I E-1$

DO $120 \mathrm{~K}=1$, IEE

$N Z Z=N T R A-N Z Z P$

DO $105 I=N Z Z O, N Z L$, NEIN

$I K D=[K O+1$

C**** Calculation of DeRIVATIVES OF THE CURVE fit POLYNOMIAL IP TO THE C**** ORDER OF THE POLYNOMIAL SELECTED

$T=E(1, K)$

$T 1=E(2, K)$

$T 2=2 . * E(3, K)$

$T 3=6 . * E(4, K)$

IF (NC-3) $60,65,50$

DO $55 L=5, N O A$

$D 5=L-1$

D $6=\mathrm{L}-2$

$D 7=L-3$

$55 T \mathrm{~T} 3=\mathrm{T} 3+\mathrm{D} 5 * \mathrm{D} 6 * \mathrm{DT} * \mathrm{E}(1, K) * X *(L-4)$

GO TC 65

$60 \quad T 3=0$.

I $F(N G-2) \quad 85,75,7 b$

65

DO $70 L=4, N O A$

$\mathrm{D} 5=\mathrm{L}-1$

$D G=L-2$

$70 \quad T 2=T 2+D 5 * D 6 * E(L, K) * X * *(L-3)$

75 DO $80 \quad L=3, N O A$

1) $b=L-1$

BC $\quad T 1=T 1+D 5 * E(L, K) * X *(L-2)$

SO TL 90

$85 \quad T 2=0$.

40 DO $95 \quad L=2, N D A$

$35 \quad T=T+t(L, K) * X * *(L-1)$

C**** dK IS a curve fitTeo polynomial fDR the temperature VARIation of 
i)** THERMAL CONUUCTIVITY OF WALL MATE?IAL.

$0 K=7.6909809+6.794 E-3 * T \quad-2.993878+-7 * T \quad * * 2$

$A L P A=D K / R$

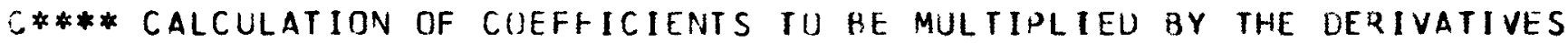

¿*** IN THE SERIES SULUTIUN.

$A L=A L O G(R I / R O)$

$U D=(R * 3 / D K * 2) *(R[* 3 / 384 .-13 . / 124) * R.[* R G * 4+(3.1128) *.(R 0 * 2) * R I$

$1 * * 3-(R 0 * 6) /(384 * * R I)-(R O * * 2 *(R I * 3) / 32) * A L U.(G(R I / R O)-(1 R O * * 4)$

$2 * R(132) * A L O G.(R(/ R(1))$

$U=(R * 2 / U K) *(R I * 3 / 16 .-R \Gamma * 4 /(16 * R I)-(R D * 2 * R I / 4) * A L O C.(R I / R D))$

$F=(.5 * R / R I) *(R I * 2-R O * 2)$

$F I=(R D * 2 /(4 . * A L P A)) *((R I / R O) * 2-1 .-2 * A L O G(R I / R O))$

$O F 2=(1 . /(8 . * A L P A) * 2) *((R I * 4-3 * R \cap * 4)-9 * R O * 2 * R I * *) * A L$

$1 \quad-4 * R O * 4 * A L+4 * R U * 2 * R I * 2)$

OF $3=(1 . /(4 . * A L P A) * 3) *((R I * * 6-10 * R) * 6) / 36 .-.25 * R O * 4 * R I * 2 *$

$1.5 * R O * 2 * R I * 4-.5 * A L * R O * 2 * R I * 4-A L * R O * 4 * R I * 2-R O * 6 * A L / 6.1$

OF $4=(1 . /(4 . * A L P A) * 4) *(13 . * R I * 8-47 * R n * 8) / 1728 .-R[* * 6 * R I * 2 / 9$.

$1+R C * 4 * R I * 4 / 16 .+2 * R \cap * 2 * R I * 6 / 27 .-A L * R O * 2 * R I * 6 / 18 .-$

$2 \quad A L * R O * 4 * K I * 4 / 4,-A L * R \cap * 6 * R I * 2 / 6,-R I * 8 * A L / 72$. 1

UNE $=11 * \mathrm{~F}$

$S E C=T 2 * U$

$T H R D=T 3 * U$

$\triangle C N E=T-T S A T$

$A S E C=T 1 * F 1$

$A T H D=T 2 * F 2$

$A F O R T=T 3 * F$

$Q I N=\quad$ ONE+SFC+THRC

DELT $=\quad A O N E+A S E C+A T H O$

SOW $=Q I V / 1000$

C*** PLOTIING AND WRITING OF RESULTS (Q/A VS TWALL-TSAT)

$Y(I K O)=Q I N$ 


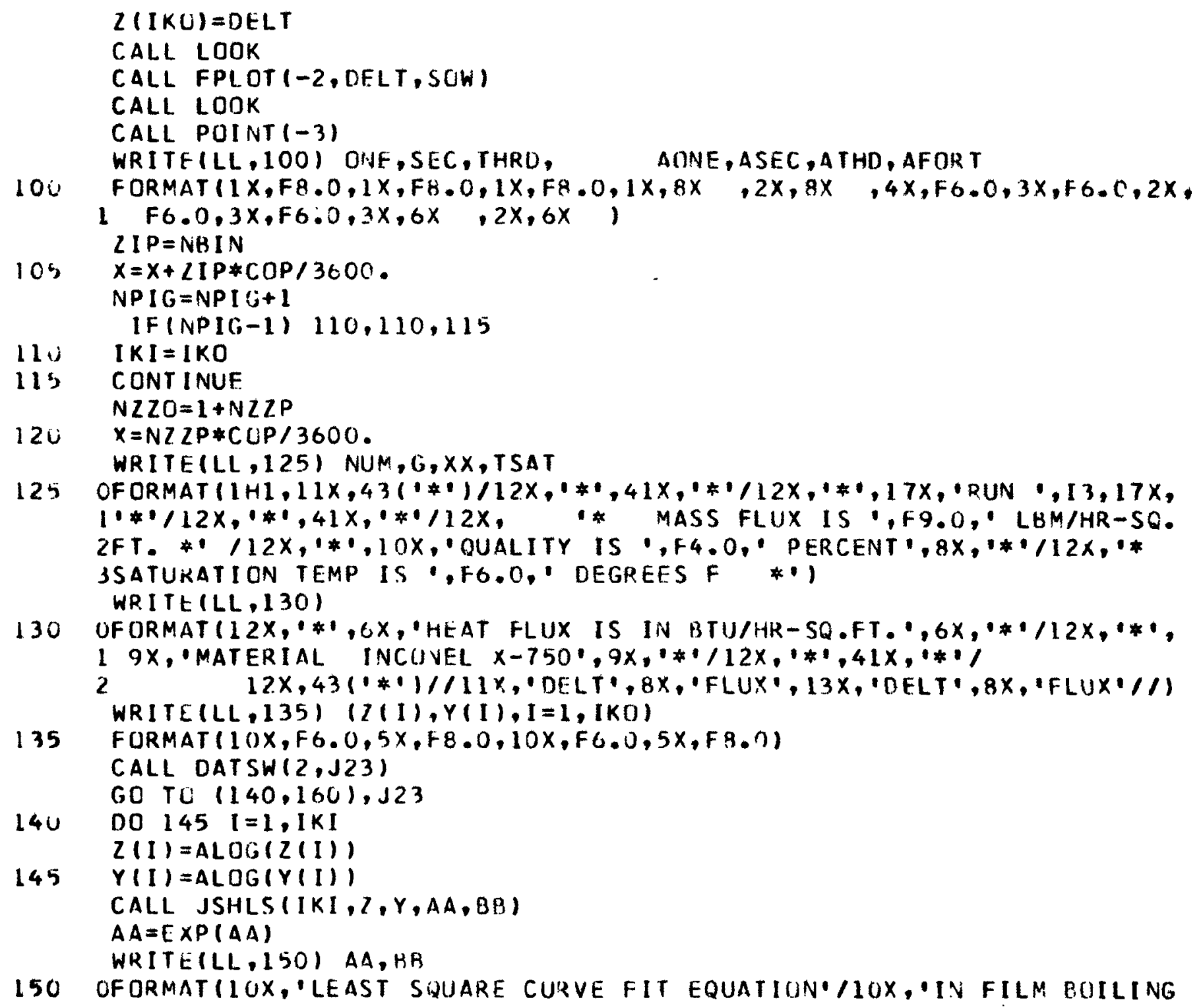




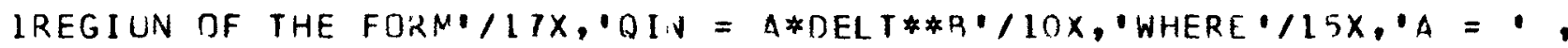
$2 E 11.3 / 15 X, B=1, E 11.5)$

$20 K=400$.

DO $155 \quad I=1,17$

$P L U M(1, I)=L O K$

$P L U M(2, I)=(A A * Z(J K * B B) / 1000$

$155 \quad Z O K K=Z O K+50$.

CALL PICTR (PLUM, 2, XLAB,XSCL, 2,17,1,1,0,-2, FT IME, 1)

16C CONTINUE

163 CONTINUE

CALL EXIT

END 


\section{TABLE 1}

G.E. SHORT TUBE QUENCH RESULTS

\begin{tabular}{|c|c|c|c|c|c|c|}
\hline $\begin{array}{l}\text { Run } \\
\text { No. }\end{array}$ & $\begin{array}{c}\text { Pressure } \\
\text { (psia) }\end{array}$ & $\begin{array}{l}\text { Preheater } \\
\text { Heat Flux }\end{array}$ & $\begin{array}{l}\text { Mass } \\
\text { Flux }\end{array}$ & $\begin{array}{c}\text { Inlet } \\
\text { Qual ity }\end{array}$ & $\Delta T_{\min }$ & $Q / A_{\min }$ \\
\hline 4 & 980 & 21,234 & 48,108 & 0.955 & 710 & 75,000 \\
\hline 5 & 995 & 19,494 & 49,630 & 0.827 & 770 & 145,000 \\
\hline 6 & 995 & 13,663 & 48,900 & 0.525 & 730 & 125,000 \\
\hline 7 & 985 & 11,923 & 42,121 & 0.489 & 840 & 150,000 \\
\hline 8 & 1003 & 43,078 & 101,235 & 0.997 & 780 & 130,000 \\
\hline 9 & 1001 & 39,249 & 100,258 & 0.903 & 900 & 220,000 \\
\hline 10 & 1001 & 37,856 & 99,423 & 0.871 & 930 & 155,000 \\
\hline 11 & 995 & 29,763 & 98,492 & 0.661 & 815 & $\underline{260,000}$ \\
\hline 12 & 995 & 24,367 & 99,649 & 0.492 & 1100 & 360,000 \\
\hline 13 & 1005 & 48,213 & 98,116 & 1.170 & & \\
\hline 14 & 1000 & 115,658 & 247,135 & 1.180 & & \\
\hline 15 & 1000 & 103,648 & 252,907 & 1.009 & & \\
\hline 16 & 1001 & 95,294 & 251,242 & 0.928 & $\underline{1030}$ & $\underline{260,000}$ \\
\hline 17 & 1015 & 0 & 47,116 & 0.964 & 930 & 145,000 \\
\hline 18 & 1013 & 0 & 48,023 & 0.724 & 900 & 150,000 \\
\hline 19 & 1002 & 0 & 47,049 & 0.749 & 950 & 160,000 \\
\hline 20 & 1015 & 0 & 47,053 & 0.538 & 950 & 175,000 \\
\hline 21 & 1017 & 0 & 44,029 & 0.382 & 850 & 130,000 \\
\hline 22 & 985 & 0 & 45,954 & 0.238 & $\underline{620}$ & $\underline{240,000}$ \\
\hline 23 & 1001 & 0 & 99,436 & 0.848 & 1160 & 70,000 \\
\hline
\end{tabular}

Note: The underlined data refer to runs in which the transient started from transition boiling. 
TABLE 2

\begin{tabular}{|c|c|c|c|c|c|c|}
\hline NEDE & 204 & AK TEMPE & URES PRI & TO TRANS & T (DEGRE & F) \\
\hline RUN & $1.2 \mathrm{Ft}$ & $4.0 \mathrm{Ft}$ & $6.0 \mathrm{Ft}$ & $7.0 \mathrm{Ft}$ & $8.0 \mathrm{Ft}$ & $10.8 \mathrm{Ft}$ \\
\hline 7 & 820 & 1300 & 1400 & $1460^{\star}$ & 1400 & 1120 \\
\hline 8 & & & 1000 & & & \\
\hline 9 & 745 & 920 & 990 & $1020^{\star}$ & 970 & 810 \\
\hline 10 & 805 & 1075 & 1170 & $1180^{*}$ & 1140 & 920 \\
\hline 11 & 925 & 1325 & 1450 & $1500^{\star}$ & 1400 & 1150 \\
\hline 12 & & & 1015 & & & \\
\hline 13 & & & 1170 & & & \\
\hline 14 & 890 & 1330 & 1440 & $1490^{*}$ & 1440 & 1180 \\
\hline 15 & 740 & 930 & 990 & $1020^{*}$ & $1020^{\star}$ & 805 \\
\hline 16 & 810 & 1060 & 1150 & $1180^{*}$ & 1130 & 910 \\
\hline 17 & 990 & 1320 & 1440 & $1485^{\star}$ & 1140 & 1140 \\
\hline 18 & & & 1010 & & & \\
\hline 19 & & & 1180 & & & \\
\hline 20 & 975 & 1330 & 1450 & $1485^{\star}$ & 1410 & 1160 \\
\hline 27 & & & 1450 & & & \\
\hline 22 & & & 1470 & & & \\
\hline 23 & & & 1225 & & & \\
\hline 24 & & & 1360 & & & \\
\hline 25 & & & 770 & & & \\
\hline 26 & & & 1450 & & & \\
\hline 27 & 975 & 1350 & 975 & 1350 & $1440^{\star}$ & 1200 \\
\hline 28 & 1055 & 1435 & $1490^{\star}$ & 1360 & 1465 & 1230 \\
\hline 29 & & & 800 & & & \\
\hline 30 & & & 1010 & & & \\
\hline 37 & 995 & 1365 & $1440^{\star}$ & 1310 & $1440^{\star}$ & 1180 \\
\hline 32 & & & 840 & & & \\
\hline 33 & & & 1395 & & & \\
\hline 34 & & & 840 & & & \\
\hline 35 & & & 1375 & & & \\
\hline
\end{tabular}




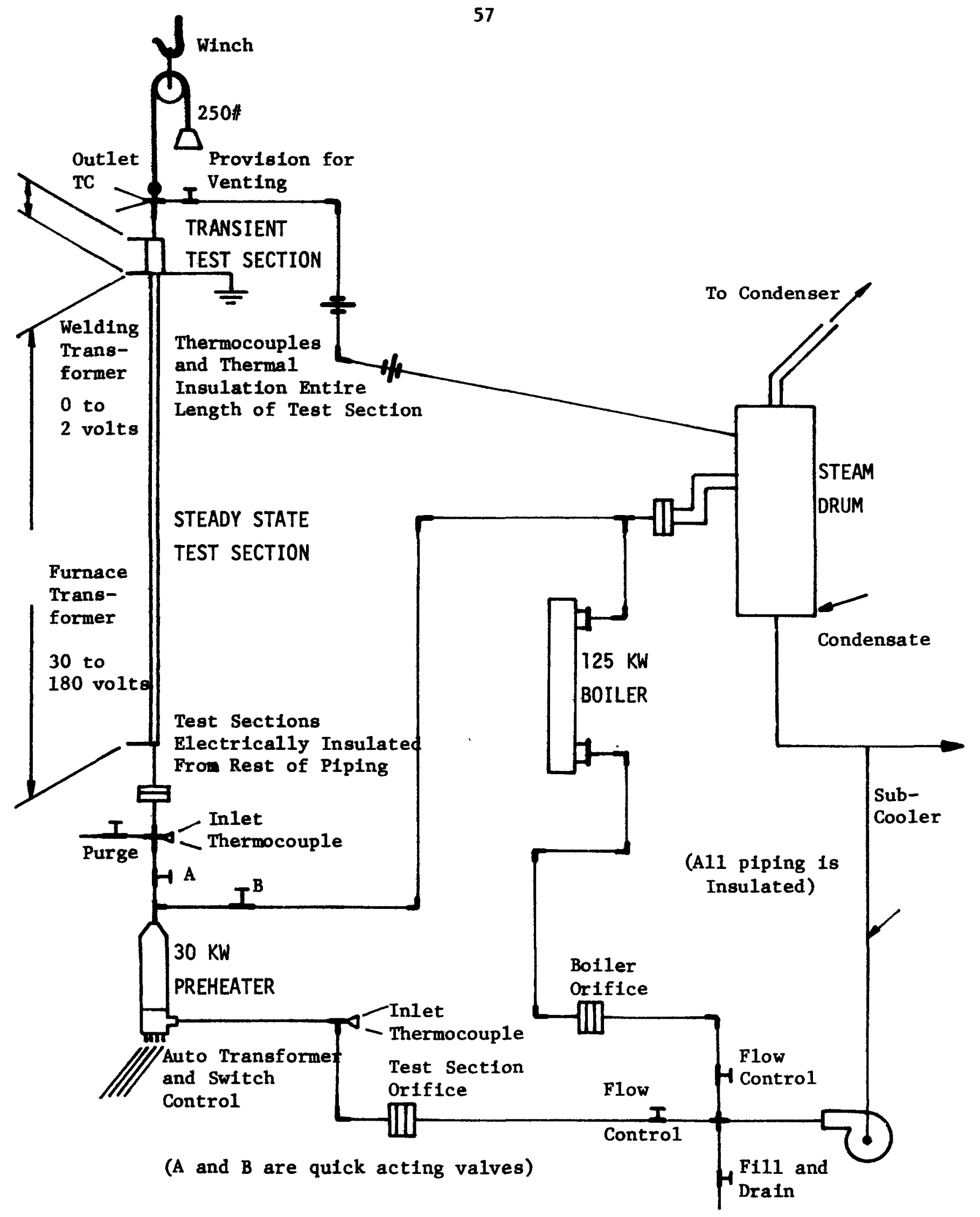

FIG. I. TEST LOOP 


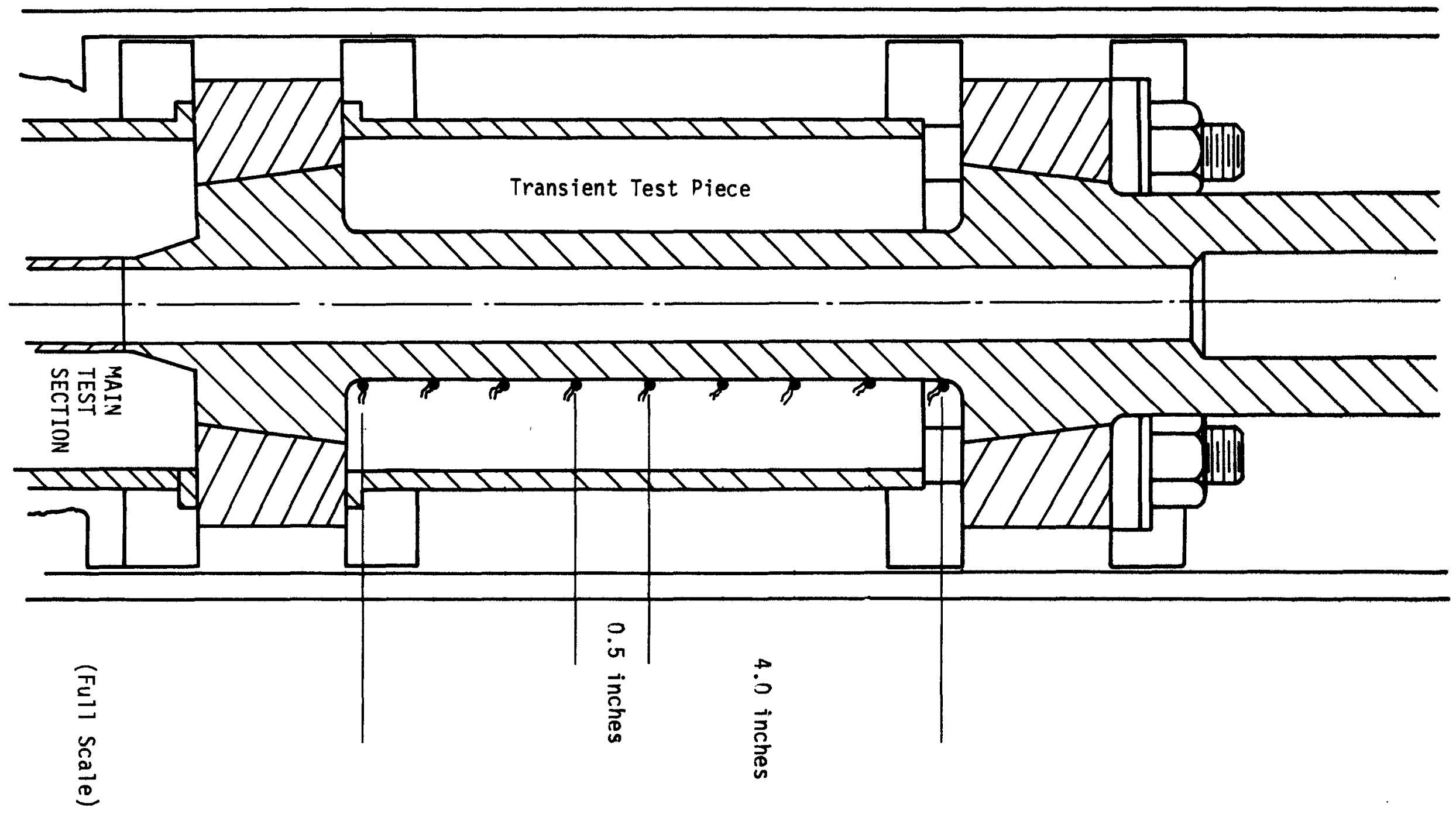

FIGURE 2 TRANSIENT TEST SECTION 


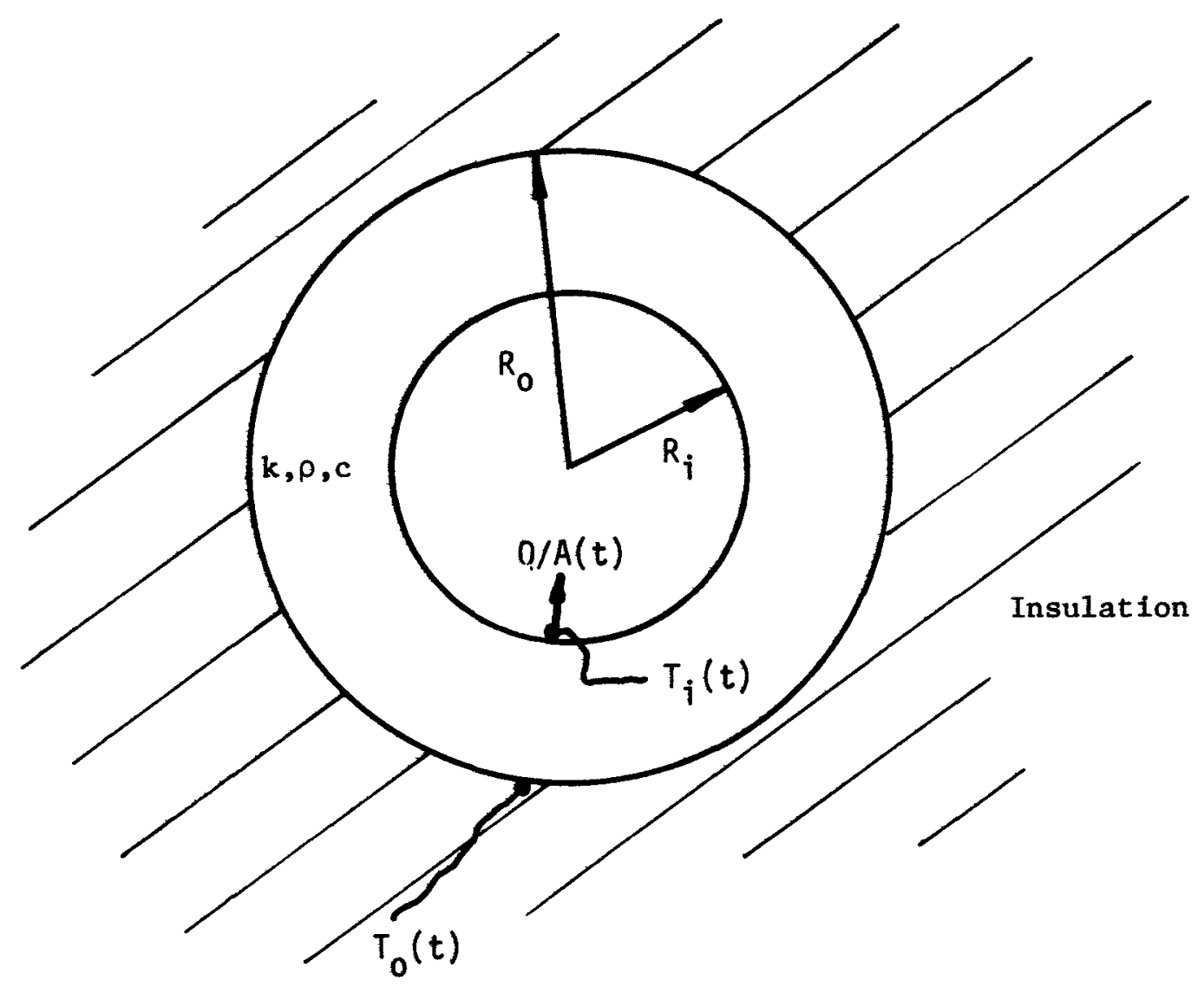

FIGURE 3 PHYSICAL GEOMETRY AND BOUNDARY CONDITIONS FOR SOLUTION OF INVERSE HEAT TRANSFER PROBLEM 


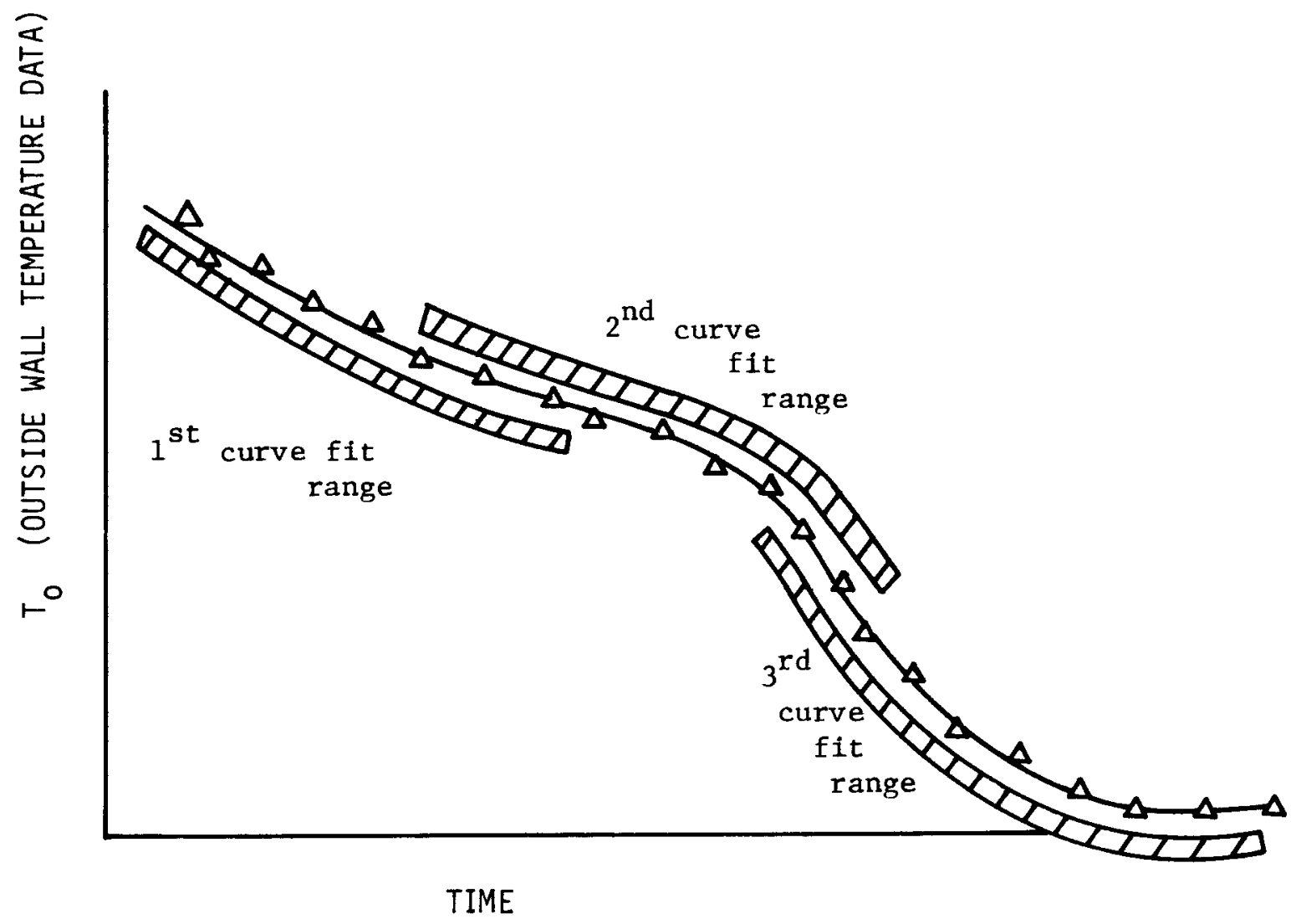

FIGURE 4 PICTORAL REPRESENTATION OF CURVE FITTING PROCEDURE USED IN OBTAINING FUNCTIONAL FORM FOR $T_{0}(t)$ AND ITS DER IVAT IVES 


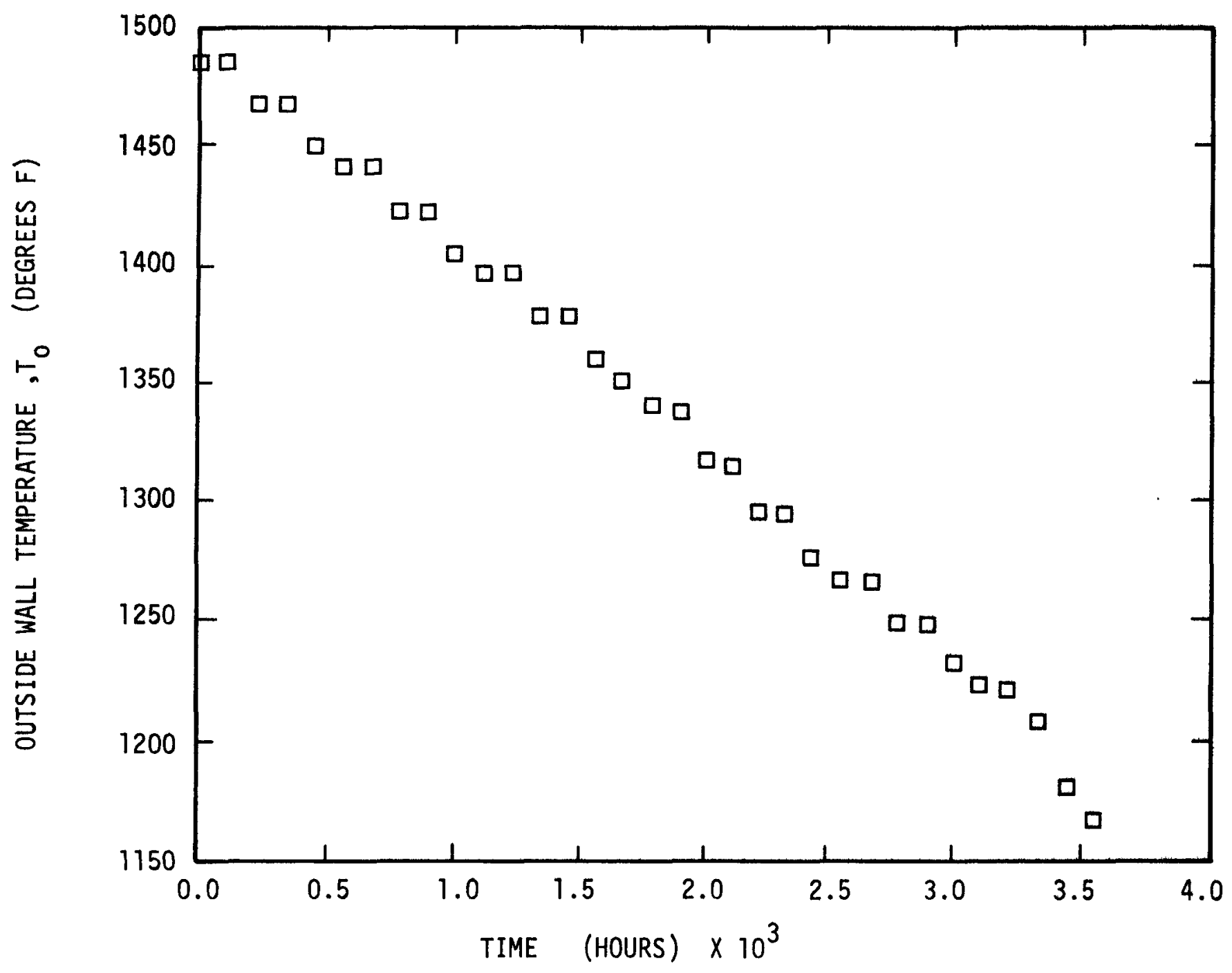

FIGURE 5 SAMPLE OF QUENCH TEMPERATURE-TIME DATA FROM THERMOCOUPLE ON OUTSIDE WALL OF TRANSIENT TEST SECTION 


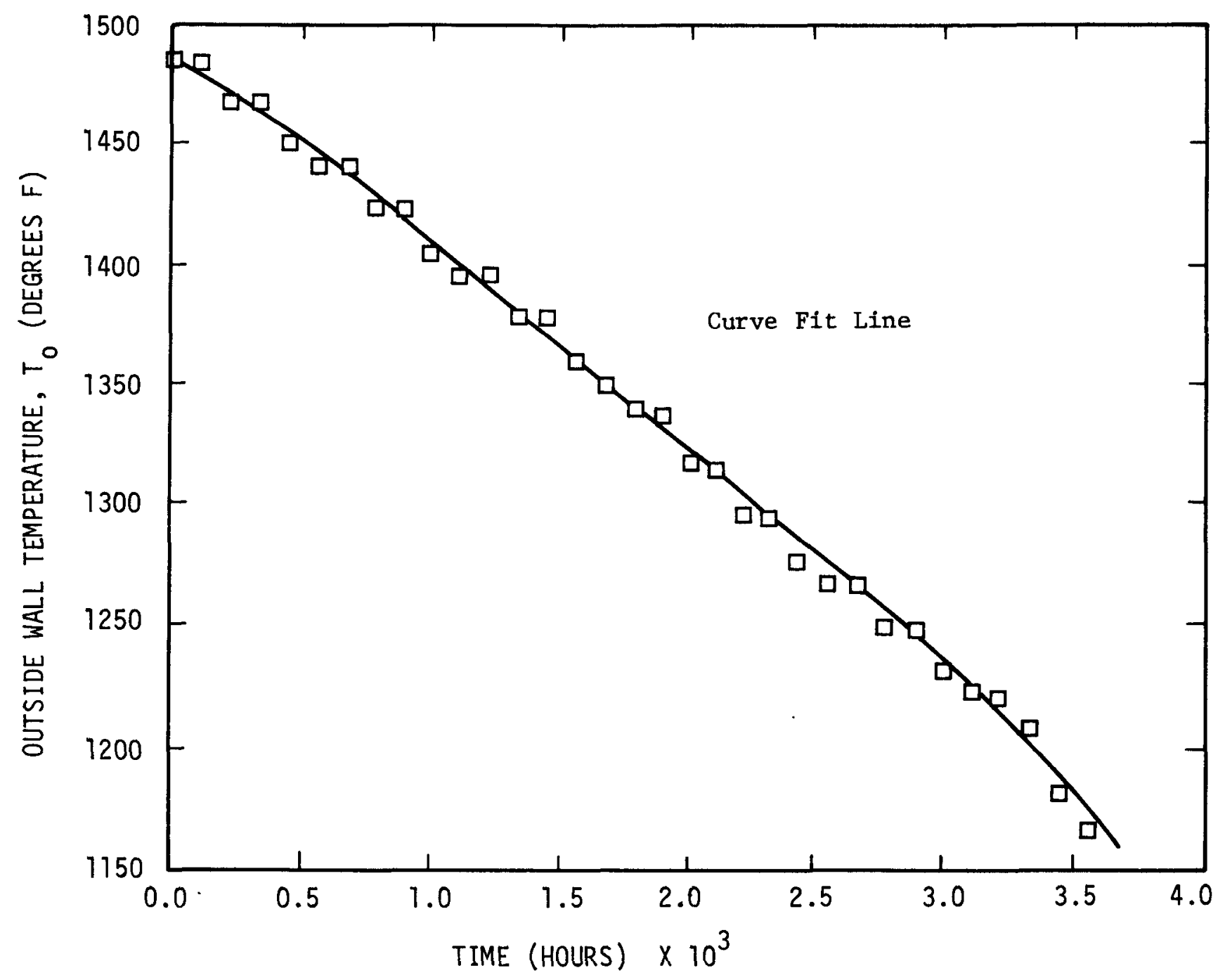

N

FIGURE 6 SAMPLE OF ACCURACY OF CURVE FITTING TECHNIQUE 


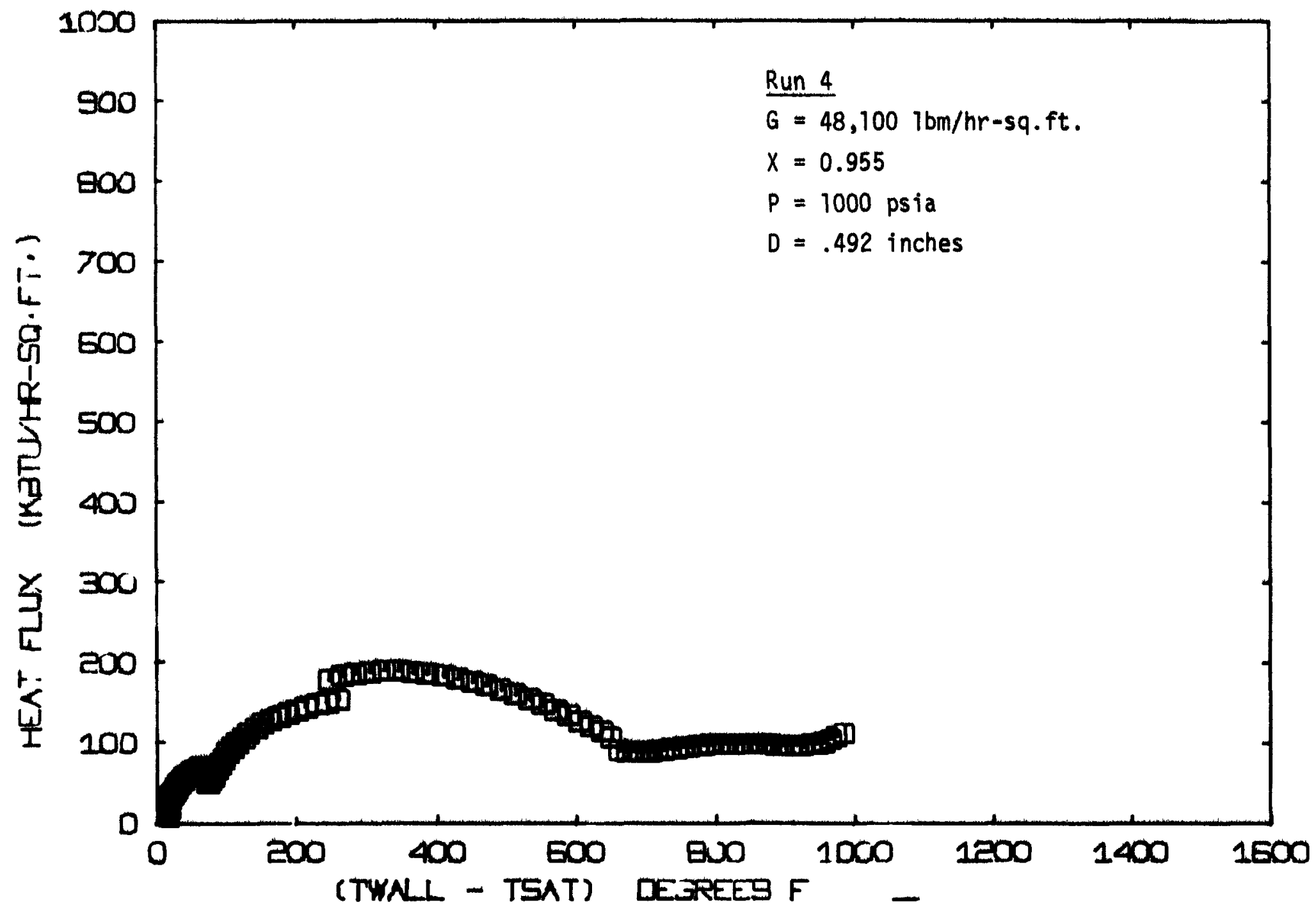

FIGURE 7 REDUCED BOILING DATA FROM G.E. TRANSIENT TEST SECTION 


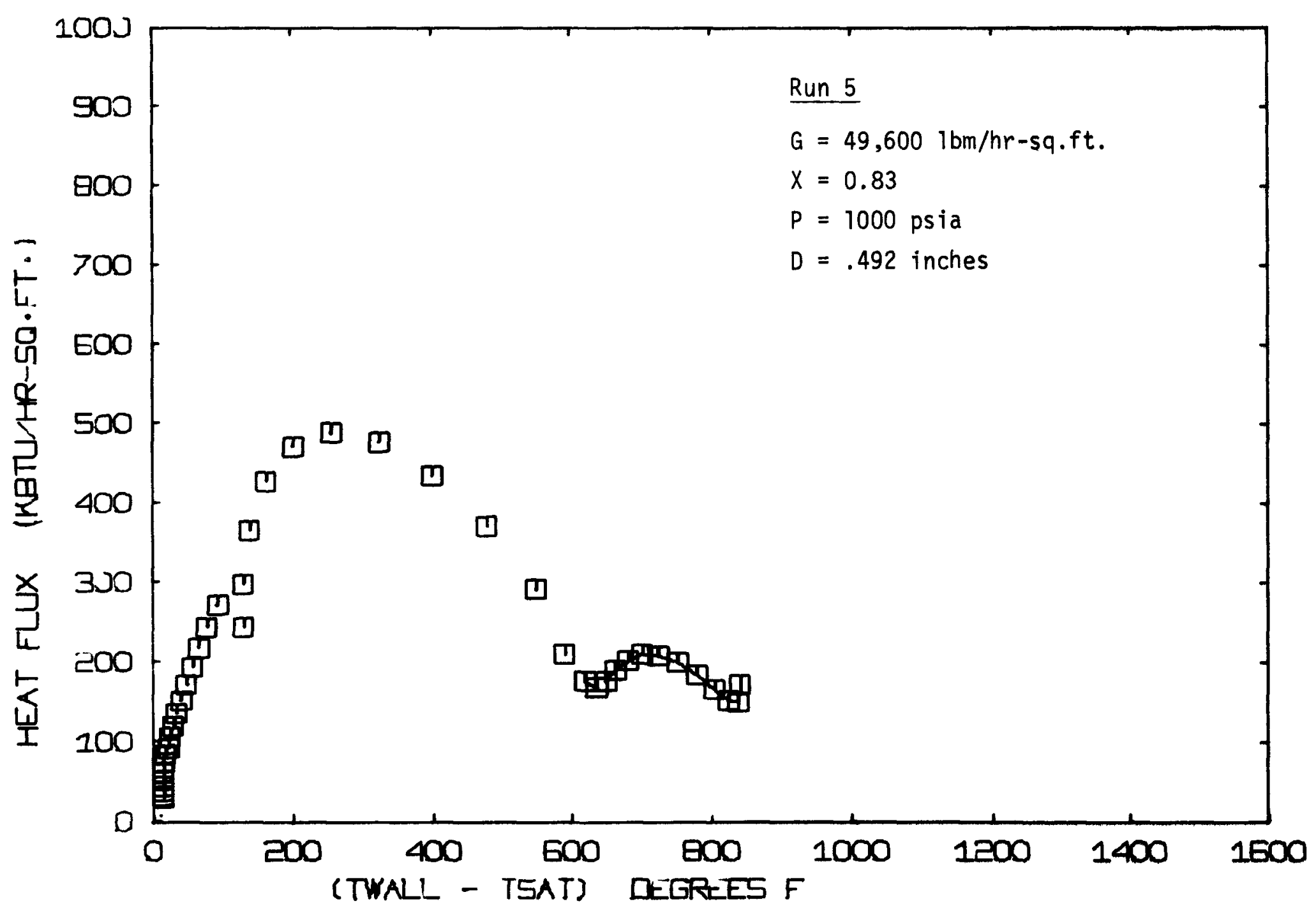

FIGURE 8 REDUCED BOILING DATA FROM G.E. TRANSIENT TEST SECTION 


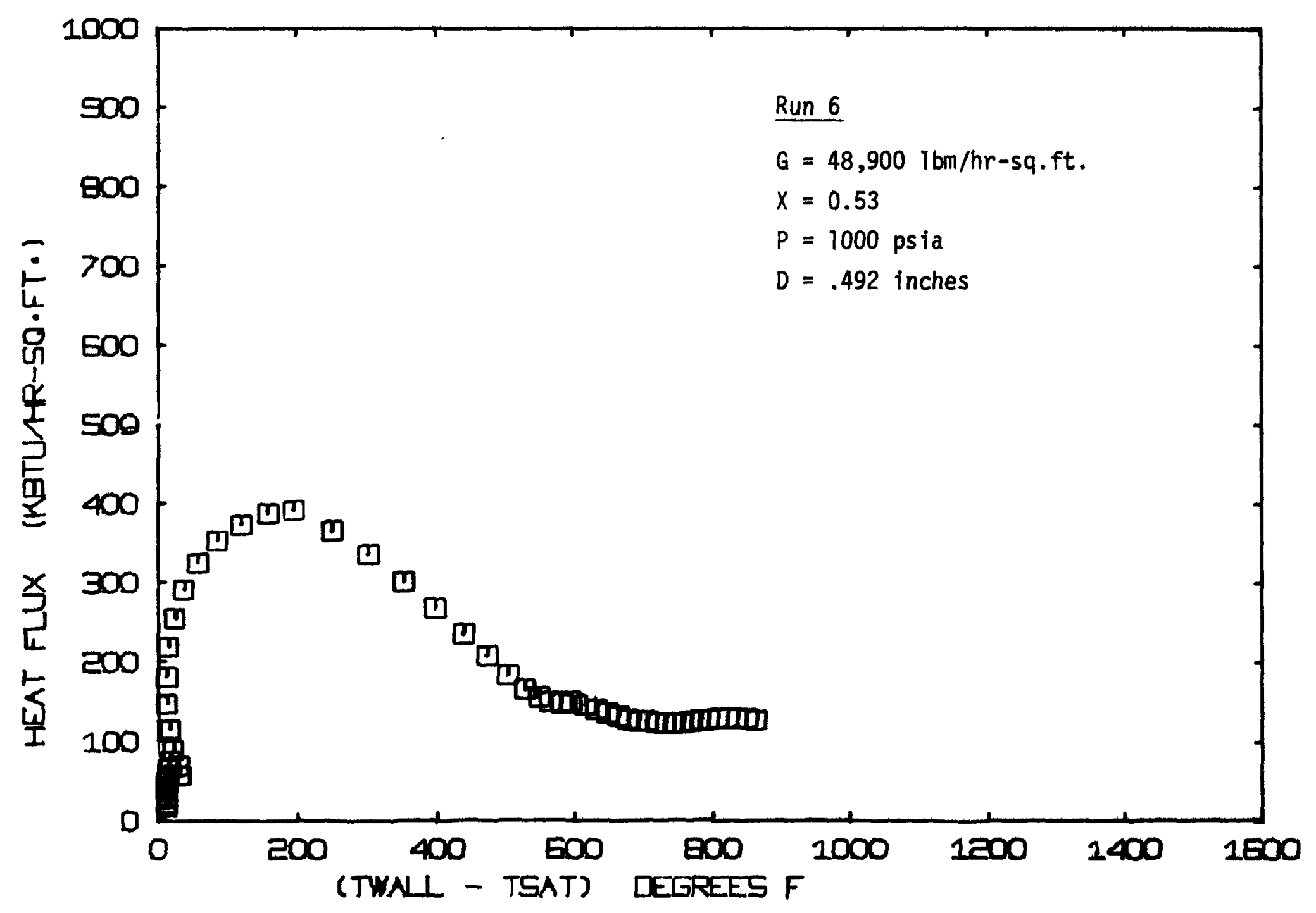

or

FIGURE 9 REDUCED DATA FROM G.E. TRANSIENT TEST SECTION 


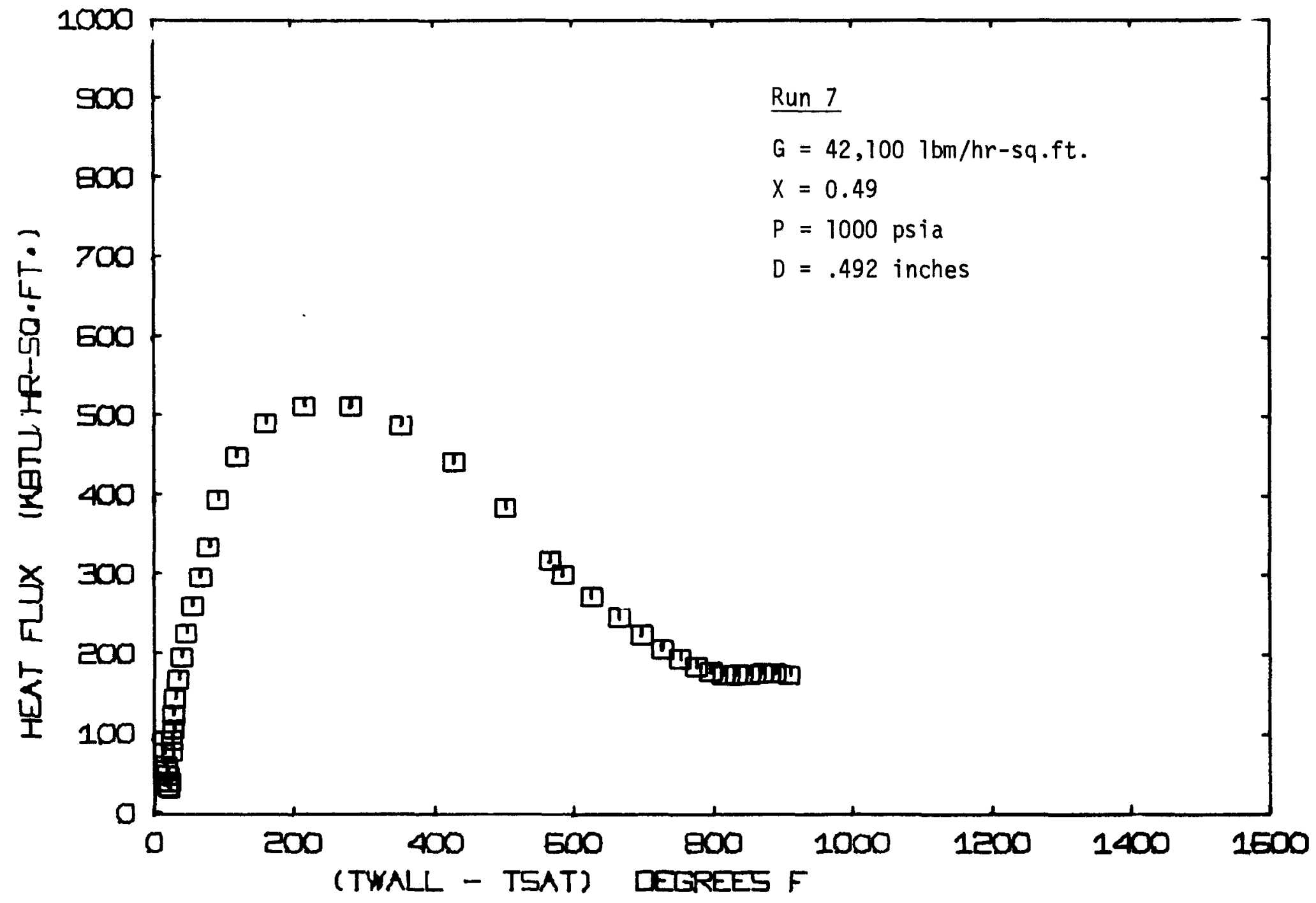

FIGURE 10 REDUCED DATA FROM G.E. TRANSIENT TEST SECTION 


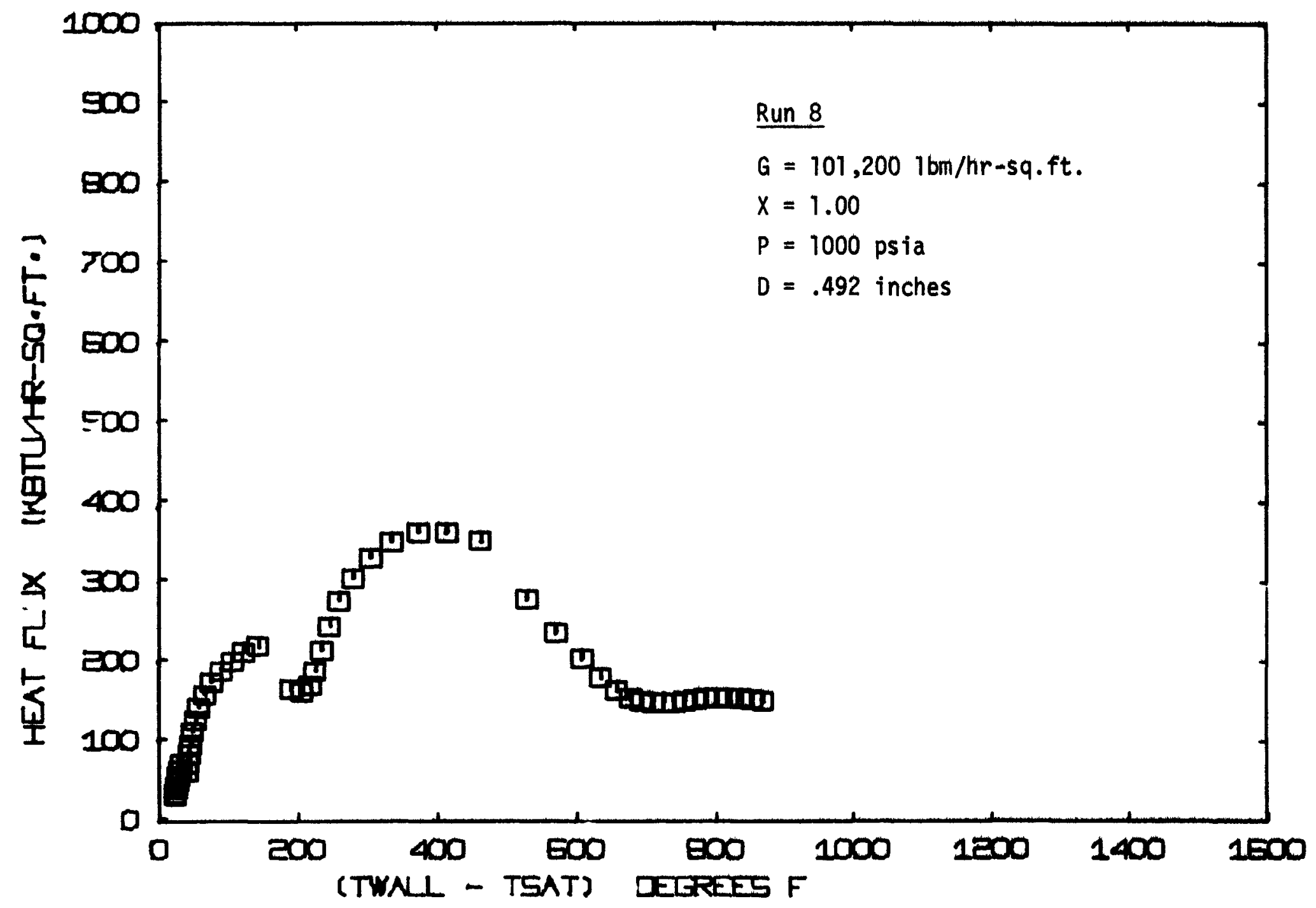

FIGURE 11 REDUCED DATA FROM G.E. TRANSIENT TEST SECTION 


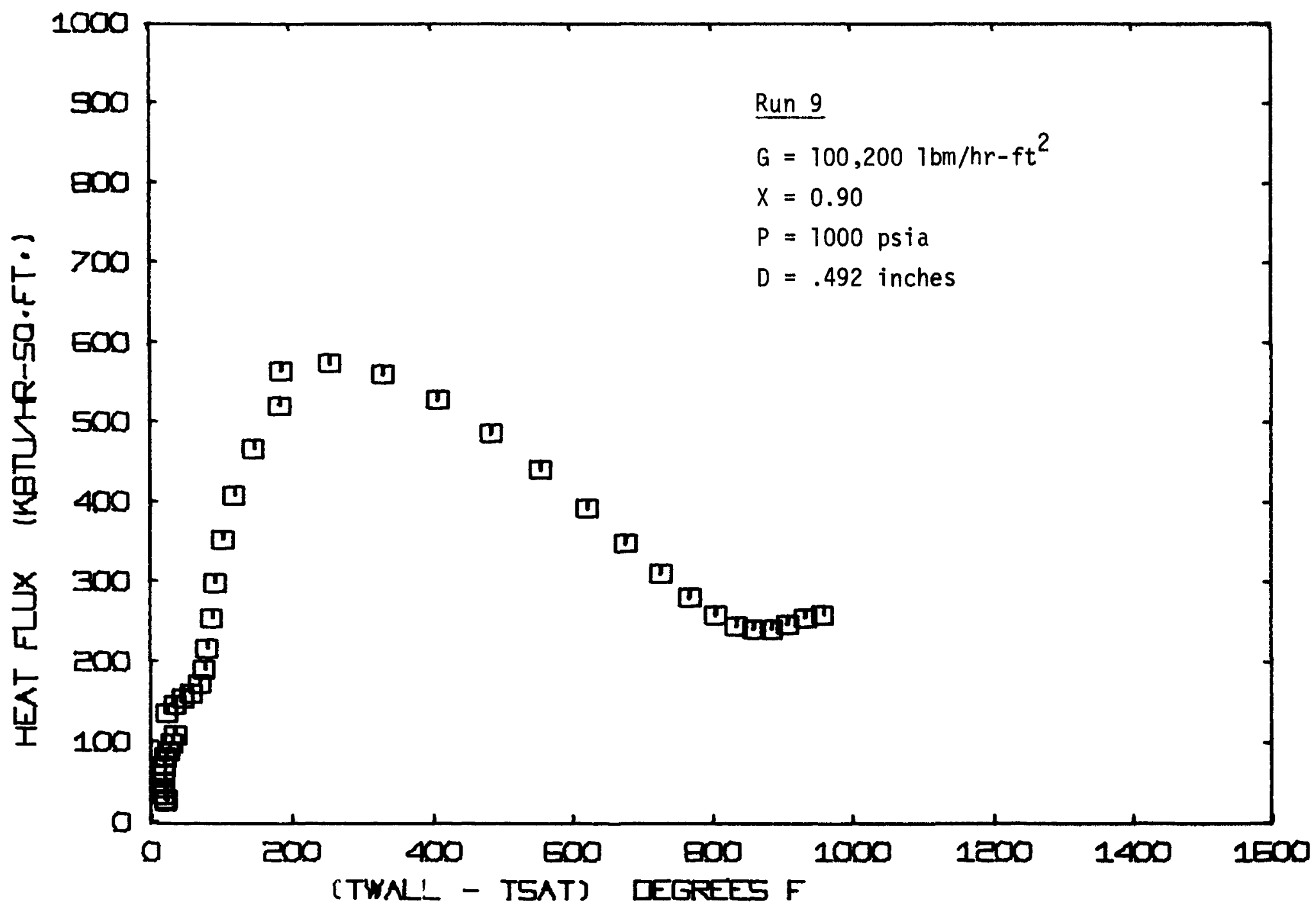

FIGURE 12 REDUCED DATA FROM G.E. TRANSIENT TEST SECTION 


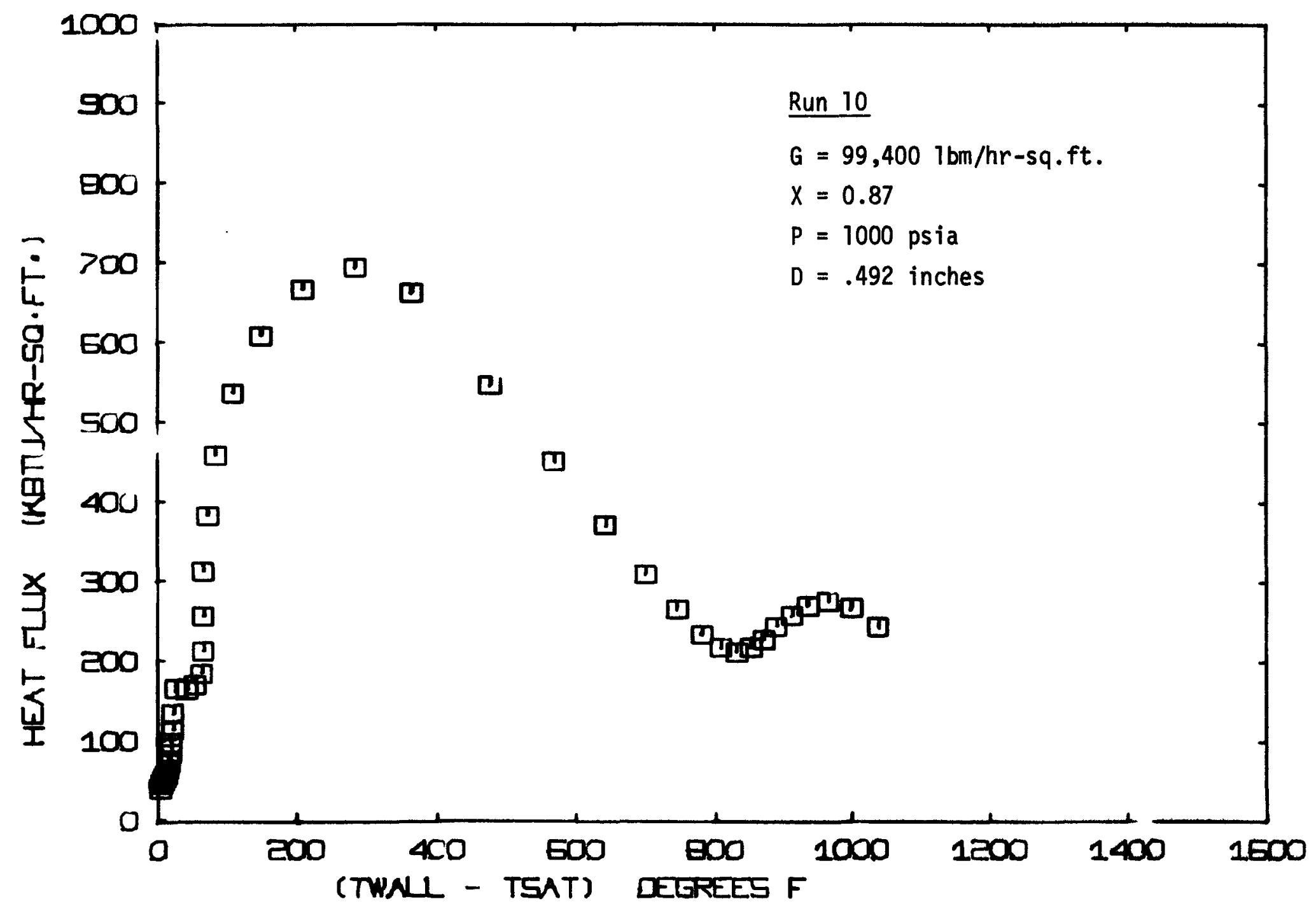

FIGURE 13 REDUCED DATA FROM G.E. TRANSIENT TEST SECTION 


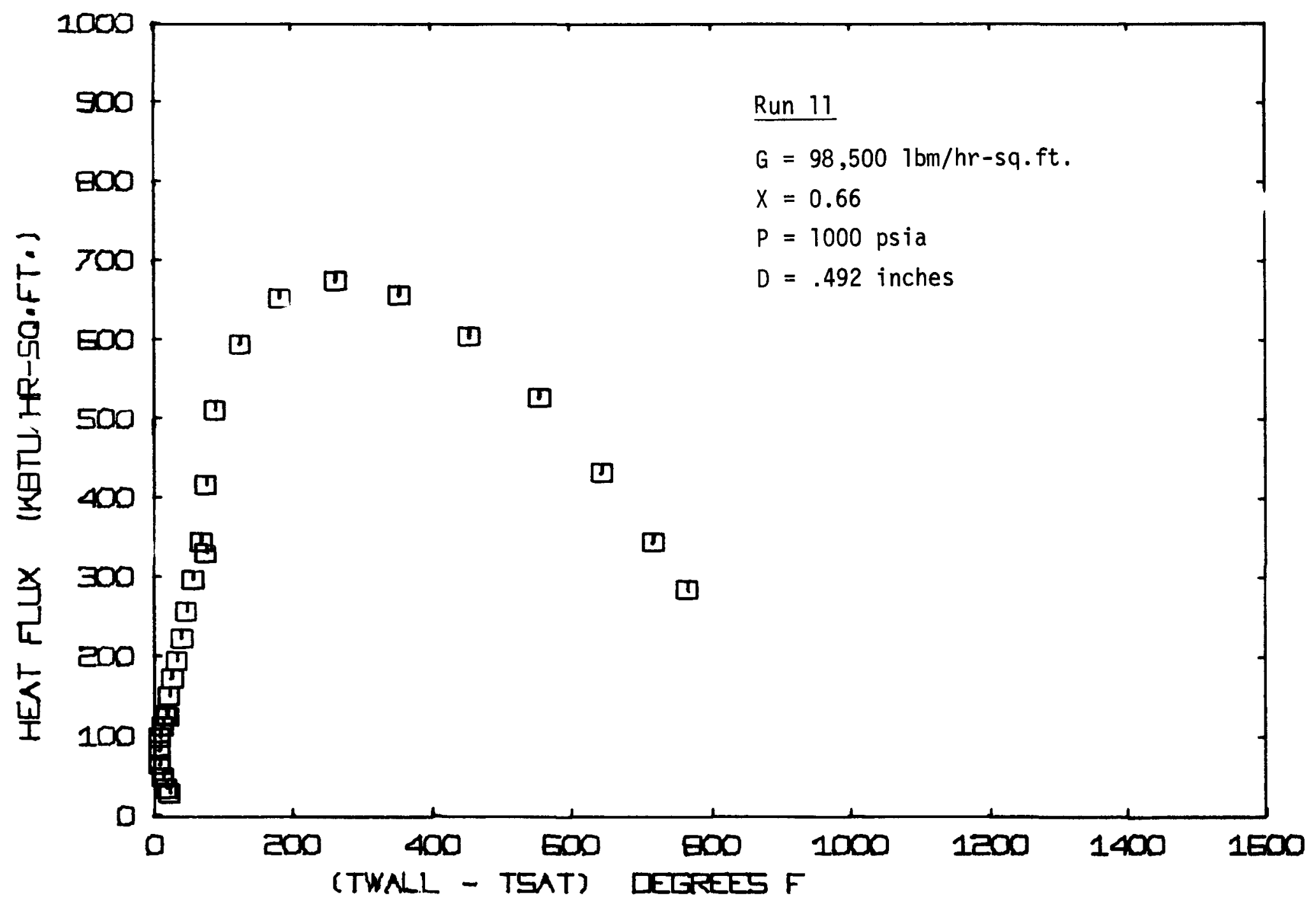

FIGURE 14 REDUCED DATA FROM G.E. TRANSIENT TEST SECTION 


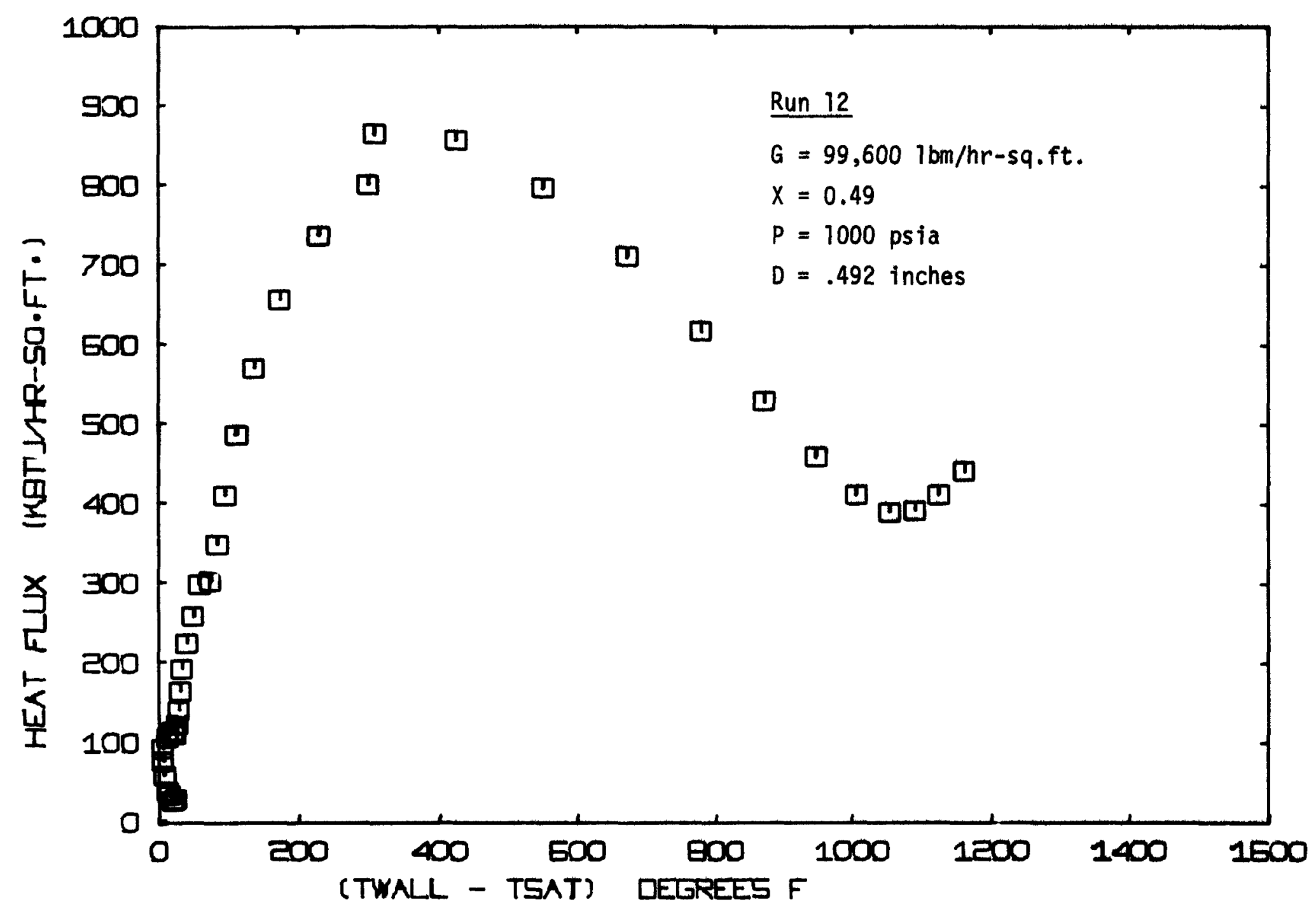




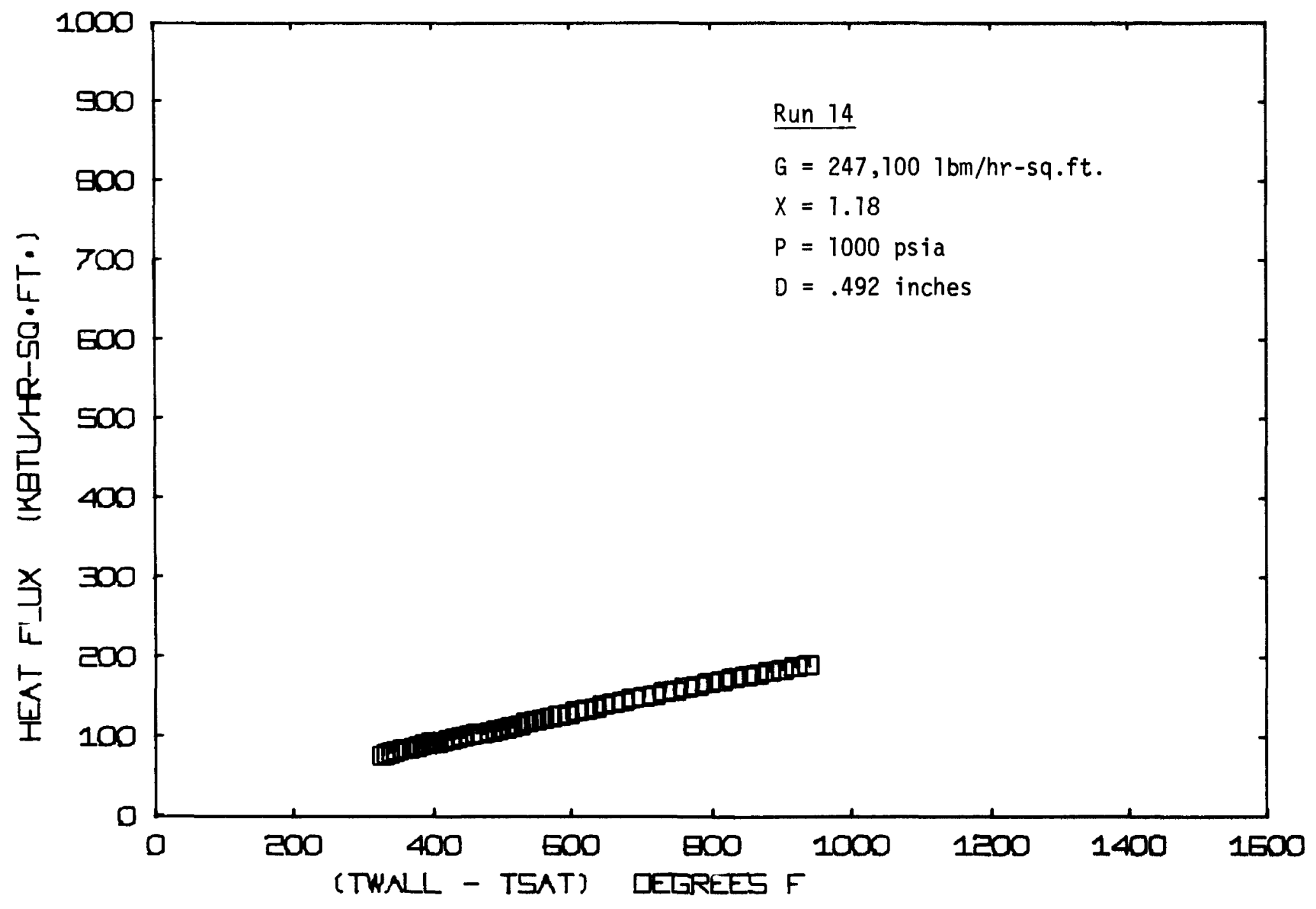

FIGURE 16 REDUCED DATA FROM G.E. TRANSIENT TEST SECTION 


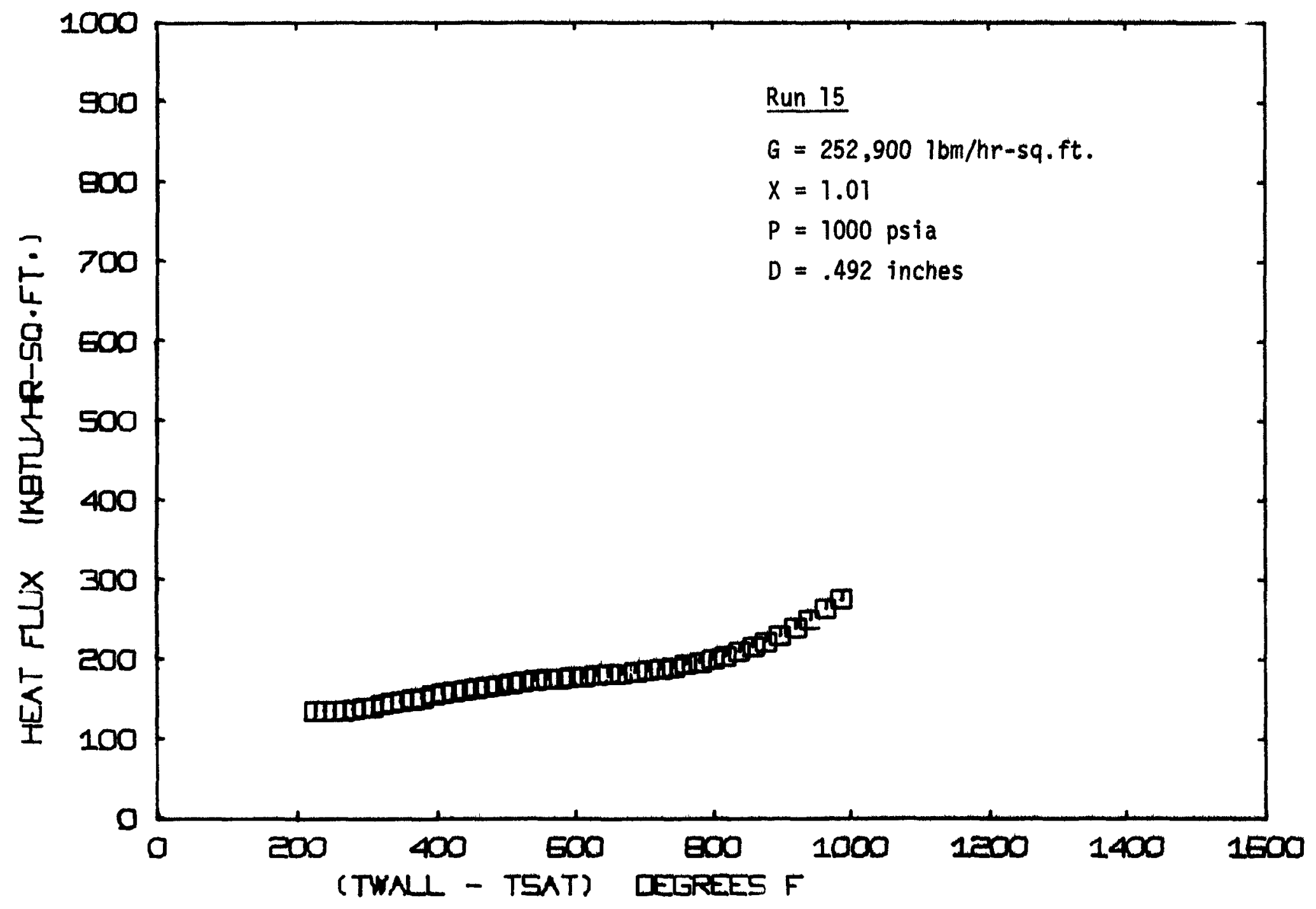

ธี

FIGURE 17 REDUCED DATA FROM G. E. TRANSIENT TEST SECTION 


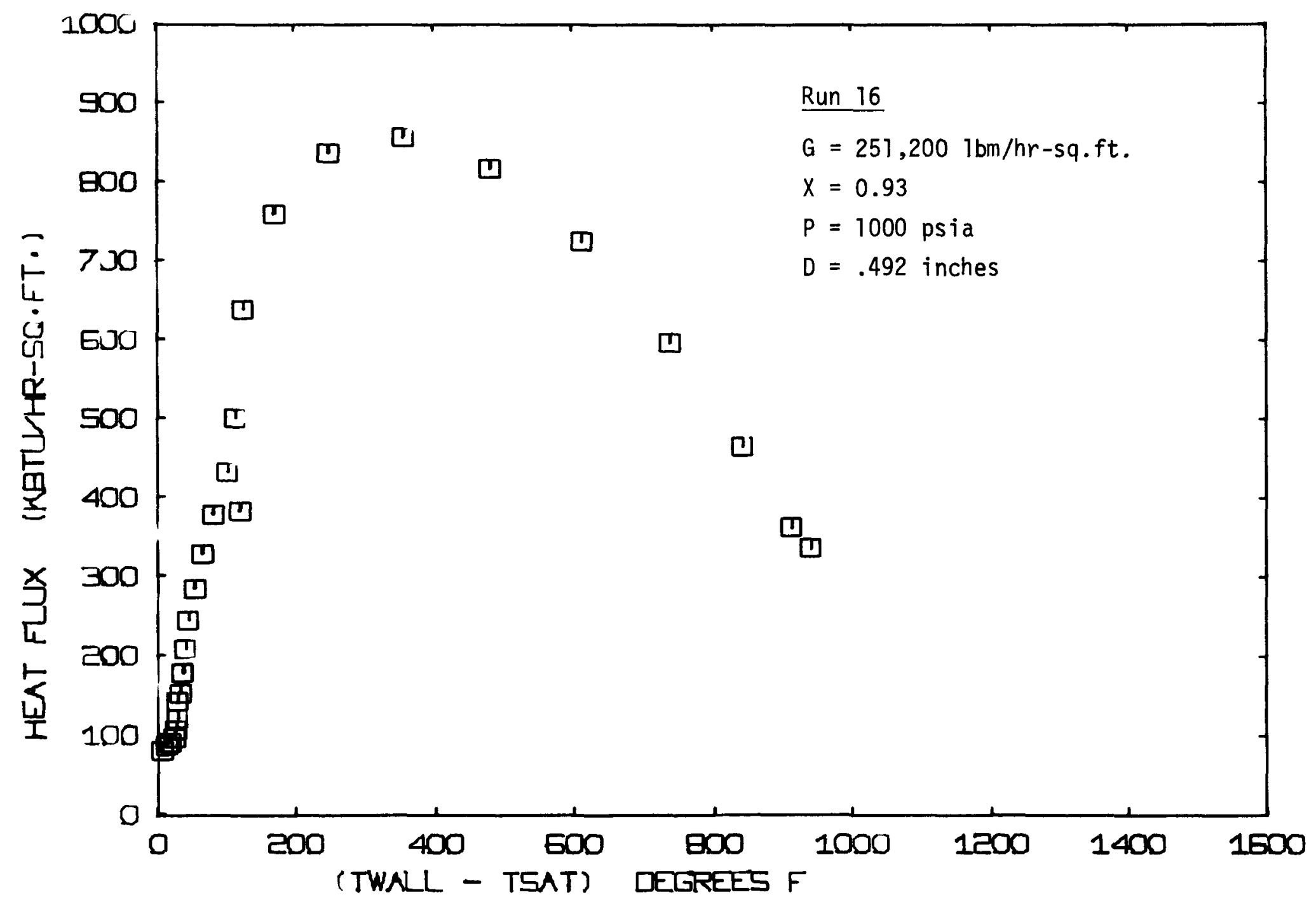

FIGURE 18 REDUCED DATA FROM G.E. TRANSIENT TEST SECTION 


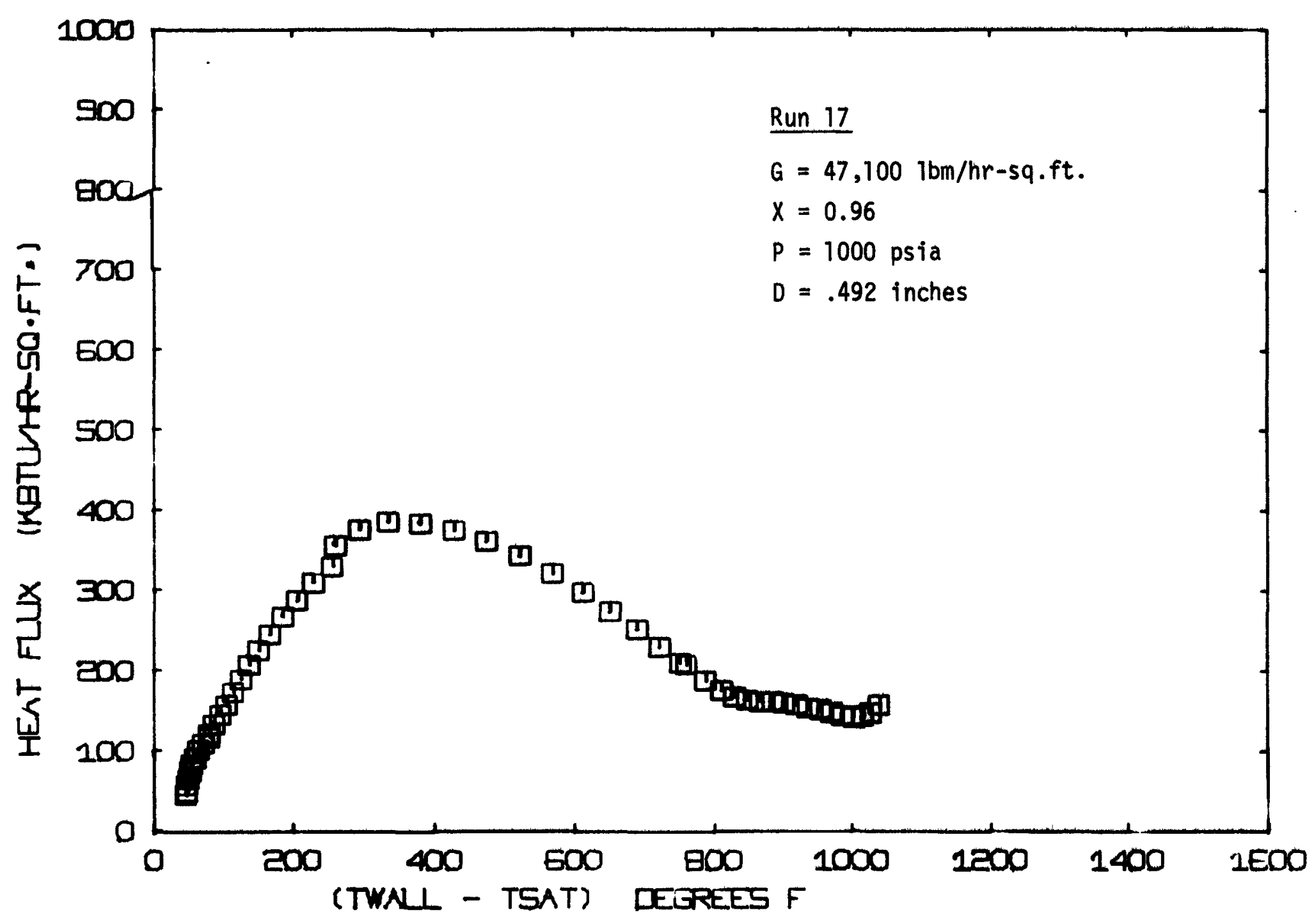




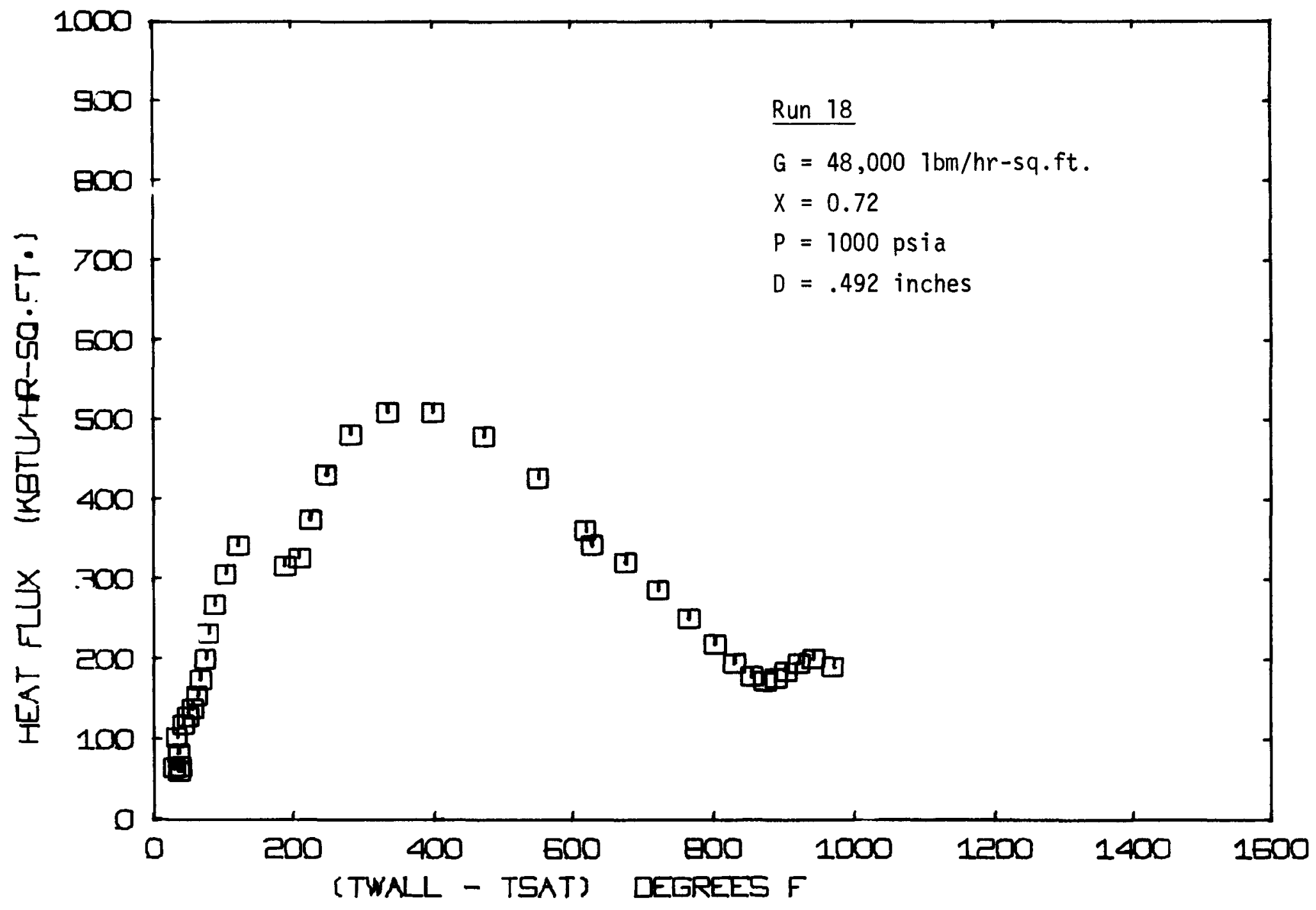

FIGURE 20 REDUCED DATA FROM G.E. TRANSIENT TEST SECTION 


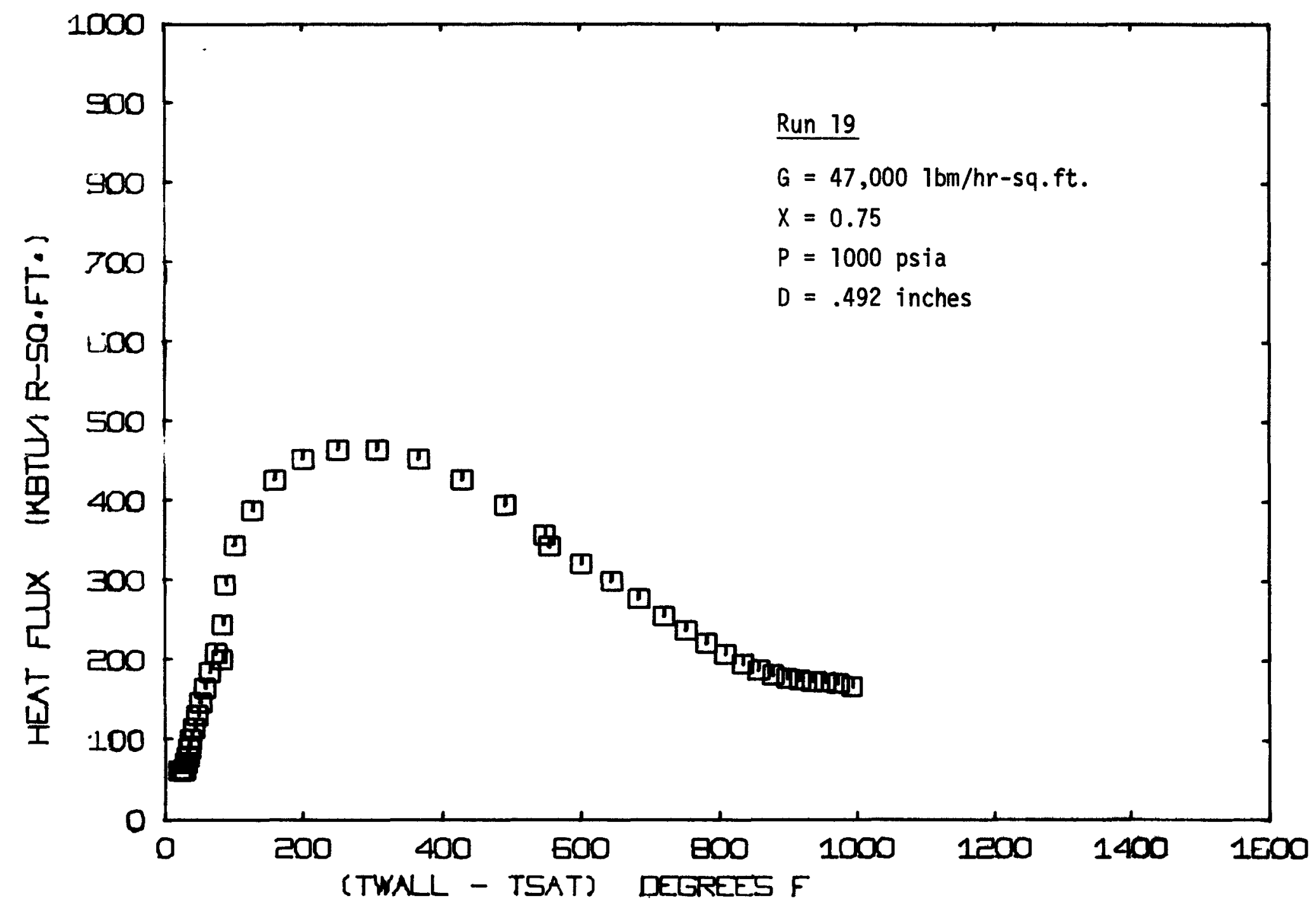




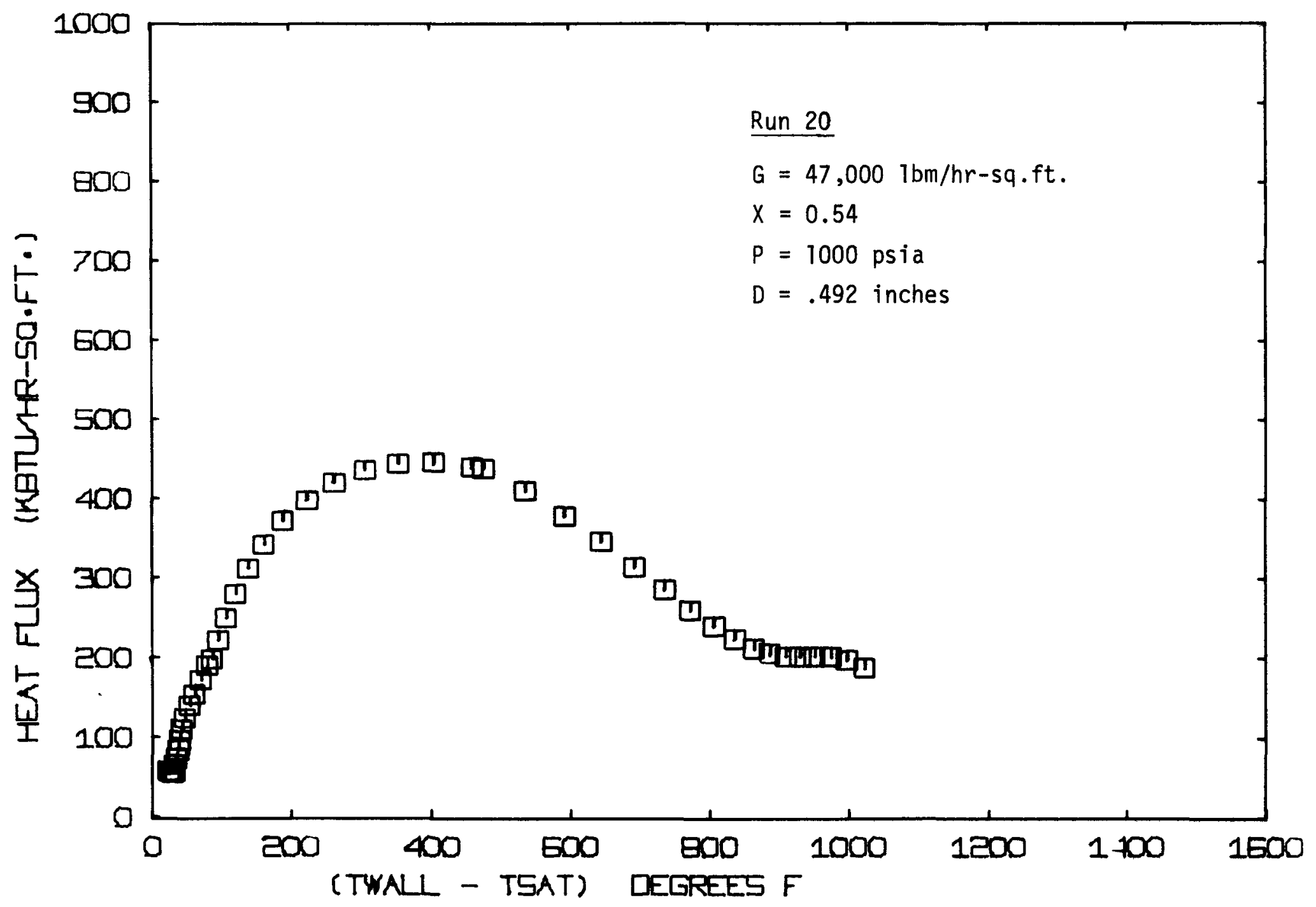

FIGURE 22 REDUCED DATA FROM G.E. TRANSIENT TEST SECTION 


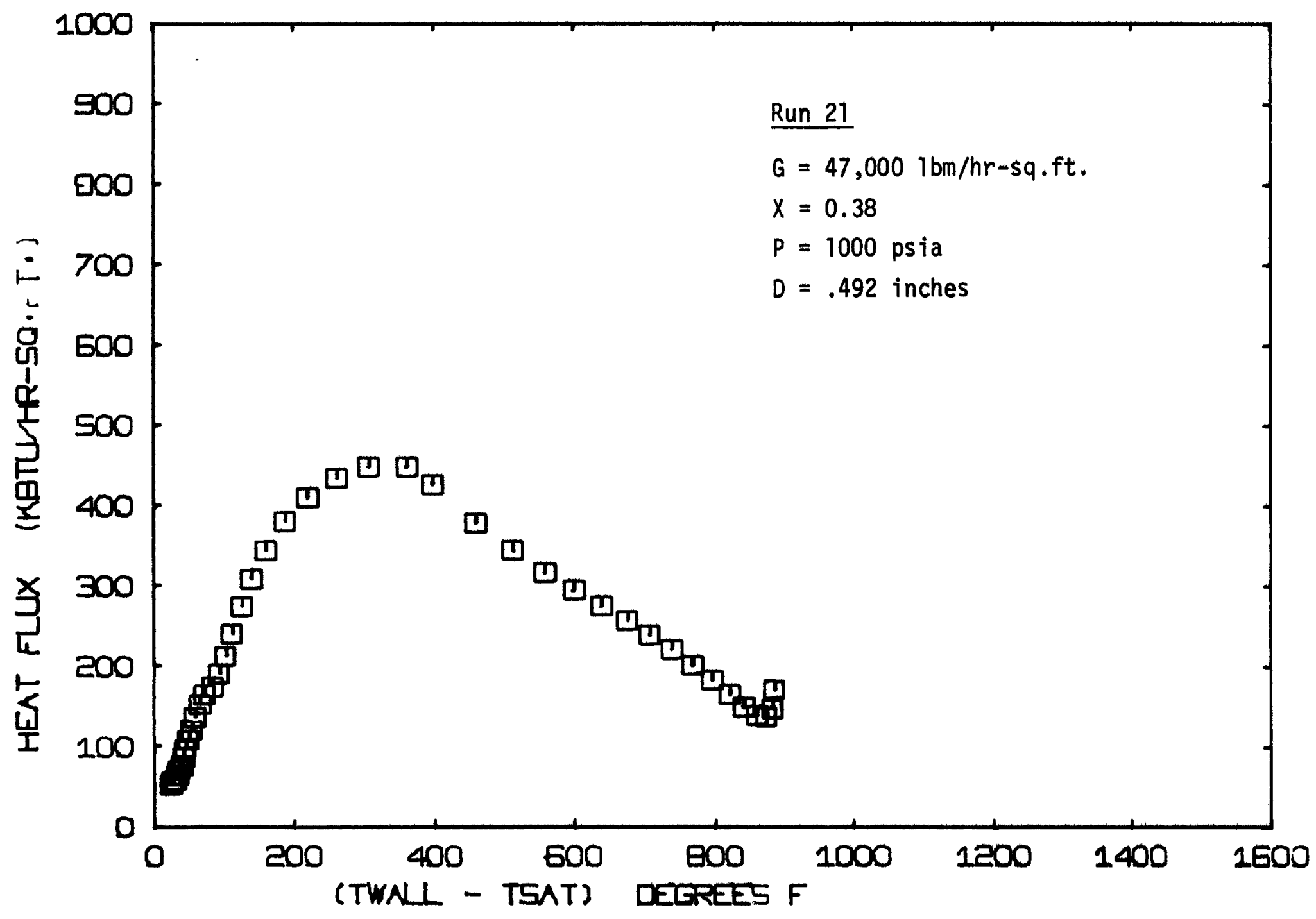




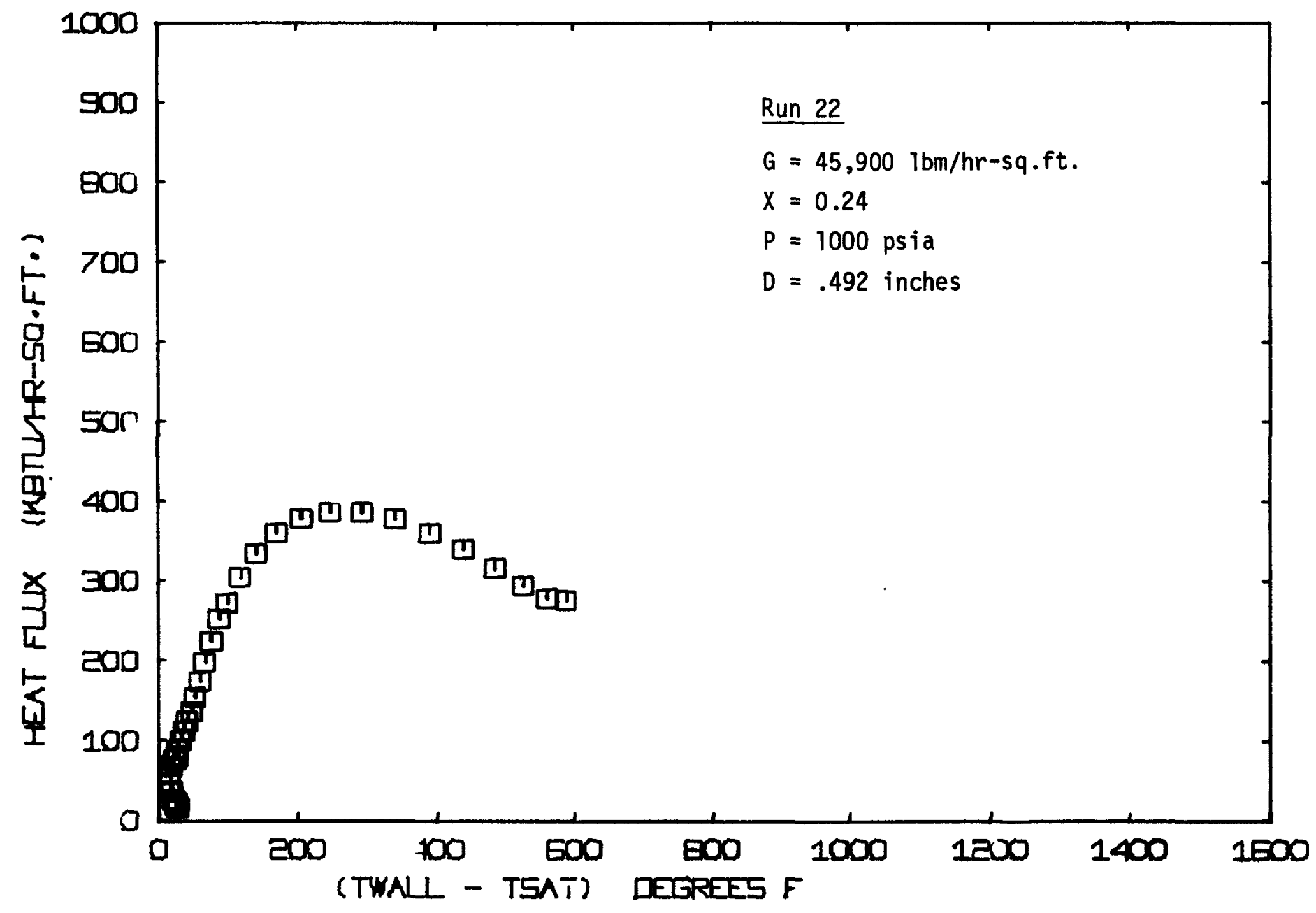

FIGURE 24 REDUCED DATA FROM G.E. TRANSIENT TEST SECTION 


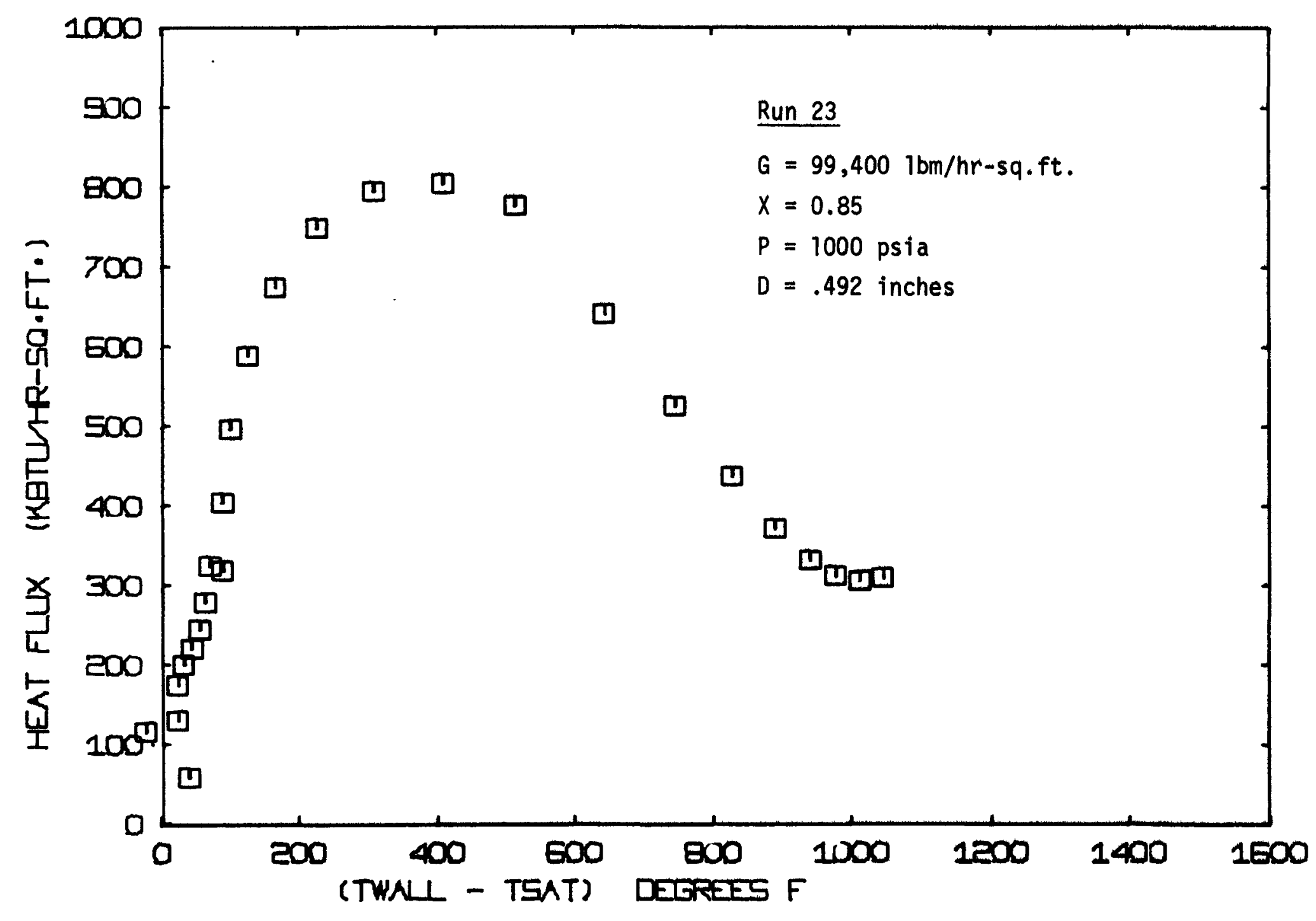




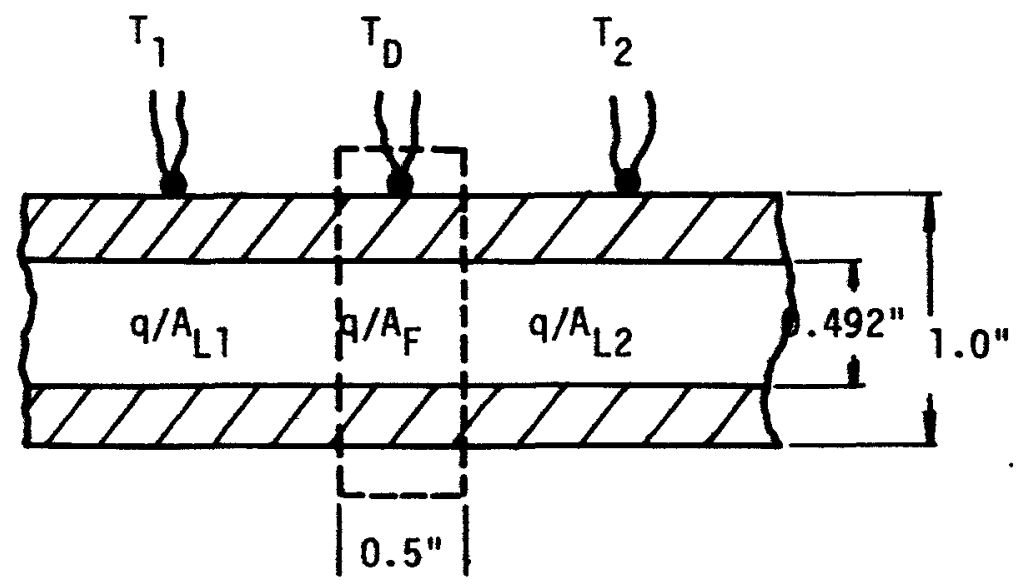

$$
\begin{gathered}
\text { PERCENT }=\frac{\left(q / A_{L 1}+q / A_{L 2}\right) A_{L}}{\left(q / A_{F}\right) A_{F}} \quad \text { where } q / A_{L 1}=\frac{K\left(T_{D}-T_{1}\right)}{\Delta X} \\
\text { and } \quad \Delta X=0.5^{\prime \prime}
\end{gathered}
$$

\begin{tabular}{|c|c|c|c|}
\hline$\underline{\text { RUN }}$ & PERCENT ERROR & $\underline{\text { RUN }}$ & PERCENT ERROR \\
\hline 4 & 24 & 14 & 20 \\
\hline 5 & 40 & 15 & 24 \\
\hline 6 & 33 & 16 & 0 \\
\hline 7 & 0 & 17 & 38 \\
\hline 8 & 26 & 18 & 12 \\
\hline 9 & 9.5 & 19 & 8 \\
\hline 10 & 0 & 20 & 6 \\
\hline 11 & 8 & 21 & 7 \\
\hline 12 & 6 & 22 & 14 \\
\hline & & 23 & 6 \\
\hline
\end{tabular}

FIGURE 26 APPROXIMATE ERROR DUE TO AXIAL CONDUCTION IN TRANSIENT TEST SECTION 


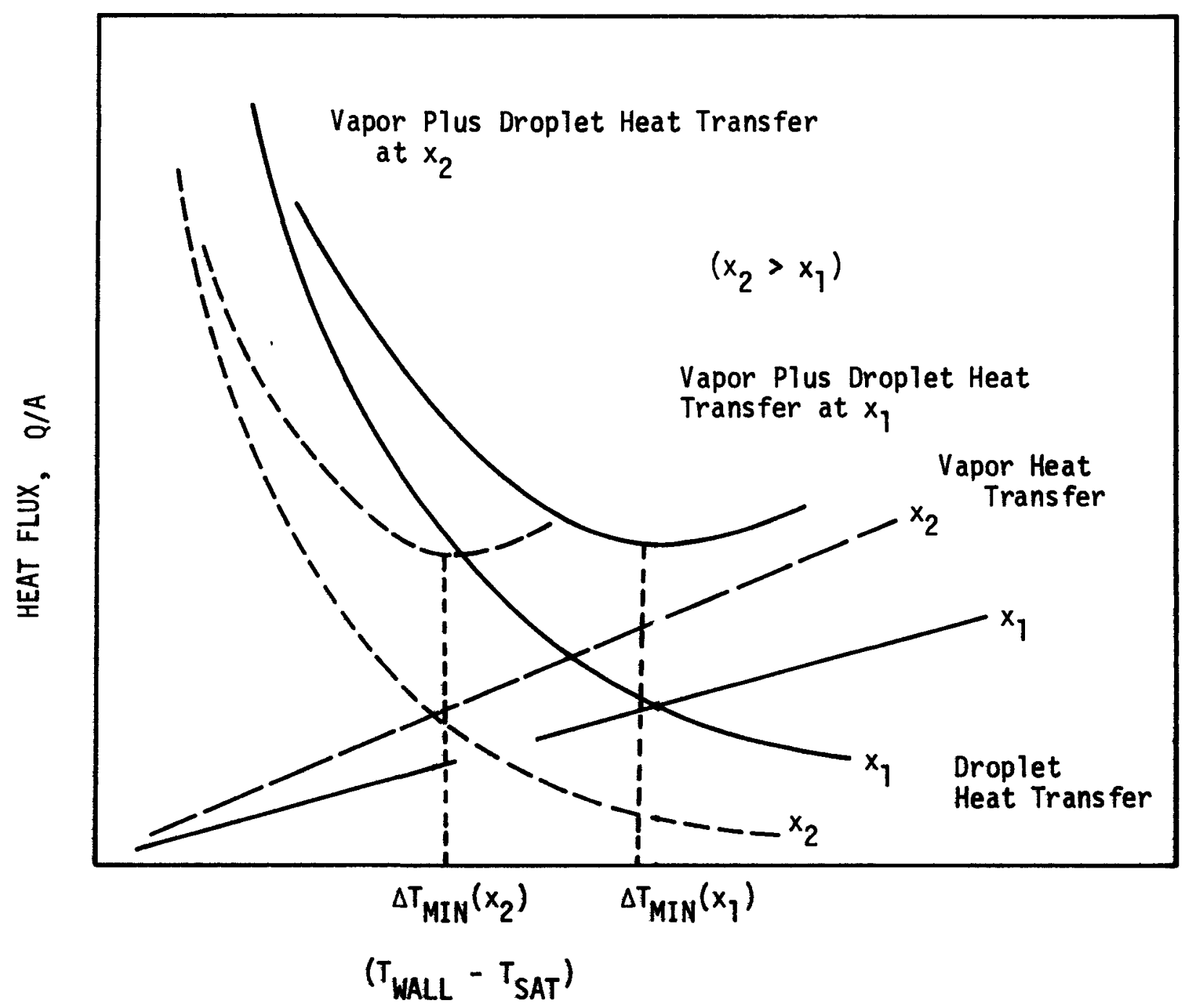

FIGURE 27 FILM BOILING MINIMUM $\triangle$ T SKETCH SHOWING EFFECT OF QUALITY 


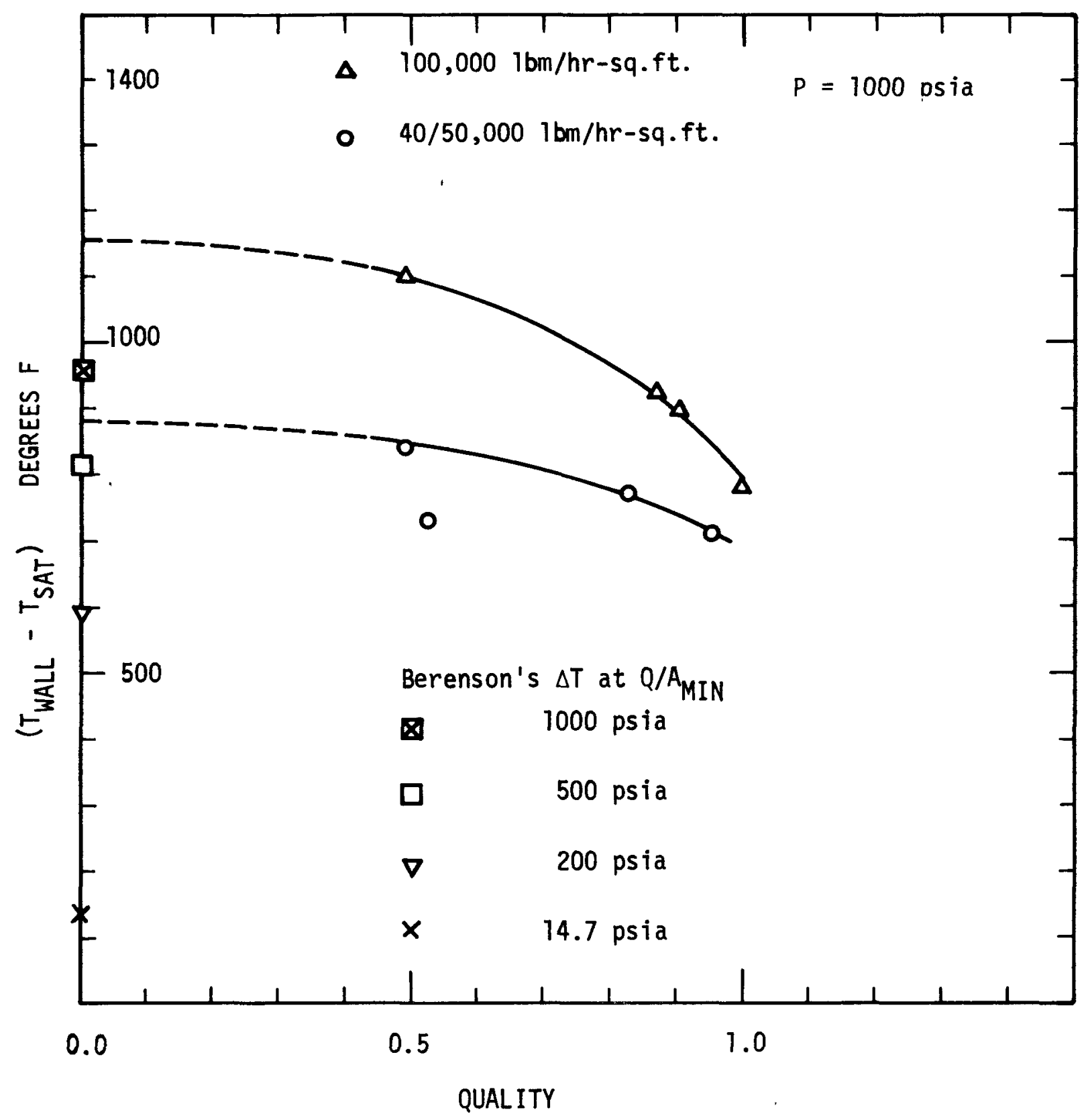

FIGURE 28 FILM BOILING MINIMUM $\Delta T$ VS EQUILIBRIUM QUALITY, EFFECT OF MASS FLUX 


$$
\begin{aligned}
\Delta T_{M I N}= & \left(0.127 \rho_{v f} h_{f g} / k_{v f}\right)\left(g\left(\rho_{1}-\rho_{v}\right) /\left(\rho_{1}+\rho_{v}\right)\right)^{2 / 3} \\
& \left(g_{0} \sigma / g\left(\rho_{1}-\rho_{v}\right)\right)^{T / 2}\left(\mu_{f} / g_{0}\left(\rho_{1}-\rho_{v}\right)\right)^{1 / 3}
\end{aligned}
$$

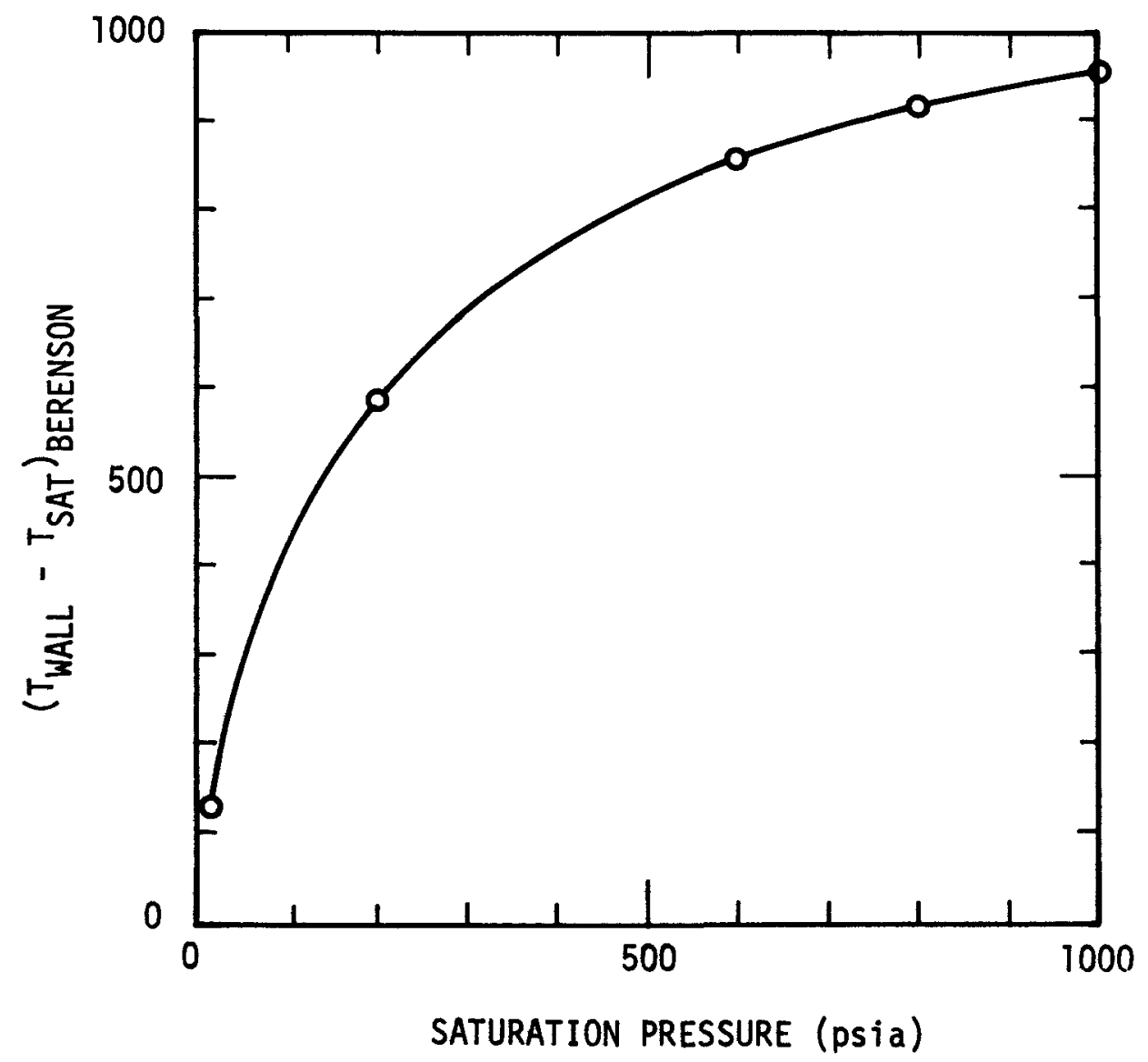

FIGURE 29 POOL FILM BOILING $\triangle T_{\text {MIN }}$, BERENSON'S CORRELATION 


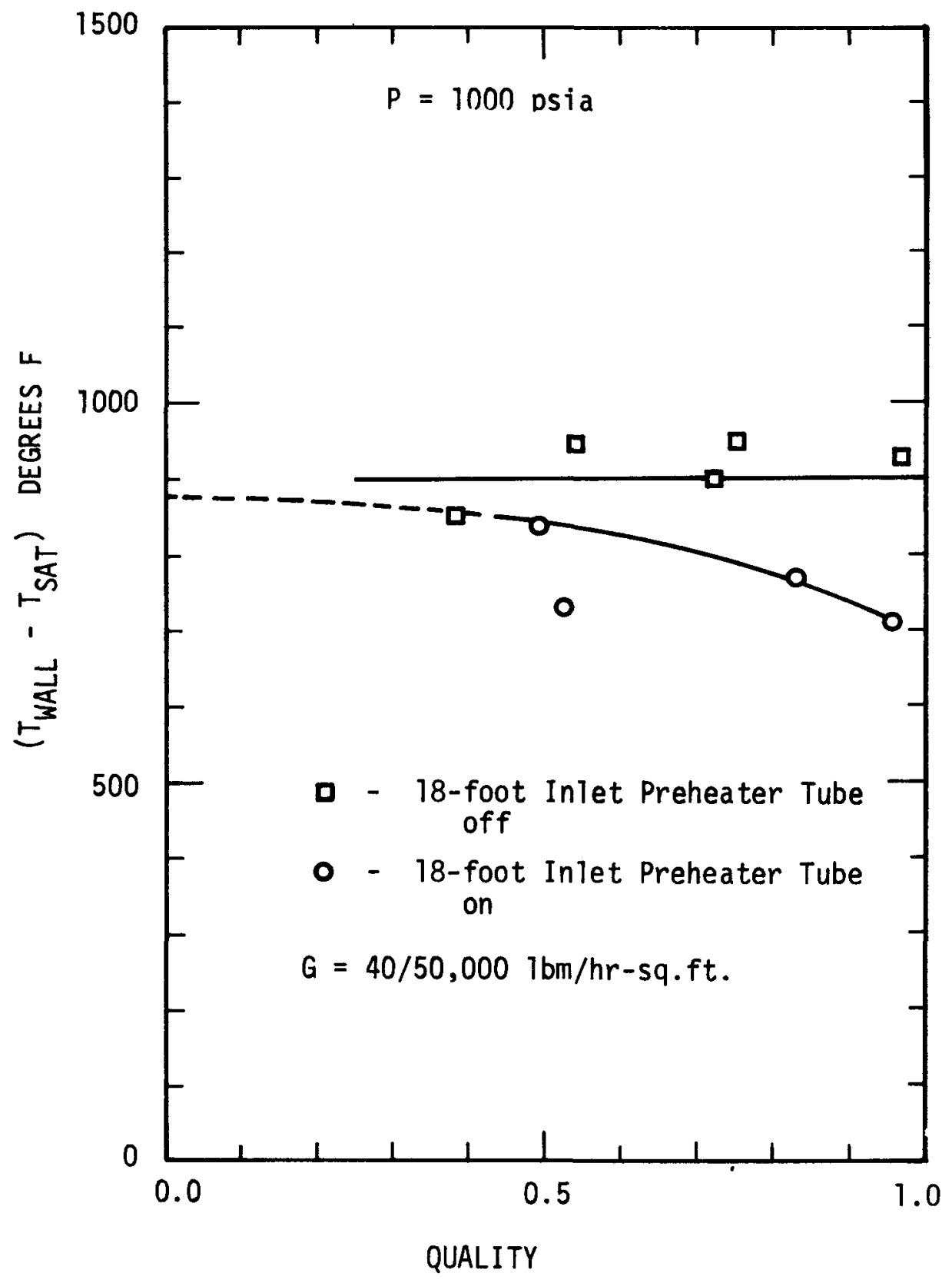

FIGURE 30 FILM BOILING MINIMUM $\triangle T$ VS EOUILIBRIUM QUALITY EFFECT OF HISTORY OF FLOW REGIME 


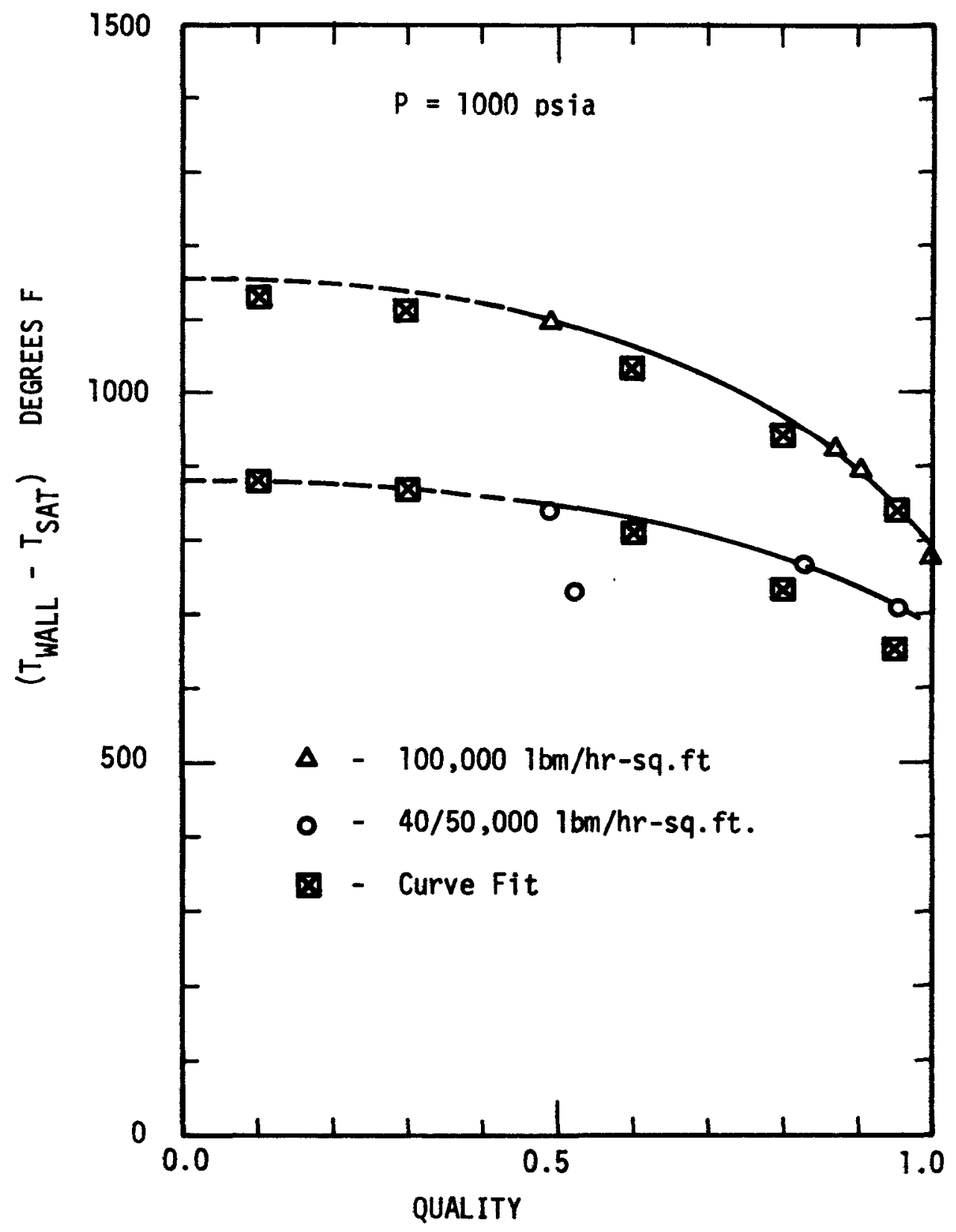

FIGURE 31 FILM BOILING MINIMUM $\triangle T$ VS EQUILIBRIUM QUALITY EFFECT OF MASS FLUX 


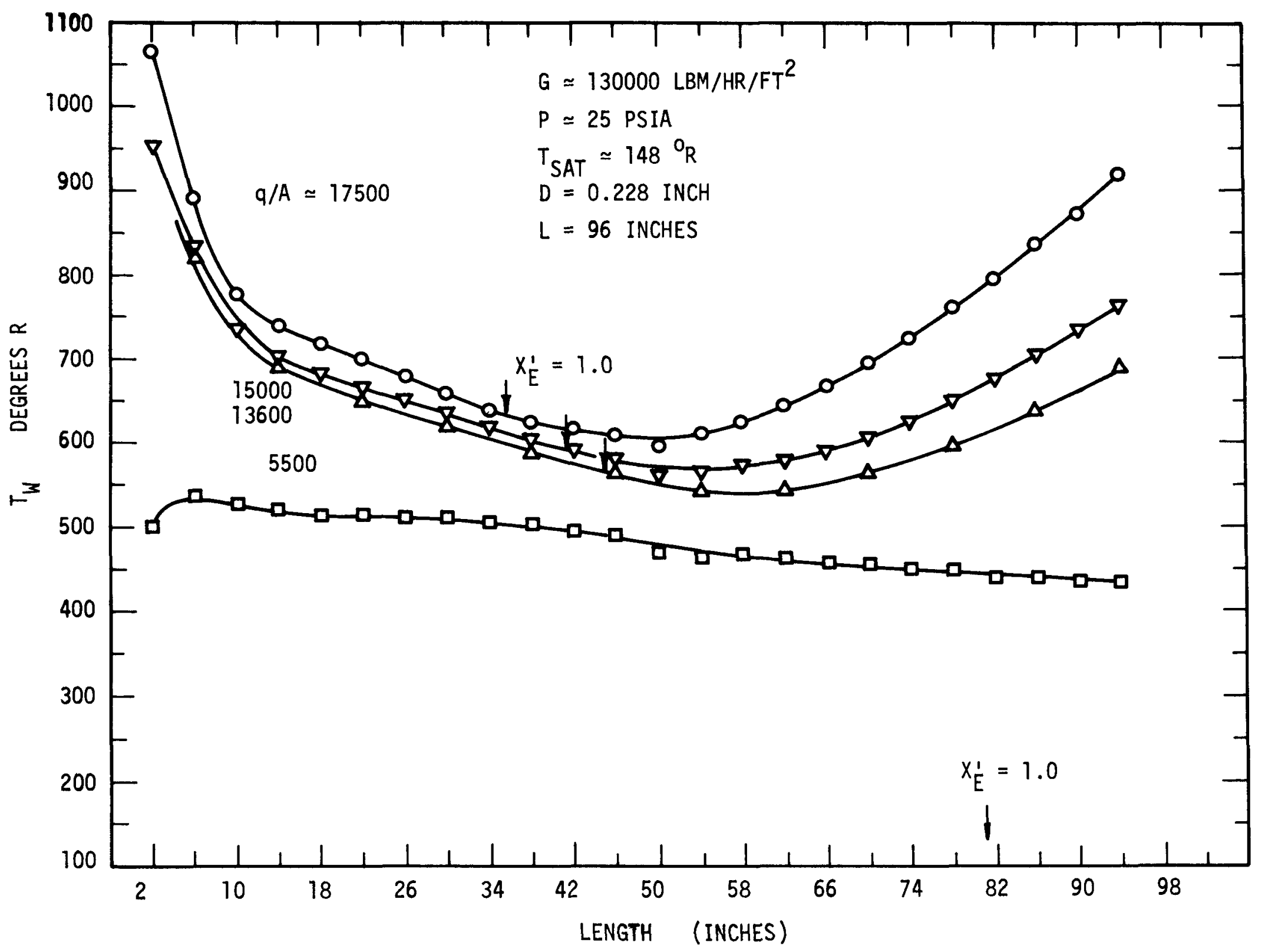

FIGURE 32 TUBE WALL TEMPERATURE PROFILES-0.228 INCH ID TUBE (FIG-10 Of REF 16) 


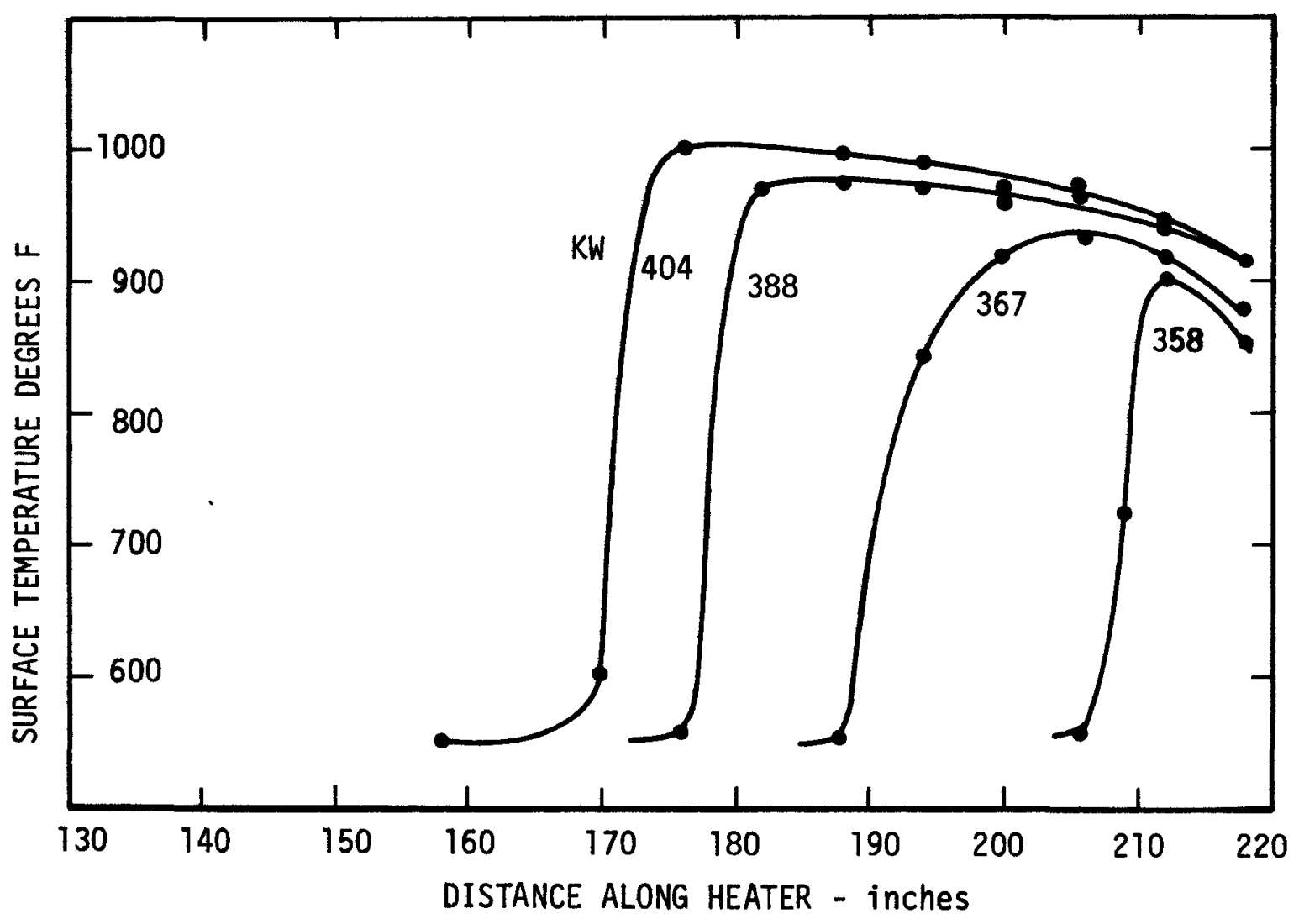

FIGURE 33 SURFACE TEMPERATURE PROFILES IN CHFC FOR A MASS VELOCITY OF $3.86 \times 10^{6} 1 \mathrm{~b} \mathrm{ft}^{-2} \mathrm{~h}^{-1}$ WITH INCREASING HEAT FLUX (FIG 9 A.E.R.E. - R5373 REF 11) 


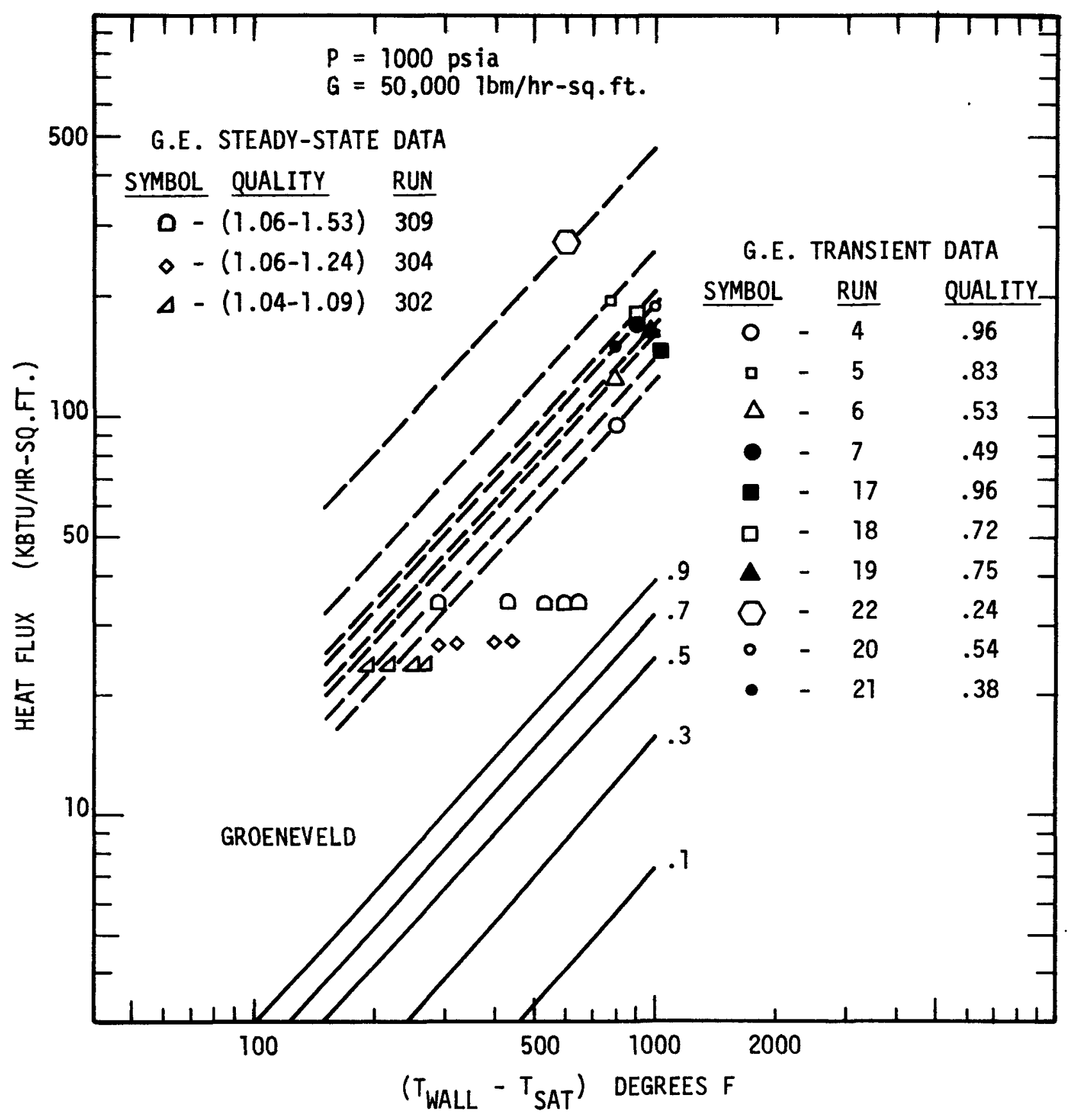

FIGURE 34 COMPARISON OF GENERAL ELECTRIC DATA WITH THE GROENEVELD CORRELATION 


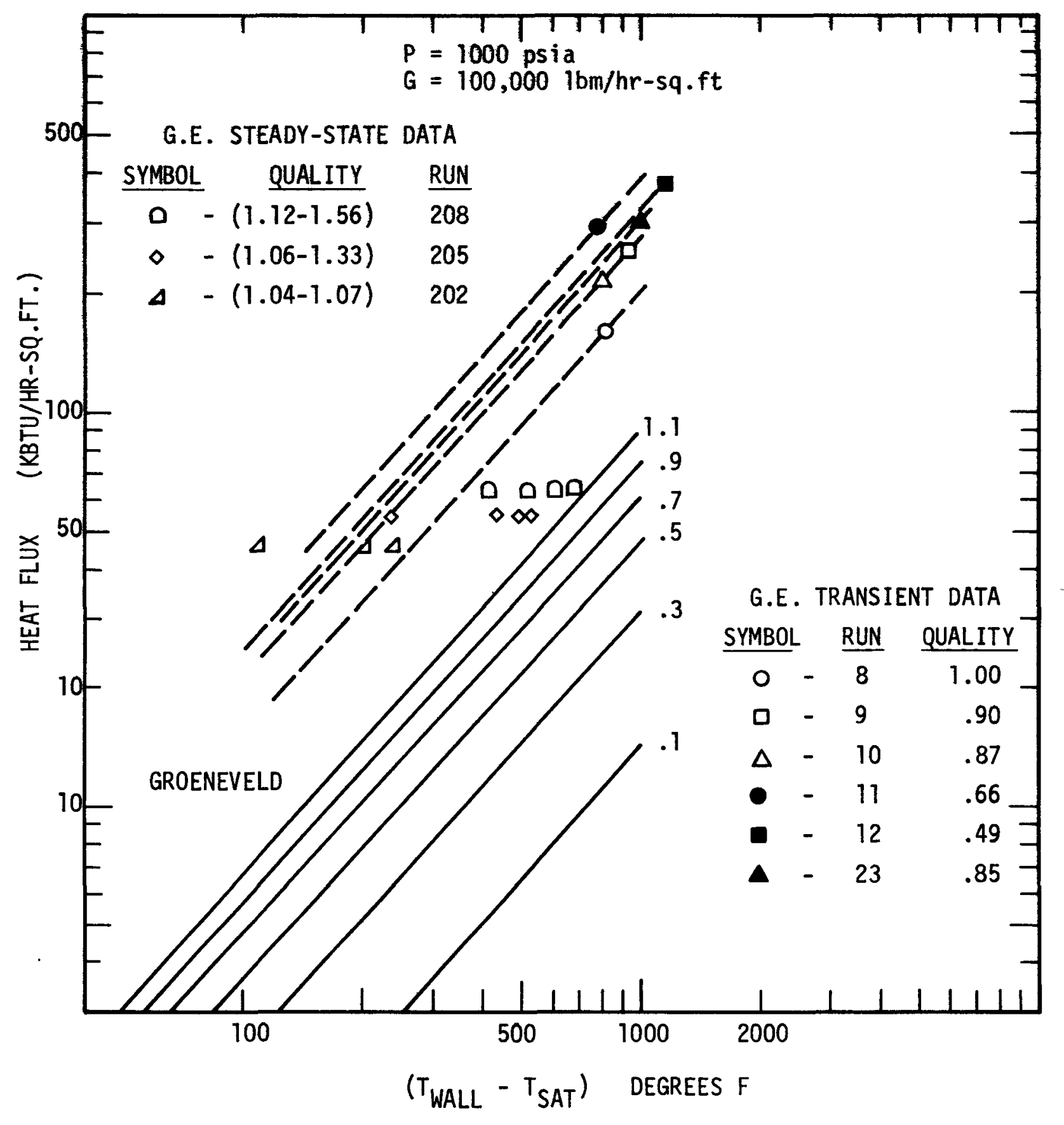

FIGURE 35 COMPARISON OF GENERAL ELECTRIC DATA WITH GROENEVELD CORRELATION 


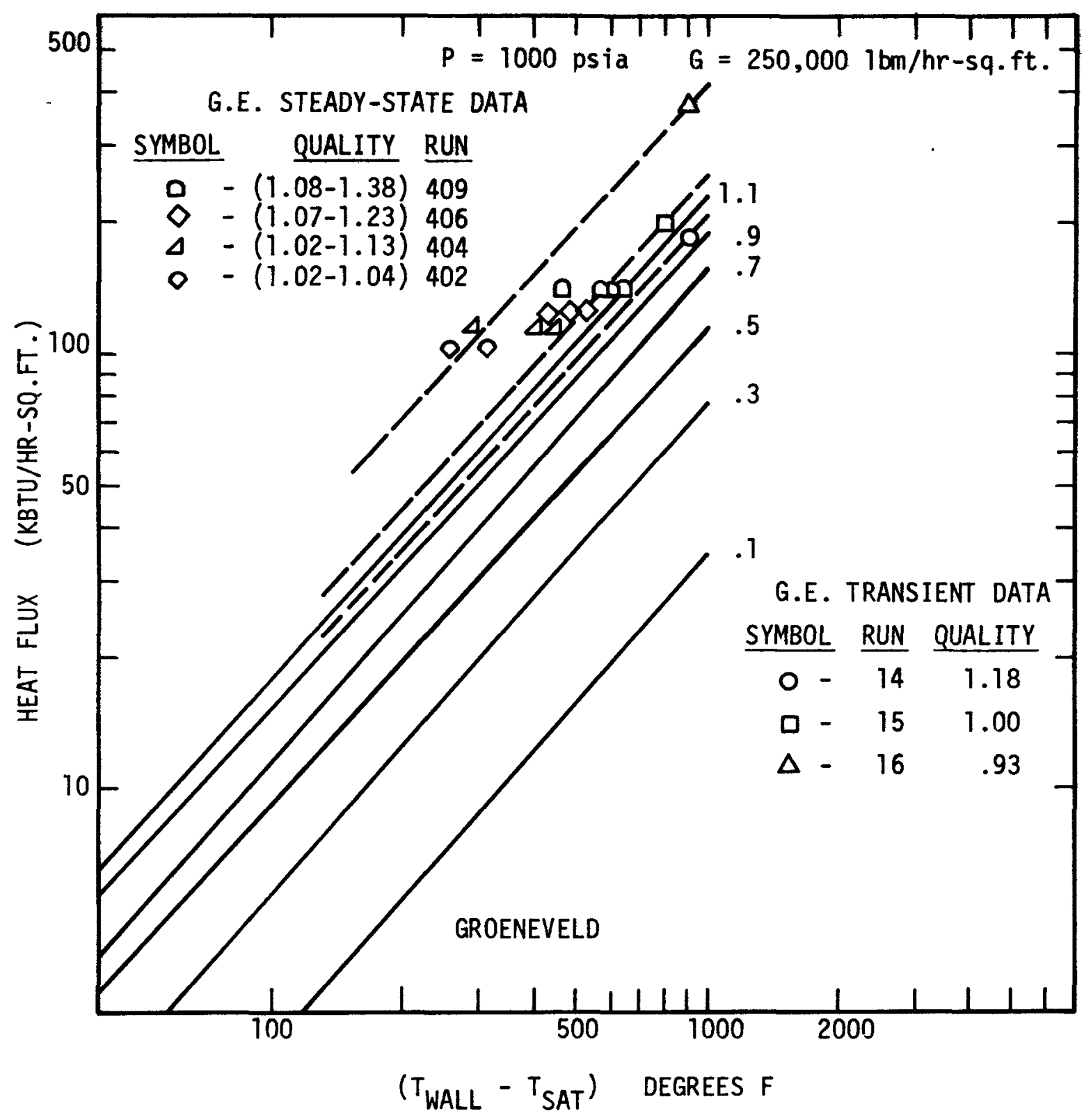

FIGURE 36 COMPARISON OF GENERAL ELECTRIC DATA WITH GROENEVELD CORRELATION 


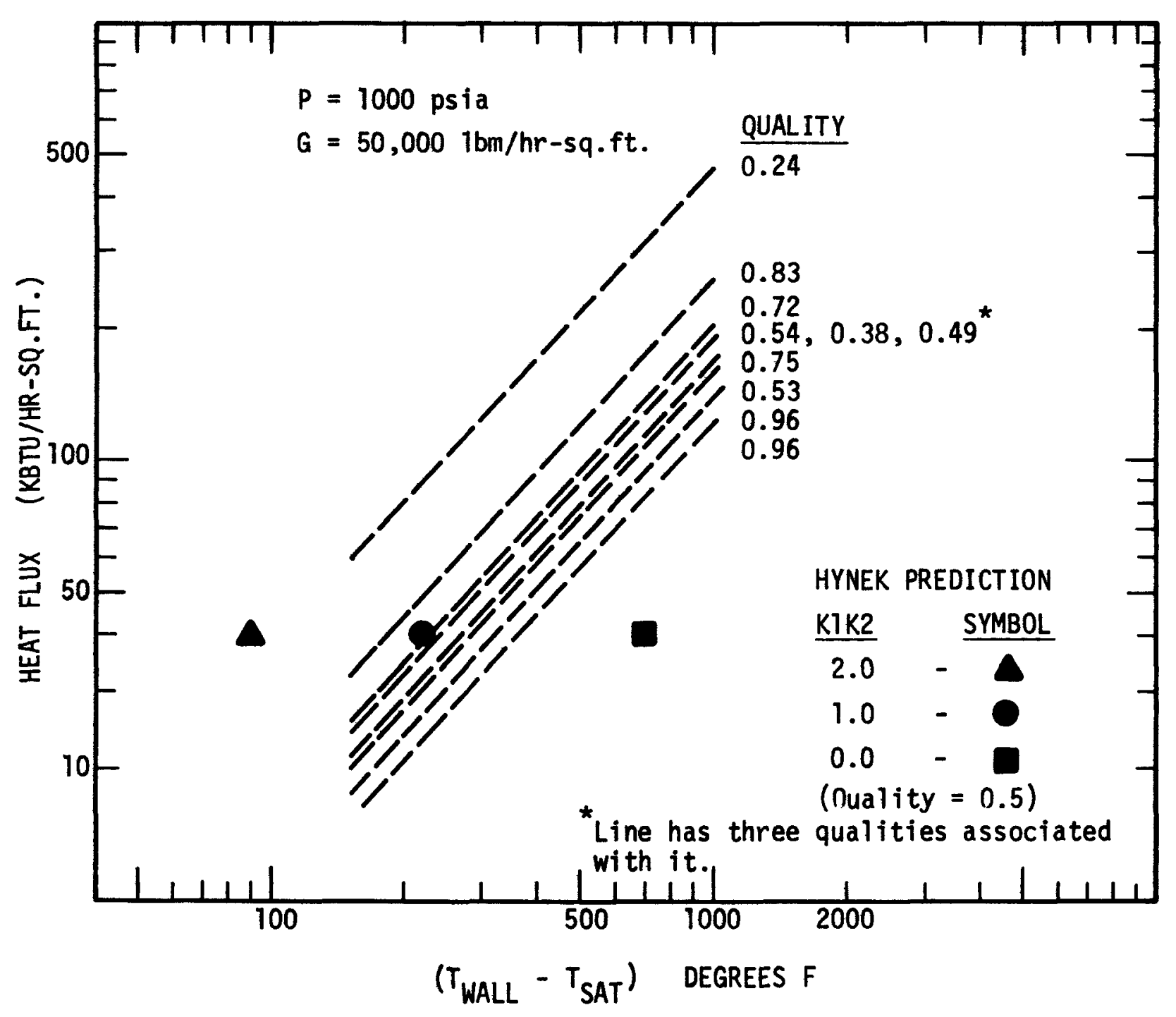

FIGURE 37 COMPARISON OF GENERAL ELECTRIC DATA WITH HEAT TRANSFER DATA GENERATED FROM TWO-STEP MODEL OF HYNEK(17) 


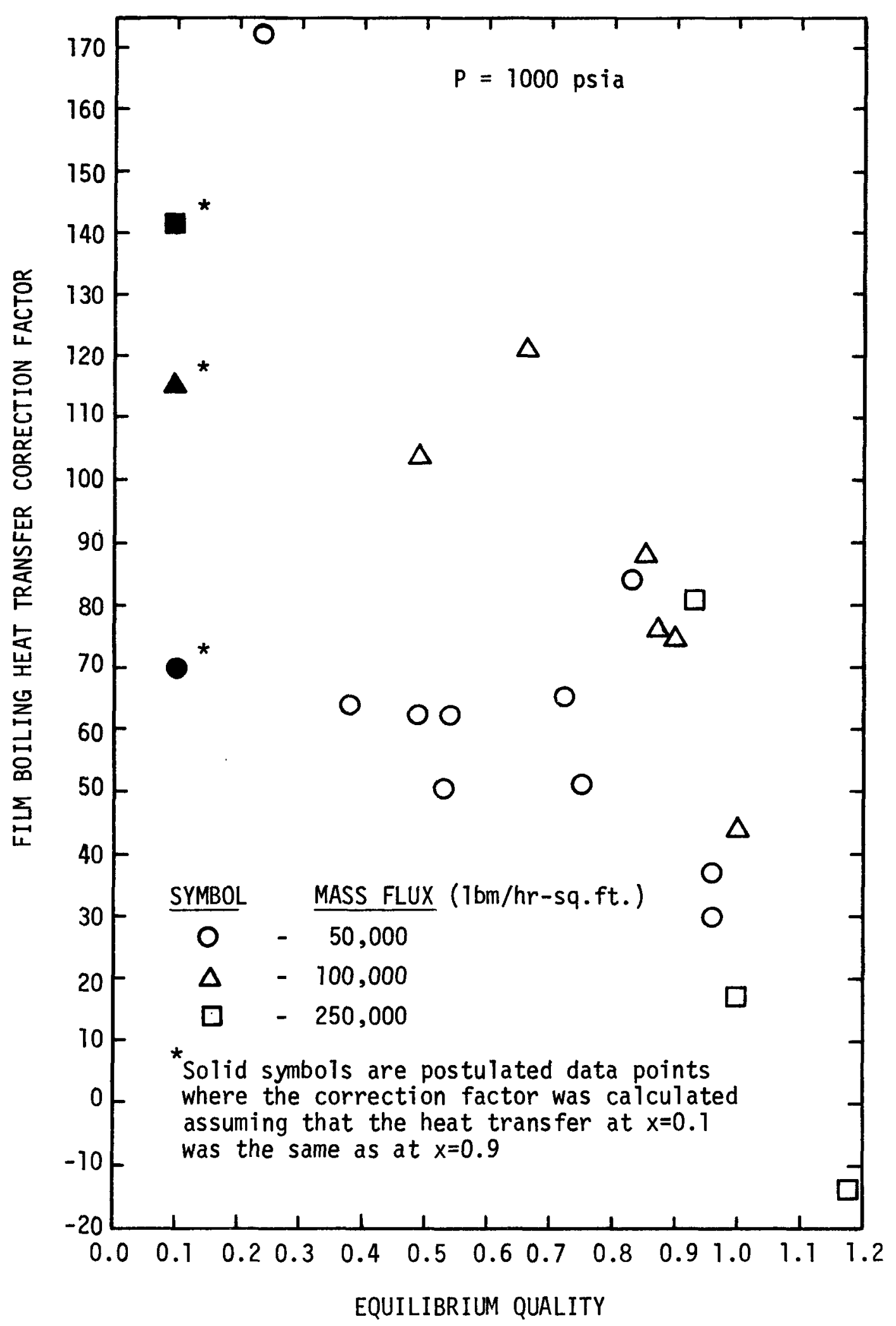

FIGURE 38 FILM BOILING CORRECTION TERM vS EQUILIBRIUM QUALITY WITH MASS FLUX AS PARAMETER FOR GROENEVELD EQUATION 


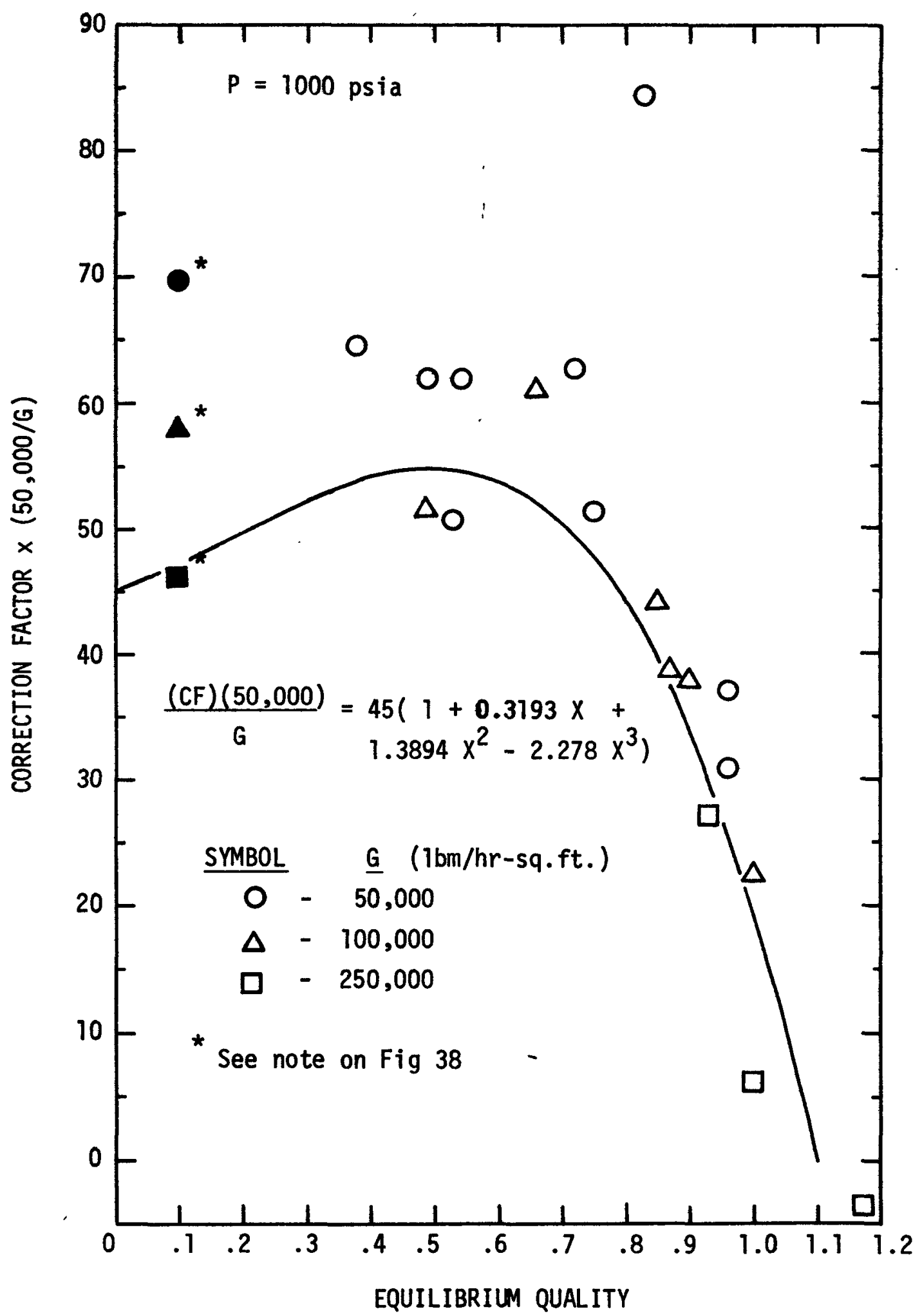

FIGURE 39 COMPARISON OF MIT FILM BOILING CORRECTION FACTOR CORRELATION FOR GROENEVELD EQUATION WITH DATA 


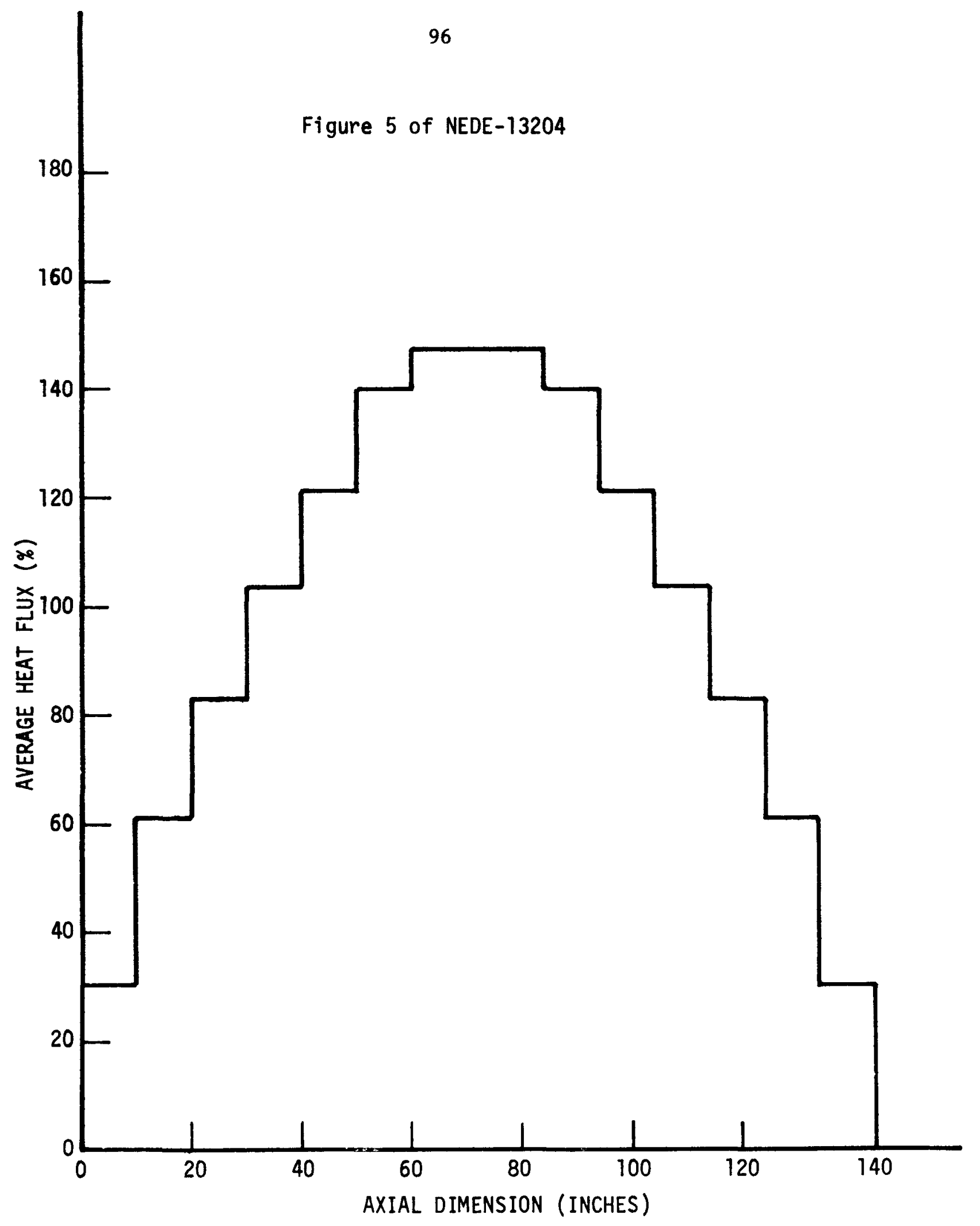

FIG. 40 AXIAL POWER SHAPE 


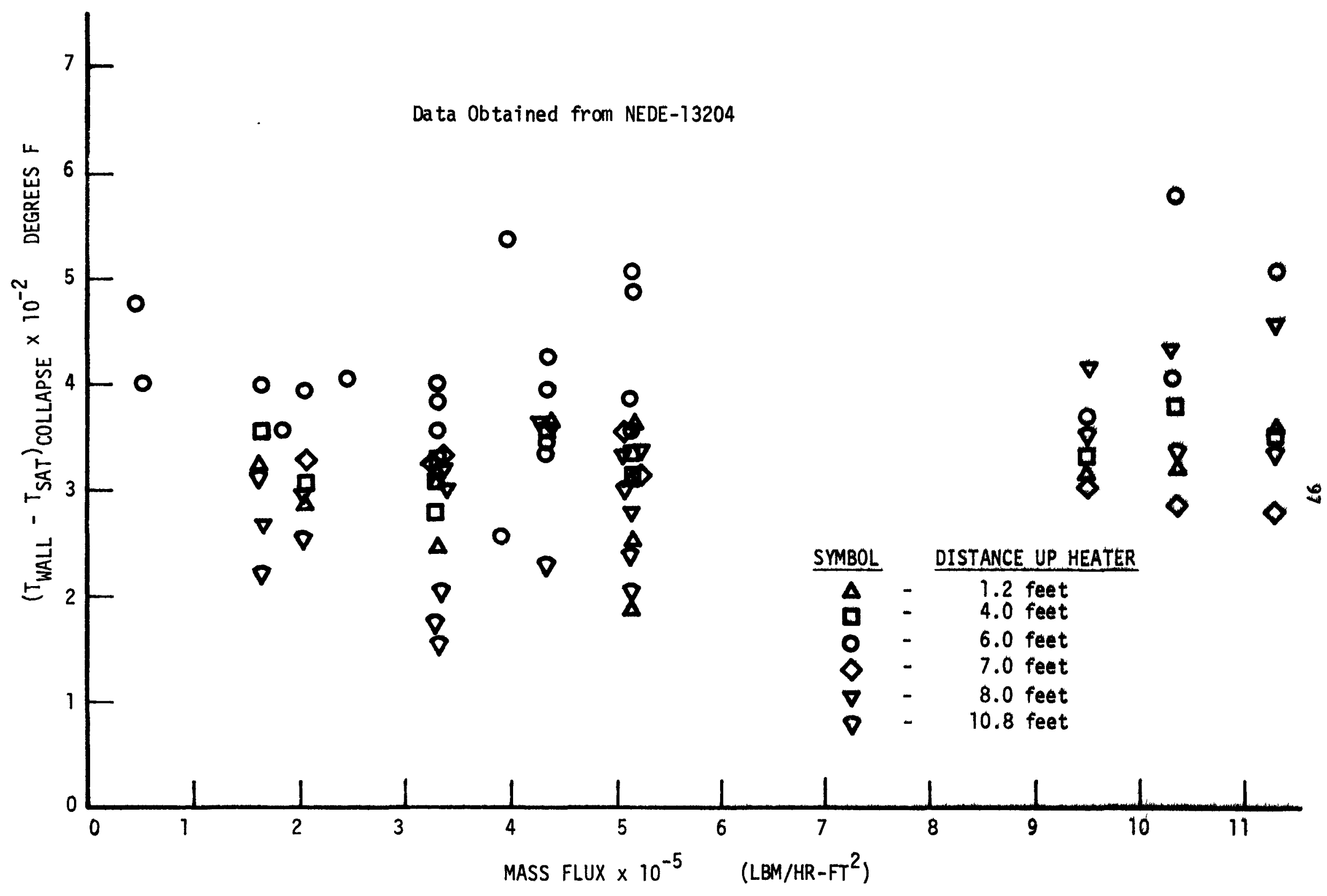

FIG. 41 COLLAPSE TEMPERATURE DIFFERENCE VS MASS FLUX 


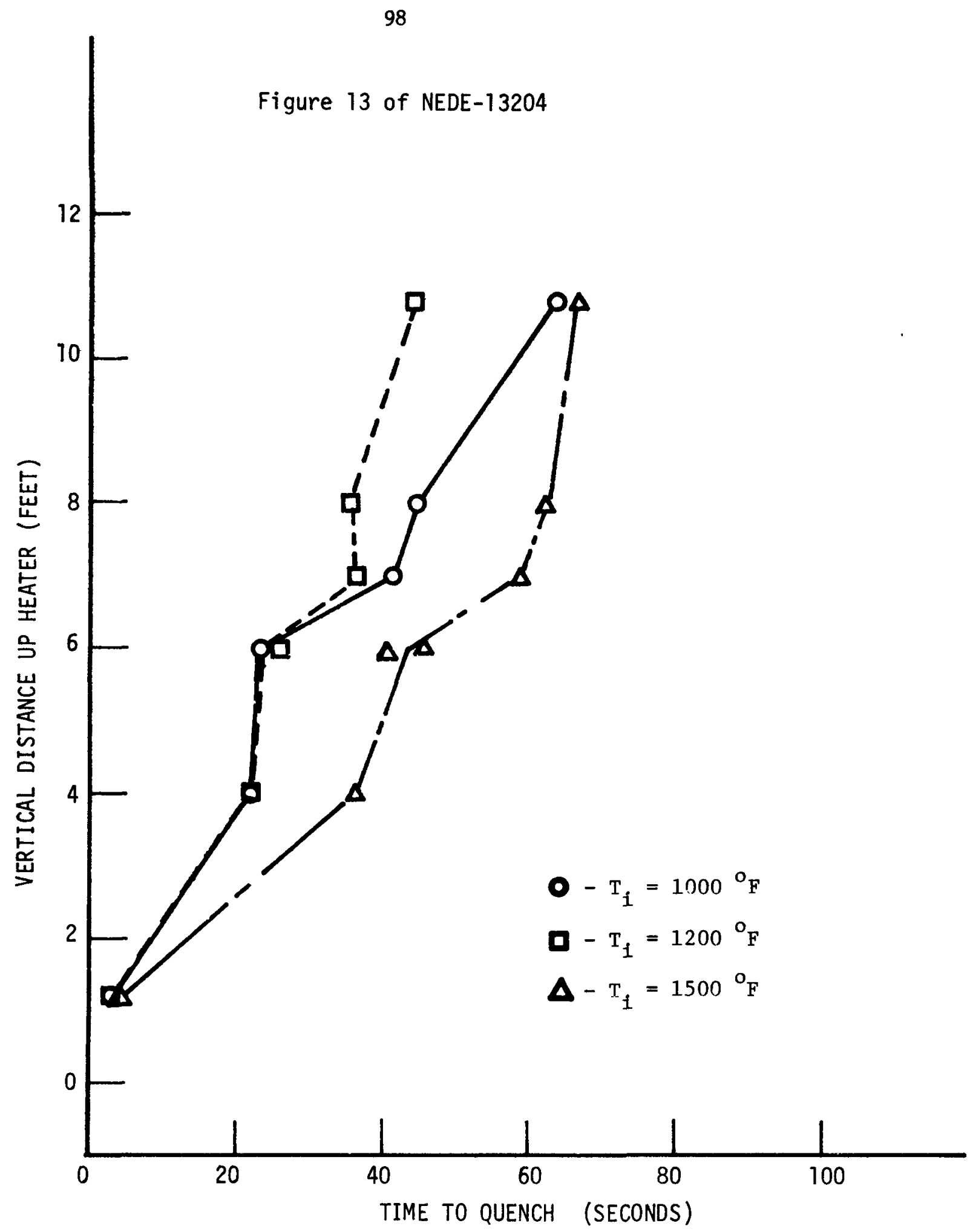

FIG. 42 QUENCH PROFILES FOR G=0.24 $\times 10^{6} \mathrm{lb} / \mathrm{hr} \mathrm{ft}^{2}$ 


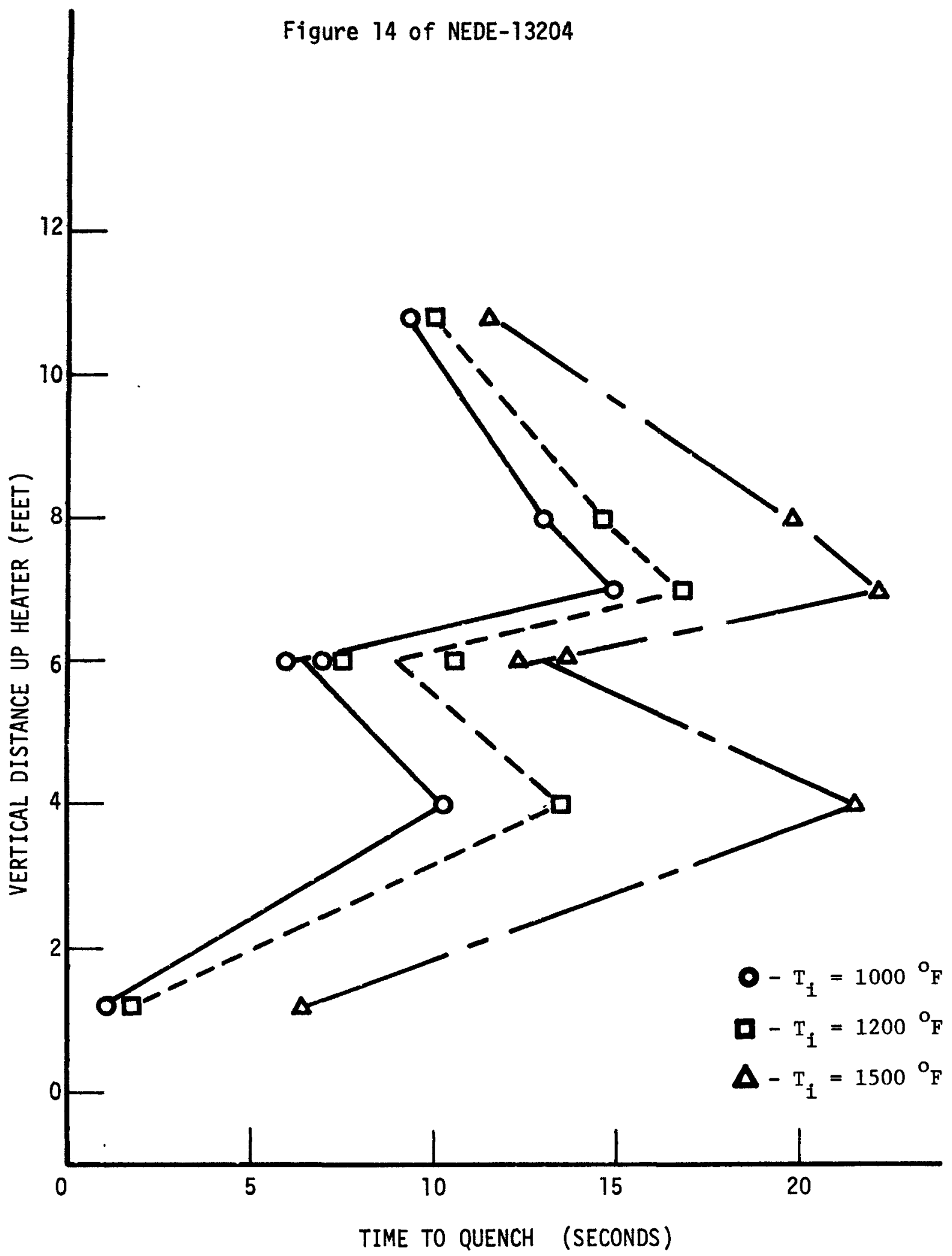

FIG.43 QUENCH PROFILES FOR G $=0.516 \times 10^{6} \mathrm{lb} / \mathrm{hr} \mathrm{ft}^{2}$ 


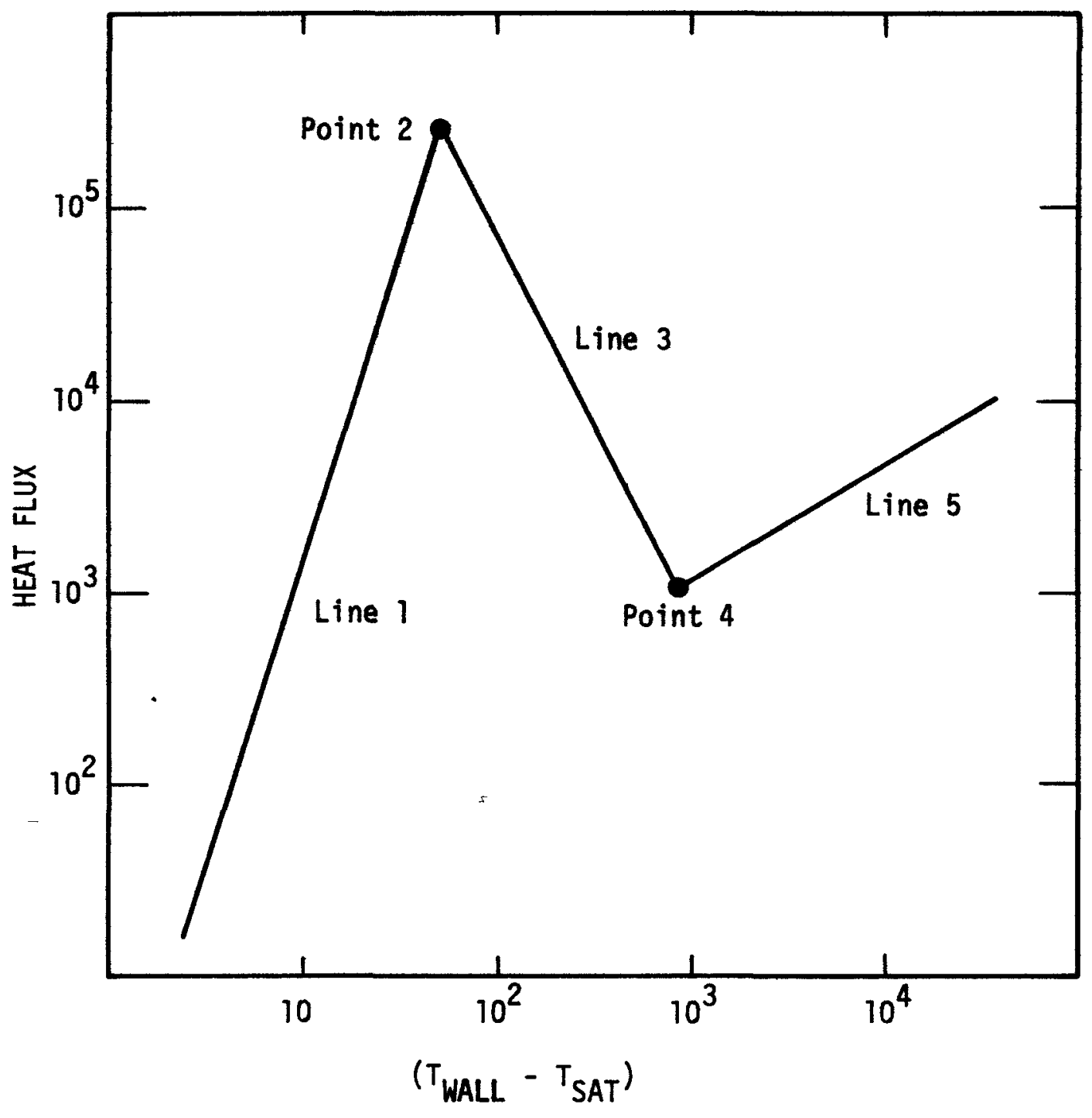

FIGURE 44 PICTORAL REPRESENTATION OF BOILING CURVE 

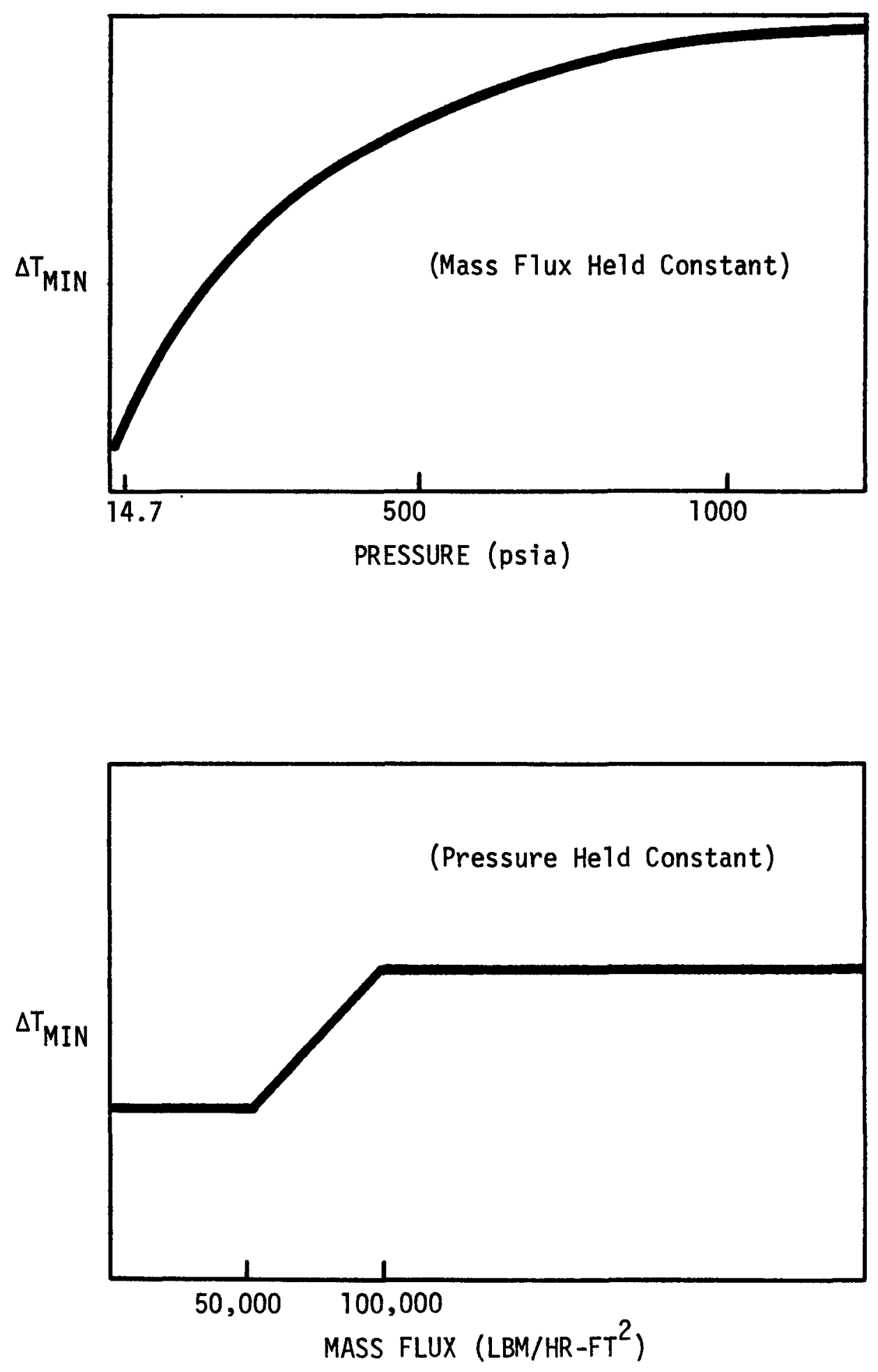

FIGURE 45 EXTRAPOLATIONS FOR ${ } T_{\text {MIN }}$ CORRELATION 

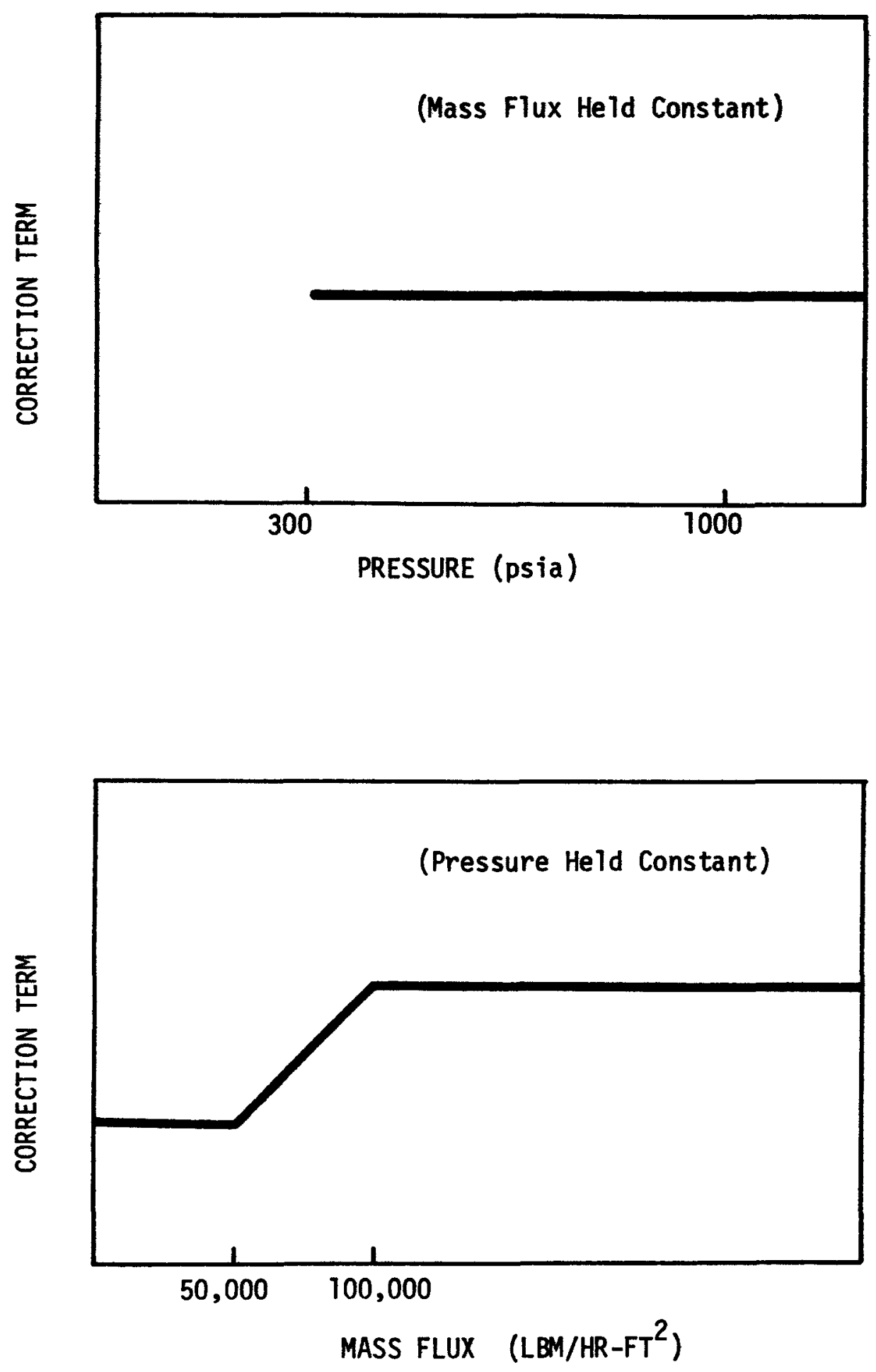

FIGURE 46 EXTRAPOLATIONS FOR CORRECTION FACTOR CORRELATION 